\title{
Vegetation Water Stress and its Impact on Land-Atmosphere Interaction
}

\author{
Ryan Eugene Emanuel \\ Charlotte, North Carolina \\ B.S., Duke University, 1999 \\ M.S., University of Virginia, 2003 \\ A Dissertation Presented to the Graduate Faculty \\ of the University of Virginia in Candidacy for the Degree of \\ Doctor of Philosophy
}

Department of Environmental Sciences

University of Virginia

May 2007

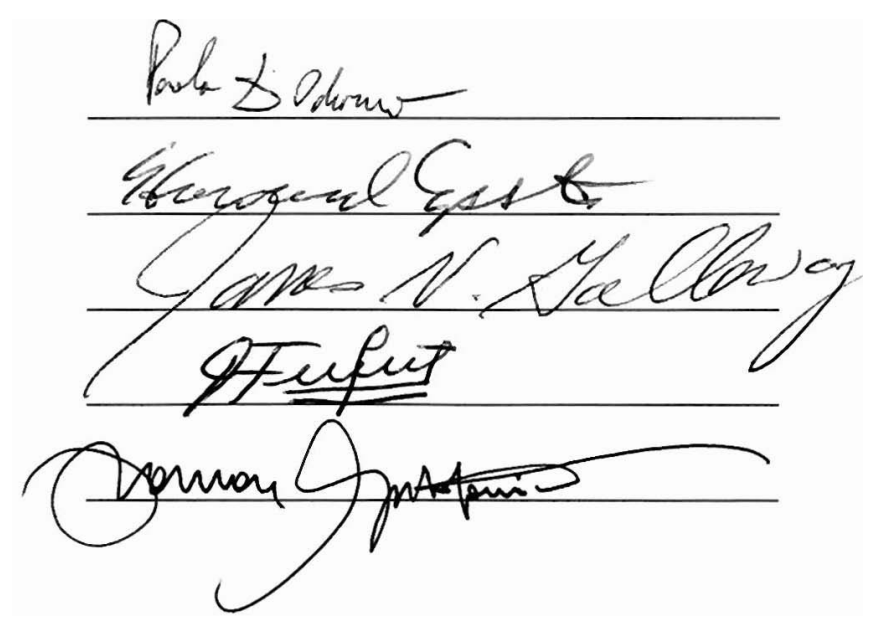




\section{Abstract}

In many terrestrial ecosystems, vegetation experiences limitation by different resources at different times. These resources include among others light, nutrients and water, all of which may affect leaf level stomatal conductance. Frequently, however, leaf-level modeling frameworks that unite these limitations rely on empirical functions to scale stomatal conductance as a function of water stress. This body of research presents a novel framework for calculating vegetation water stress that considers ecophysiology in addition to soil and atmospheric conditions. In doing so, I define a threshold of vegetation water stress that represents the balance between stomatal conductance required for biochemical activity and stomatal conductance required to satisfy the steady-state requirements of whole-plant hydrodynamics. This balance point attempts to unify these two oftentimes divergent concepts in the science of plant-water relations. I demonstrate that this threshold of vegetation water stress is functionally dependent upon local environmental conditions (light, temperature, and atmospheric vapor pressure), parameters representing different vegetation types, and nutrient status, and demonstrate, that as environmental conditions become more favorable for assimilation, the likelihood of water stress increases. This model of vegetation water stress is applied to a simple crop canopy in Virginia using flux tower data, and to two ecosystems in the northern Rocky Mountains using leaf-chamber data. Finally, the model of vegetation water stress is integrated into a soil-vegetation-atmosphere transfer model to evaluate the effects of heterogeneous water stress on catchment-scale fluxes of water vapor in a small (300 ha) watershed in the northern Rocky Mountains. 


\section{Table of Contents}

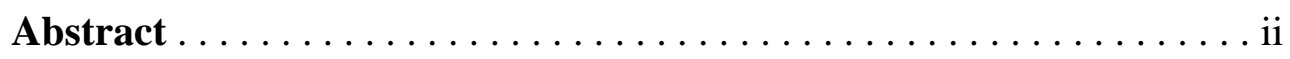

Table of Contents $\ldots \ldots \ldots \ldots \ldots \ldots \ldots \ldots \ldots \ldots \ldots \ldots \ldots \ldots$ iii

List of Tables $\ldots \ldots \ldots \ldots \ldots \ldots \ldots \ldots \ldots \ldots \ldots \ldots \ldots \ldots \ldots \ldots$

List of Figures $\ldots \ldots \ldots \ldots \ldots \ldots \ldots \ldots \ldots \ldots \ldots \ldots \ldots \ldots \ldots \ldots$

Acknowledgements $\ldots \ldots \ldots \ldots \ldots \ldots \ldots \ldots \ldots \ldots \ldots \ldots \ldots \ldots \ldots$

Chapter 1: Introduction $\ldots \ldots \ldots \ldots \ldots \ldots \ldots \ldots \ldots \ldots \ldots \ldots \ldots \ldots \ldots$

Chapter 2: A Dynamic Soil Water Threshold for Vegetation Water Stress Derived from Stomatal Conductance Models ..............4

Chapter 3: Spatial and Temporal Influences of Soil Moisture on the Ecophysiology of a Montane Conifer Forest . . . . . . . . . . 46

Chapter 4: Vegetation Water Stress Effects on the Hydrologic Balance of a Northern Rocky Mountain Watershed ................ 83

Chapter 5: Summary. ....................... 146 


\section{List of Tables}

Table

Page

2.1: Model-Specific Parameters

2.2: Constants for Stomatal Conductance Models

.21

2.3: Parameter Estimates from the Literature...................................23

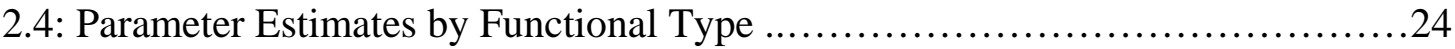

3.1: Kolmogorov-Smirnov Statistics for Site Comparisons ..................... 59

3.2: Ecophysiological Model Parameters ...................................... 66

3.3: Rank Correlation for $\psi *$ versus Ecophysiological Variables ..................68

3.4: KS Statistics for Water Stress at Forest and Meadow Sites ....................69

3.5: Rank Correlation for Soil Moisture Versus Ecophysiological Variables ..........72

4.1: Rank Correlation for Water Stress Versus Spatial Variables...................126

4.2: Principal Water Balance Terms for Each Model Run..........................133 


\section{List of Figures}

Figure

2.1: Conceptual Model

2.2: Blandy Precipitation and Soil Moisture. 17

2.3: Simulated Versus Observed Stomatal Conductance .26

2.4: Modeled Time Series of Transpiration and Micrometeorology 27

2.5: Behavior Analysis Results .30

2.6: Sensitivity of Dynamic Water Stress Threshold. 31

2.7: Simulated Stomatal Conductance. ... 36

2.8: Water Stress Threshold for Three Functional Types .37

2.9: Water Stress Threshold versus Foliar Nitrogen for Needle-Leaves 39

3.1: Overview of Stringer Creek Watershed .51

3.2: Frequency Distribution of Soil Moisture at Forest Sites 59

3.3: Frequency Distribution of Soil Moisture at Meadow Sites....................60

3.4: Frequency Distribution of Ecophysiological Response at Forest Sites ...........62

3.5: Frequency Distribution of Ecophysiological Response at Meadow Sites ........62

3.6: Meteorology of Forest and Meadow Sites................................65

3.7: Frequency Distribution of $\psi *$ at Forest Sites................................67

3.8: Frequency Distribution of $\psi *$ at Meadow Sites.............................67

3.9: Frequency Distribution of $\psi *$ and $\psi_{s}$ at Forest Sites ........................69

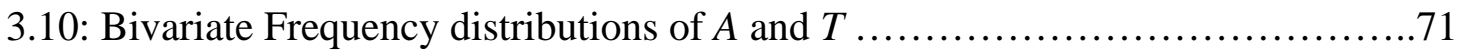

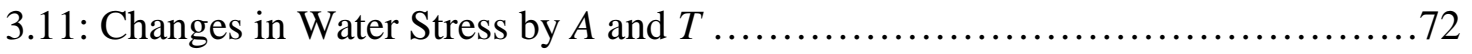

3.12: Correlation Coefficients Mapped to Forest Variable Space ...................73 
4.1: ASTER Image of Little Belt Mountains, MT .............................90

4.2: Location of Flux Towers and Weather Stations within Watershed................91

4.3: Lidar-Derived Topographic Index....................................93

4.4: Lidar-Derived Vegetation Height Index......................................94

4.5: Canopy Surface Temperature Versus Air Temperature......................100

4.6: Time Series of Catchment-Scale Hydrological Processes ....................106

4.7: Change in Modeled Soil Moisture versus Modeled Transpiration...............109

4.8: Joint Probability Distributions for Relative Humidity, Temperature, Date........110

4.9: Half-Hourly Spatial Averages of Water Stress Intensity......................112

4.10: Time Series of Water Stress Components...............................116

4.11: Frequency Distribution of Stress Intensity Through Time.....................117

4.12: Watershed-Averaged Transpiration Versus Stress Intensity ..................119

4.13: Stress as a Function of Topography and Vegetation........................121

4.14: Seasonal Transpiration as a Function of Topography and Vegetation ...........123

4.15: Frequency Distribution of Stress Intensity for Actual, Altered Weather..........125

4.16: Changes in Evapotranspiration with Altered Weather...........................126

4.17: Areas of High $Z_{V e g}$ and High $T I$ in Watershed..............................129

4.18: Uniform, Randomly Distributed Vegetation in Watershed......................130

4.19: Frequency Distribution of Stress Intensity for Vegetation Distributions.........131

4.20: Time Series of Stress Intensity for Actual and Mean-Height Vegetation........132

4.21: Frequency Distribution of VPD for Altered Weather Simulations..................133

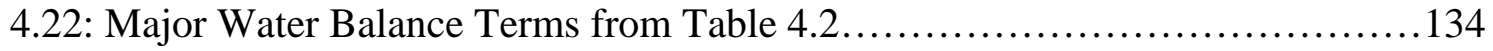




\section{Acknowledgements}

I began my graduate studies nearly six years ago, but the seeds of my interest in hydrology were sewn long before then. I am thankful for my parents, who fostered in me, from a very early age, an interest in rivers, mountains and wild places. I am also thankful for the invitation of Harold Eddins to join his staff at the USGS Water Resources Division in Charlotte, NC in 1995. From that time forward, the call of hydrology was irresistible, due in no small part to the professional and personal examples of the USGS staff in Charlotte and Raleigh. My decision to pursue an academic career grew from interactions with several faculty members during my years of study at Duke. Peter Malin and Stuart Rojstaczer both gave me far more time and attention than I deserved, and for their counsel I am quite grateful. I am also thankful for the example of David Silbey, who elevated lecturing to a fine art.

John Albertson provided a fast-paced start to my graduate studies the University of Virginia, and I am grateful for the high expectations that he set for me. I am also grateful to Howie Epstein; his perpetual guidance during the past several years has been a great encouragement. I am similarly thankful for the unwavering support of Paolo D’Odorico, who gave me a long leash to pursue my academic interests while keeping me focused enough to still call me his student. My co-advisors Paolo and Howie have introduced me to several legendary figures in our field. Though our meeting was brief, I was profoundly impacted by the advice of Ignacio Rodriguez-Iturbe, who encouraged me to be a hard thinker as well as a hard worker. Additionally, I am grateful to Steve Running for his 
generosity of time and intellect, and for taking a genuine interest in the Tenderfoot fieldwork.

This dissertation research would not have been possible without the intellectual and financial support I received from numerous sources. In addition to my advisors, I am grateful to committee members Jim Galloway, José Fuentes and Roman Krzysztofowicz for their helpful comments and counsel. Without the help of Dan Muth, Jin Wang and Todd Scanlon, I would not have been able to collect all of the data and develop the modeling strategies for this research. Others who contributed important logistical support, data or analytical tools to this research include Brian McGlynn, Diego Riveros, Vince Pacific and Kelsey Jencso from Montana State University, Danny Welsch from Frostburg State University, Ward McCaughey and Matt Jolly from the US Forest Service, and Rob Payne from the Colorado School of Mines. Financial support for this research was provided by the NSF (grants \#EAR-0236621, EAR-0403924), DOE-NIGEC (Great Plains Regional Center, grant \#DE-FC-02-03ER63613; Southeastern Regional Center, grant \# DE-FC-02-03ER63613), generous graduate research fellowships from Blandy Experimental Farm, and teaching and research awards from the Department of Environmental Sciences.

None of this work would have been accomplished without the constant love and support of Cayce and Laurel, who encourage me to pursue my dreams. 


\section{Chapter 1: Introduction}

There are few terrestrial environments in which vegetation does not affect significantly the cycling of mass and the flow of energy between the land surface and the atmosphere. In particular, terrestrial vegetation plays a major role in determining rates of water vapor transfer from land to atmosphere. This dissertation focuses primarily on the control of evapotranspiration from vegetated land surfaces in natural environments. Specifically, I invoke the well-understood concept of vegetation water stress; however, in this dissertation I formalize this concept by defining water stress theoretically as an intersection of ecological, hydrological and meteorological conditions centered on the supply of, and demand for, water. Additionally, I define water stress practically as an intersection of process-based ecophysiological models of plant-water relations and carbon dioxide assimilation.

A number of modeling frameworks exist to describe our current understanding of plantwater relations. By plant-water relations, I mean the role of plants in extracting water from the soil, transporting it through their tissues, and evaporating it to the atmosphere in tandem with uptake of carbon dioxide. By extension, I also mean the influence of soil water availability on these transport processes. Conservation of mass dictates that the transport of water by a plant through the soil-plant-atmosphere continuum reduce the amount of water in the soil near the plant, and a growing body of experimental work (existent since at least the mid-twentieth century) confirms a dependence of transport processes on soil water content. Because water transport through the soil-plant- 
atmosphere continuum both affects and is affected by soil water content, plant-water relations comprise a complex and significant component of the highly nonlinear relationship that exists among climate, vegetation, hydrology and pedology that governs the soil water balance. Thus, a discussion of soil water content that focuses on vegetation processes in either one context or the other (influenced by or influencing soil water content) fails to capture the full complexity of plant-water relations as it relates to many problems of importance for terrestrial ecology, catchment hydrology and even regional and global change.

By quantifying vegetation water stress in terms of soil, plant, atmosphere and hydrology, I bring to the growing field of ecohydrology ${ }^{1}$ a new tool for studying biosphereatmosphere interaction that treats water stress as a dynamic phenomenon, varying not only with vegetation and soil conditions, but also in response to a physical environment that may change hour-by-hour.

Here I present the development and application of this tool in three chapters: Chapter 2 exposes the need, and lays the theoretical framework for a new explanation of vegetation water stress, defining a dynamic threshold of vegetation water stress in terms of existing ecophysiological models, and applying the model over a simple crop canopy in Virginia. Chapter 3 explores soil moisture controls on leaf-level ecophysiology, applying the model of vegetation water stress to two vegetation types in the northern Rocky Mountains. Finally, Chapter 4 integrates the model of vegetation water stress into a land-

\footnotetext{
${ }^{1}$ Recognizing that ecohydrology has been adopted as a description of multiple fields of study, I refer to ecohydrology as defined by Rodriguez-Iturbe (2000).
} 
atmosphere exchange model, using the definition of water stress to explore the relationship among soil, vegetation and evapotranspiration at the landscape scale.

Together, these three chapters demonstrate the applicability of a new modeling

framework under different environmental conditions and at various spatial and temporal

scales, and as a result, they refine our understanding of vegetation water stress and its impact on the terrestrial hydrologic cycle.

\section{References}

Rodriguez-Iturbe, I. (2000), Ecohydrology: A hydrologic perspective of climate-soilvegetation dynamics, Water Resources Research, 36, 3-9. 


\section{Chapter 2: A Dynamic Soil Water Threshold for Vegetation Water Stress} Derived from Stomatal Conductance Models ${ }^{1}$

\section{Abstract}

In many terrestrial ecosystems, vegetation experiences limitation by different resources at different times. These resources include among others light, nutrients and water.

Frequently, however, leaf-level modeling frameworks that unite these limitations rely on empirical functions to scale stomatal conductance as a function of water stress. These functions use prescribed values of soil water content to mark the transition between water-stressed and unstressed conditions without accounting for the dependence of such a water content threshold on atmospheric and hydrologic conditions and nutrient availability. To address the phenomenon of a variable threshold to water stress, we combine an existing water-limited stomatal conductance model with an existing assimilation (photosynthesis) -limited stomatal conductance model. In this manner, we simulate variable controls on stomatal conductance and use a combination of the two models to define the threshold at which soil water content becomes limiting to transpiration. Modeled plant processes are used to define this water stress threshold as functionally dependent upon local environmental conditions (light, temperature, and atmospheric vapor pressure), parameters representing different vegetation types, and nutrient status. Simulations demonstrate that as environmental conditions become more favorable for assimilation, the likelihood of water stress increases. Specifically, there exist ranges of leaf temperature, light and humidity for which water stress is maximized.

\footnotetext{
${ }^{1}$ Emanuel, R. E., P. D’Odorico, H. E. Epstein (2007), A dynamic soil water threshold for vegetation water stress derived from stomatal conductance models, Water Resour. Res., 43 W03431, doi:10.1029/2005WR004831. Reproduced by permission of AGU.
} 


\section{Introduction}

The complex dynamics resulting from the interactions between physical and biological processes make the understanding of ecosystem response to changes in environmental conditions (e.g., water, light, nutrients) extremely difficult. This is particularly true in the case of ecosystems that are limited by different resources at different times. For example terrestrial ecosystems in the eastern U.S. may undergo severe water stress during dry years (e.g., the first years of this century), while nutrients are likely to limit productivity during wet years. In the context of this study, we define water stress as water-limited $\mathrm{CO}_{2}$ assimilation and transpiration. Understanding ecosystems such as these using models based only on one limiting factor can lead to partially correct or to misleading conclusions. As one case in particular, our current understanding of the mechanisms controlling stomatal conductance is hindered by models that do not consider explicitly limitation by different factors at different times. A comprehensive understanding of the controls on stomatal conductance requires a modeling strategy that has the ability to discriminate between individual limiting factors.

Plants represent an important coupling point between terrestrial cycles of carbon and water. This coupling is ubiquitous among terrestrial ecosystems, with much research historically focusing on agricultural systems in which water availability is linked directly to crop production [Begg and Turner, 1976]. A number of studies have approached this issue from the perspective of direct inhibition of plant physiological activities by water stress [e.g. Jarvis, 1976; Jones and Turner, 1978; Morgan, 1984; Pelleschi et al., 1997] whereas others have considered regulation of plant activity by water stress through 
chemical feedback mechanisms [e.g. Zelitch and Waggoner, 1962; Gollan et al., 1986; Passioura, 1988; Saab et al. 1990]. All of these studies share a common reliance upon stomatal conductance as a regulator of plant water content, and many of them demonstrate functional dependence of stomatal conductance on water availability.

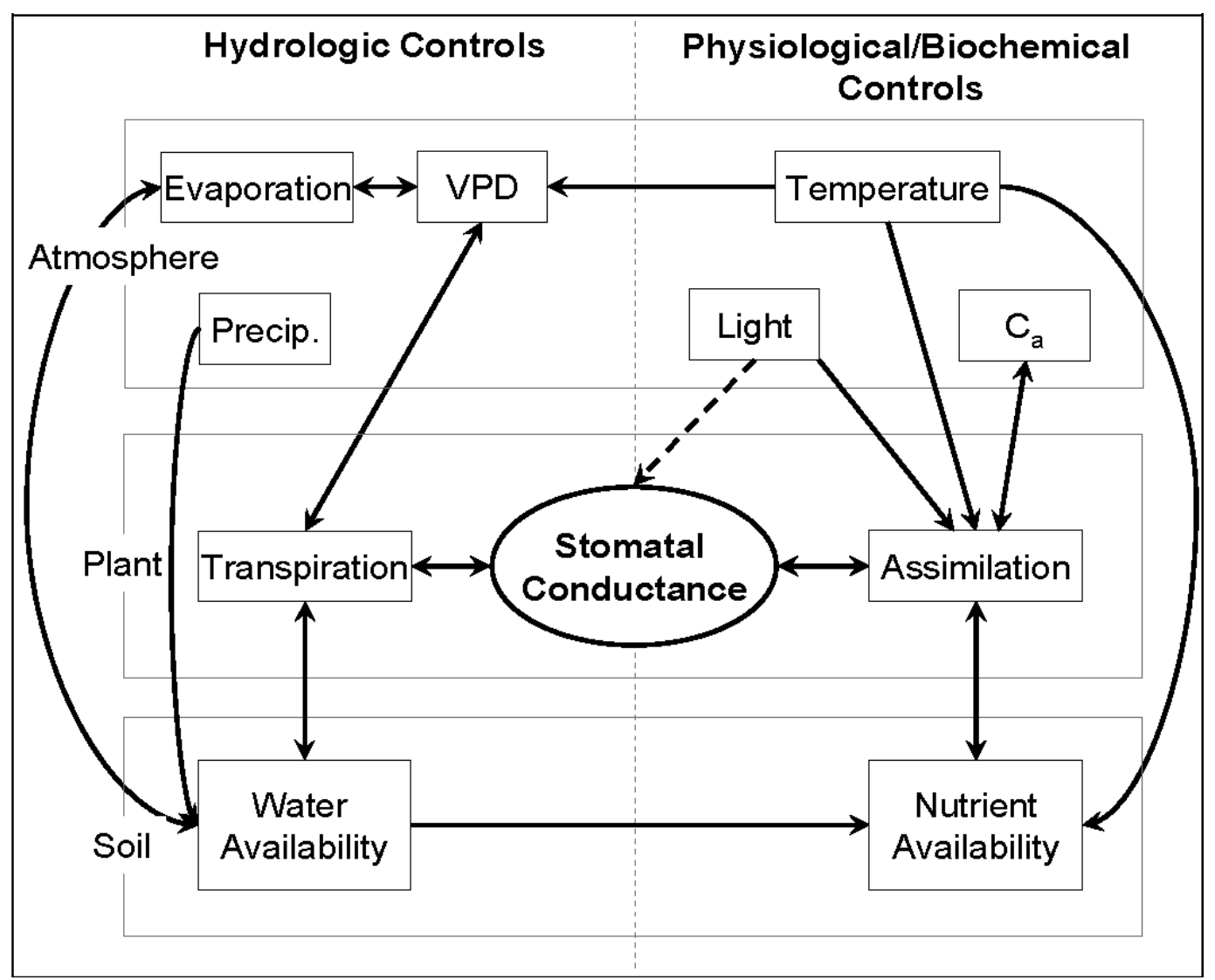

Figure 2.1: Conceptual model for the hydrologic and physiological controls on stomatal conductance within the soil-plant-atmosphere continuum.

Stomatal conductance is also controlled by the biochemical and physiological processes associated with carbon dioxide assimilation (Figure 2.1, right hand side). Generally, assimilation (photosynthesis) rates are limited physically by diffusion rates through stomata 
and biochemically by enzymatic activity, the conversion of light energy to chemical energy, and respiration associated with physiological activity [Cowan and Farquhar, 1977; Farquhar et al., 1980; Harley et al., 1985; Collatz et al., 1991; Bonan, 2002]. It is through these biochemical processes that stomatal conductance, via assimilation, is regulated by leaf temperature, sunlight and carbon dioxide availability. Additionally, foliar nitrogen content (and thus nitrogen availability) has been linked to photosynthetic capacity [Field and Mooney, 1986; Dang et al., 1997; Meir et al., 2002], due to the high nitrogen content of the carbon-fixing enzyme, Rubisco [Evans, 1989].

Attempts to address water-limitation in the context of photosynthesis-limited stomatal conductance primarily involve scaling a photosynthesis-limited model by some factor representing water stress. Thornthwaite and Mather [1955], Budyko [1958], Eagleson [1982], Jacquemin and Noilhan [1990], Avissar and Pielke [1991], and many others have defined a piecewise-linear function that scales transpiration or stomatal conductance between the threshold of water stress (i.e. the soil moisture status at which water becomes limiting to stomatal conductance and transpiration), and the wilting point soil moisture; however this technique does not address environmental dependencies of such a water stress threshold or of the scaling function itself. Rather, this scheme makes an a priori assumption of the soil water content at which water limitation commences. Later studies [e.g. Rodriguez-Iturbe et al., 1999; Albertson and Kiely, 2001; Fernandez-Illescas et al., 2001; Porporato et al., 2001; Daly et al., 2004] established critical links between soil texture, soil hydraulic properties and water-limited transpiration, but they treat the water stress threshold as an intrinsic property of soils and vegetation. These studies have, 
however, discussed water stress as a dynamic parameter whose variability has the potential to affect processes such as transpiration.

Other models of stomatal conductance base soil water limitation on a steady-state assumption balancing soil water uptake and transpiration (Figure 2.1, left hand side) [e.g. Dewar, 2002; Gao et al., 2002; Buckley et al., 2003; Katul et al., 2003]. These models provide a process-based link between rates of stomatal conductance and soil moisture status, and, by assuming a continuous functional dependence of conductance upon soil moisture, they eliminate altogether the need to scale transpiration between the limiting and wilting points. However, a continuous dependence of stomatal conductance on soil moisture seems to contradict earlier conclusions that there exists a range of soil moistures to which stomatal conductance (and thereby transpiration) is insensitive [see Leuning, 1995].

The main objective of this paper is to situate two common types of stomatal conductance models (moisture-limited hydraulic and the moisture-independent biochemical models), within the framework of observed plant behavior. Instead of using a priori assumptions of soil water limitations to stomatal conductance, we outline a different method for using characteristic parameters of an ecosystem (namely plant physiological properties and soil properties) to determine how environmental state variables (particularly light, temperature and vapor pressure deficit) interact to define quantitatively the threshold at which stomatal conductance becomes water limited. By relating a semi-empirical model of stomatal response to light, temperature, and nutrients (Leuning's [1995] adaptation of 
the Ball et al. [1985] model coupled with the physiological model of Farquhar et al. [1980]) to a hydraulic model of water-limited stomatal conductance [Gao et al., 2002], we present a framework for exploring the interplay between plant biochemical and hydraulic controls (i.e., the availability of light, nutrients and water) on the movement of water through the soil-plant-atmosphere continuum. We believe that this framework could be used to investigate dynamic water stress in terms of other biochemical or hydraulic submodels Although each submodel provides a simplified representation of the actual physiological processes controlling stomatal conductance, the analysis presented in this paper provides a basis for further study of the complex relationship between vegetation and the physical environment. 


\section{Methods}

\section{Model Framework}

The modeling framework utilizes two separate leaf-level submodels of stomatal conductance to water vapor transfer, one estimating conductance using a $\mathrm{CO}_{2}$ assimilation model that is independent of soil moisture and another estimating waterlimited conductance. Other models exist, particularly for water-limited conductance, that could be adopted as submodels in the context of this framework depending on modeling objectives and time scales. For the moisture-independent submodel, we chose Leuning's [1995] adaptation of the Ball et al. [1987] stomatal conductance $\left(g_{s-A}\right)$ model

$$
g_{s-A}=b+m \frac{A_{n} f\left(D_{v}\right)}{C_{s}-\Gamma_{*}}
$$

where $b$ is an empirical parameter representing residual stomatal conductance in the absence of photosynthesis due to light limitation, $m$ is an empirical coefficient, $A_{n}$ is the rate of net photosynthesis, $C_{s}$ is the $\mathrm{CO}_{2}$ concentration outside the leaf, $\Gamma_{*}$ is the $\mathrm{CO}_{2}$ compensation point (a function of ambient $\mathrm{O}_{2}$, the dual affinity of Rubisco for $\mathrm{O}_{2}$ and $\mathrm{CO}_{2}$, and leaf temperature), $D_{v}$ is the difference between saturation vapor pressure at the leaf surface $\left(e_{s}\right)$ and actual vapor pressure of the surrounding atmosphere $\left(e_{a}\right)$, and $f\left(D_{v}\right)=D_{v}^{-0.5}$. When coupled with the Farquhar et al. [1980] model of photosynthesis, $g_{s-A}$ from Equation 2.1 is a function of the biochemical processes associated with carbon assimilation, namely the enzymatic activity of Rubisco and light dependent regeneration 
of the assimilatory substrate Ribulose-bisphosphate (RuBP). $A_{n}$ and $g_{s-A}$ modeled in this fashion are independent of soil water availability. Specifically, $A_{n}$ is calculated as

$$
A_{n}=\min \left(J_{E}, J_{C}\right)-R_{D}
$$

where $J_{E}$, light-limited carbon assimilation, and $J_{C}$, Rubisco-limited carbon assimilation, are defined by Collatz et al. [1991] as

$$
\begin{aligned}
& J_{E}=\alpha \times a \times Q \frac{C_{i}-\Gamma_{*}}{C_{i}+2 \Gamma_{*}} \\
& J_{C}=\frac{V C_{\max }\left(C_{i}-\Gamma_{*}\right)}{C_{i}+K_{C}\left(1+\left[O_{2}\right] / K_{O}\right)}
\end{aligned}
$$

where $Q$ is photosynthetically active radiation (PAR) at the leaf surface, $\alpha$ and $a$ are the quantum efficiency and leaf absorptance to PAR, respectively, $C_{i}$ is internal $\mathrm{CO}_{2}$ concentration, $V_{C \max }$ is maximum carboxylation rate, $\left[\mathrm{O}_{2}\right]$ is oxygen concentration and $K_{C}$ and $K_{O}$ are the Michaelis-Menten reaction-rate parameters. $V c_{\max }, \Gamma *, K_{C}$ and $K_{O}$ are evaluated as exponential functions of leaf temperature and parameter values at $25{ }^{\circ} \mathrm{C}$ [Collatz et al., 1991]. $R_{D}$, daytime respiration, is also evaluated as an exponential function of temperature and $R_{D 25}$, the parameter value at $25^{\circ} \mathrm{C} . \mathrm{s} 2.1-2.3$ make the simplifying assumption that PAR, leaf temperature and atmospheric vapor pressure are independent variables. However, the partitioning of net radiation (of which PAR is a 
major component) at the leaf surface is itself a function of stomatal conductance, and causes changes both in temperature and vapor pressure [Jones, 1999]. The present analysis assumes that PAR, surface temperature and surface vapor pressure are measured independently, and therefore does not consider the effect of stomatal conductance on leaf energy balance. Equation 2.1 is most successful at estimating stomatal conductances for well-watered systems [Leuning, 1995]. In fact, the model in this form does not account for water-limitation. Thus, Equation 2.1 is here used as a moisture-independent submodel.

For the water-limited submodel of stomatal conductance, we selected a hydromechanical model by Gao et al. [2002] that assumes a steady-state balance between water uptake by roots and water loss by transpiration. The Gao et al. [2002] model was selected because it includes no a priori assumption of a threshold for soil water limitation [e.g. Dewar 2002; Katul et al., 2003], and it contains few parameters relative to other models [e.g. Buckley et al., 2003]. This model does have several limitations, including its assumption of steady flow through the soil-plant-atmosphere continuum, its simplistic treatment of the relationship between stomatal conductance, leaf water potential and turgor pressure [see Buckley et al., 2003], and its inability to account for xylem cavitation [see Sperry, 2000]. At short time scales (sub-daily), these limitations may affect model performance due to the presence of transient (i.e. non-steady) states of plant hydraulics and the shortterm effects of cavitation on plant hydraulic conductance. Nevertheless, we employed the Gao et al. [2002] model because of its simplicity and its continuous (linear) dependence of stomatal conductance upon soil water potential. This model reduces 
whole-plant hydrodynamics to a relation between soil water potential $\psi_{s}$ and stomatal conductance $\left(g_{s-W}\right)$, and takes the form

$$
g_{s-W}=\frac{g_{0 m}+k_{\psi} \psi_{s}+k_{\alpha \beta} Q}{1+k_{\beta g} d_{v}}
$$

where $g_{0 m}$ is the maximum residual stomatal conductance at saturated soil conditions, $Q$ is PAR and $k_{\psi}, k_{\alpha \beta}$, and $k_{\beta g}$ are model-specific parameters. $d_{v}$ is $D_{v}$ normalized by atmospheric pressure. According to Gao et al. [2002], $k_{\psi}$ relates soil water potential to stomatal conductance by assuming direct proportionality between $g_{s}$ and the deformation of leaf guard cells caused by changes in turgor pressure. $k_{\alpha \beta}$ is the sensitivity of $g_{s-W}$ to changes in PAR as a result of the effect of PAR on $\mathrm{K}^{+}$concentrations in the guard cells rather than direct control of photosynthesis by PAR. $k_{\beta g}$ is a parameter that describes the ease of guard cell deformation, efficiency of soil-to leaf conductance, and response of $g_{s-}$ ${ }_{W}$ to changes in $d_{v}$. These parameters were derived from observable plant processes; however, Gao et al. [2002; 2003] estimated parameter values both for specific plant species and broader functional types through nonlinear regression of Equation 2.4 using corresponding leaf-level measurements of independent variables and $g_{s-W}$.

To account for variable limitation of stomatal conductance by different factors at different times, we define stomatal conductance as $g_{s-m i n}$, the minimum of $g_{s-A}$ and $g_{s-W}$, or 


$$
g_{s-\min }=\min \left(g_{s-A}, g_{s-W}\right)
$$

Equation 2.5 mimics both the observed natural phenomenon and common modeling practice of limiting stomatal conductance by soil moisture below a certain threshold. This equation is the relationship necessary to describe the variable limitation of stomatal conductance by factors controlling both assimilation and transpiration. More importantly, Equation 2.5 expresses stomatal conductance explicitly 1) as a response to the biochemistry of photosynthesis and 2) as a principal element of the soil-plantatmosphere continuum.

\section{Water Stress Threshold}

By combining Equations 2.4 and 2.5, we define a threshold for water stress from the soil water potential required to balance stomatal conductances of the water-limited submodel $\left(g_{s-W}\right.$, Equation 2.4) and assimilation-limited submodel $\left(g_{s-A}\right.$, Equation 2.1) as

$$
\psi_{*}=\frac{g_{s-A}\left(1+k_{\beta g} d_{v}\right)-g_{0 m}-k_{\alpha \beta} Q}{k_{\psi}}
$$

where $\psi_{*}$ is an explicit function of $Q$ and $d_{v}$, and implicitly dependent upon $A_{n}$ (and its functional dependencies) and $C_{s}$ through the $g_{s-A}$ term. We limit $\psi_{*}$ to a maximum value of 0 . The value of $\psi_{*}$ relative to $\psi_{s}$ indicates whether the system is water limited or not. If $\psi_{s}<\psi_{*}$ a plant is water-stressed, otherwise some other factor limits stomatal 
conductance. This water stress threshold is defined not only by vegetation-specific submodel parameters, but also by micrometeorological variables that may change greatly through the course of a single day (specifically light, temperature, $\mathrm{CO}_{2}$ concentration and humidity). These functional dependencies result in a water stress threshold that is dynamic with respect to vegetation type and also in response to micrometeorology.

\section{Calculating Stomatal Conductance from Observed Micrometeorological Data} Half-hourly micrometeorological data were collected from a crop field at Blandy Experimental Farm in Virginia, USA $\left(39.06^{\circ} \mathrm{N}, 78.07^{\circ} \mathrm{W}\right.$, elevation $\left.183 \mathrm{~m}\right)$ between 20 April 2001 and 29 May 2001 (days 110 through 149). The model was parameterized using a 20 day subset of data (days 110 through 129). Eddy covariance was used to measure water vapor and carbon dioxide fluxes at a height of $3.5 \mathrm{~m}$ above the ground surface near the center of a 10 ha field of rye. The site and measurements are described in further detail by Emanuel et al. [2006]. Leaf-level stomatal conductances were scaled from tower-based measurements of ET using the resistance analogy

$$
R_{\text {Tot }}=R_{c a n}+R_{a v}
$$

where $R_{T o t}{ }^{2}$ is the total ecosystem resistance to water vapor transfer, $R_{\text {can }}$ is the canopy resistance to water vapor transfer and $R_{a v}$ is the aerodynamic resistance to water vapor transfer $\left(\mathrm{s} \mathrm{m}^{-1}\right) . R_{a v}$ was estimated from the stability corrections to the logarithmic wind profile

\footnotetext{
${ }^{2}$ For a discussion of the role of leaf boundary layer resistance, see Chapter 4.
} 


$$
R_{a v}=\frac{\left[\ln \left(\frac{z-d_{o}}{z_{o m}}\right)-\Psi_{m}\right]\left[\ln \left(\frac{z-d_{o}}{z_{o v}}\right)-\Psi_{v}\right]}{k^{2} u}
$$

where $z$ is measurement height, $d_{o}$ is the zero-plane displacement, $z_{o m}$ and $z_{o v}$ are the roughness heights for momentum and water, and $k$ is the von Karman constant. Additionally, $u$ is the mean horizontal wind velocity $\left(\mathrm{m} \mathrm{s}^{-1}\right)$, and $\Psi_{m}$ and $\Psi_{v}$ are the diabatic functions for momentum and water vapor [e.g. Brutsaert, 1982]. $R_{c a n}$ is commonly estimated from surface energy fluxes and atmospheric vapor pressure deficit using the Penman-Monteith equation [Monteith, 1973]; however, by measuring plant canopy skin temperature $\left(T_{c}\right)$ directly using a sensor temperature-corrected infrared thermometer (IRTS-P, Campbell Scientific/Apogee Instruments, Logan UT) and assuming vapor-saturated air at the canopy (leaf) surface, we obtain a direct measurement of $d_{v}$ and calculate $R_{T o t}$ as

$$
R_{T o t}=\frac{d_{v}}{E T}
$$

where ET is evapotranspiration $\left(\mathrm{m} \mathrm{s}^{-1}\right)$ measured by eddy covariance. Since no rain fell during or immediately prior to the calibration period (based on records from a nearby meteorological station; Figure 2.2), we neglected soil evaporation and assumed that the soil was dry enough to consider ET equal to the transpiration rate during this time. We 
estimated saturation vapor pressure $\left(e_{s}\right)$ from $T_{c}$ using Richards' [1971] empirical formula.

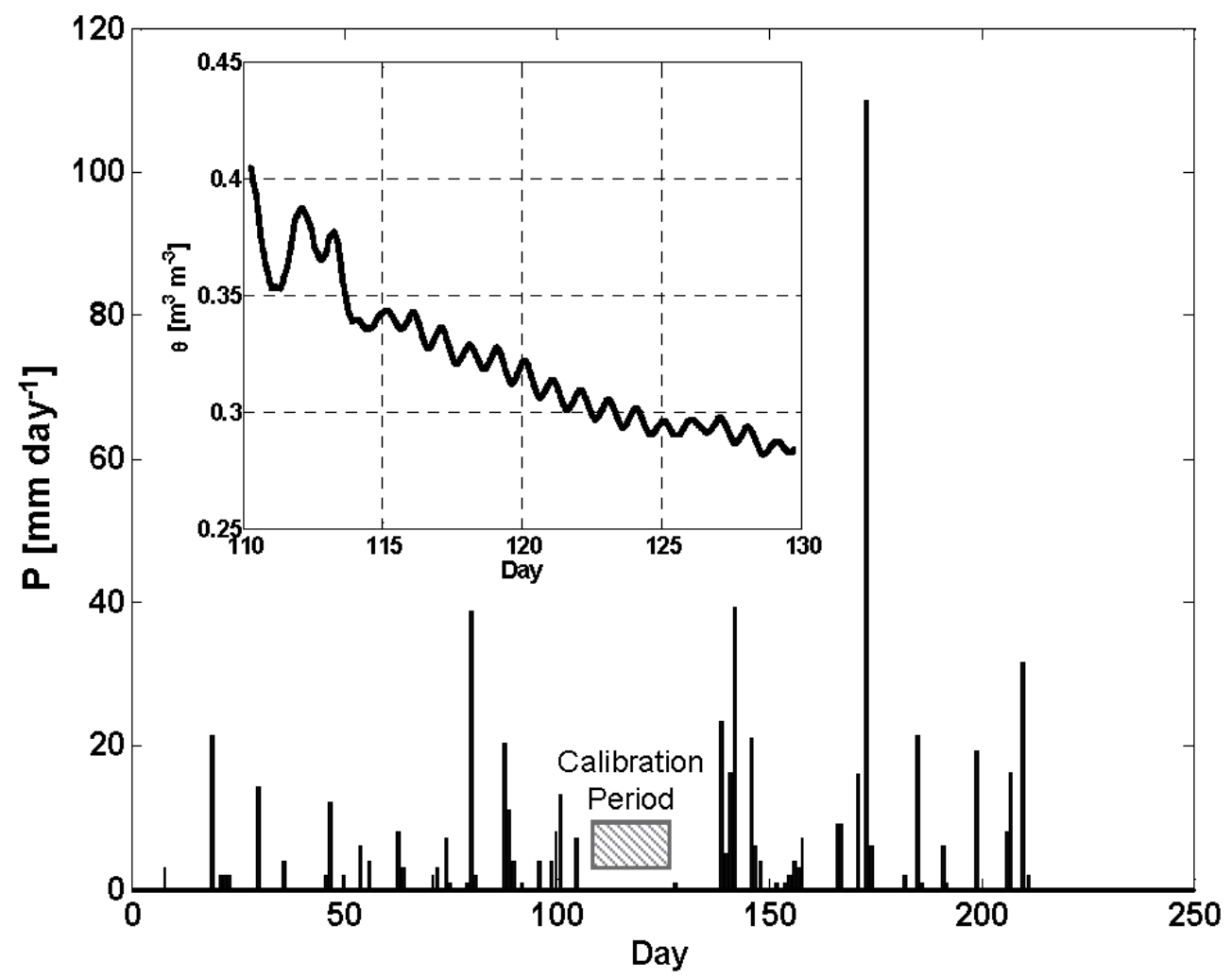

Figure 2.2: Precipitation near Blandy Experimental Farm for 2001. Inset: Soil moisture $(\theta)$ during the calibration period (days 110-129).

By computing $R_{T o t}$ and $R_{a v}$, and solving Equation 2.7 for $R_{c a n}$, we estimate canopy conductance $g_{c a n}\left(\mathrm{~m} \mathrm{~s}^{-1}\right)$ as the reciprocal of $\left(R_{\text {Tot }}-R_{a v}\right)$, and stomatal conductance at the leaf-level as

$$
g_{s-E C}=\frac{g_{c a n}}{L A I}
$$


where $L A I$ is leaf area index $\left(\mathrm{m}^{2} \mathrm{~m}^{-2}\right)$ and $g_{s-E C}$ is the leaf-level stomatal conductance calculated from eddy covariance measurements. Two simplifying assumptions are implied by this scaling strategy: 1) the canopy is represented by a single 'big-leaf' and 2) micrometeorological variables measured at or above the canopy surface (namely PAR, canopy skin temperature and atmospheric humidity) are representative of conditions at the leaf surface.

Additionally, we measured volumetric soil moisture integrated through the root zone (0$30 \mathrm{~cm}$ ) using a time domain reflectometry probe installed perpendicular to the ground surface near the base of the flux tower. PAR was measured approximately $2 \mathrm{~m}$ above the plant canopy using a quantum sensor (LI190, Licor Biosciences, Lincoln, NE). These measurements are also described in greater detail by Emanuel et al. [2006]. We make additional simplifying assumptions that this soil moisture and PAR measurements are representative of conditions within the measurement footprints of the other instruments.

\section{Model Application}

The case study of rye cultivation at Blandy Experimental Farm was used to parameterize and test the combined model of stomatal conductance (Equations 2.1-2.5). Soils at the study site have been previously classified as silt loam [Soil Conservation Service, 1982], and bulk density samples collected at the site indicate a porosity $n$ of 0.58 . Using this information, volumetric soil moisture was converted to soil water potential using empirical equations found in Clapp and Hornberger [1978]. 
Nonlinear least-squares regression was used to estimate each submodel's four core parameters (Table 2.1) independently based on half-hourly measurements made between days 110 and 129 . For the assimilation-limited submodel we estimated $V_{c \max 25}$ (maximum carboxylation rate at $25^{\circ} \mathrm{C}$ ), $R_{d 25}, m$ and $b$; and for the water-limited submodel we estimated $g_{0 m}, k_{\psi}, k_{\alpha \beta}$ and $k_{\beta g}$. Other terms relating to the photosynthesis submodel and field specific conditions were held constant for this study (Table 2.2). Eddy covariance measurements were selected for use based on the Moving Point Test of Gu et al. [2005]. To be conservative, we chose the wettest $12.5 \%$ percent of the data to parameterize the assimilation-limited submodel as an operational means of representing “well-watered conditions" stipulated by Leuning [1995]. The remaining subset, consisting of the driest $87.5 \%$ of the data, was used to parameterize the water-limited submodel. Parameters estimated from nonlinear regression were used to simulate $g_{s-m i n}$ with Equation 2.5. The model was validated by comparing $g_{s-m i n}$ to $g_{s-E C}$ for an additional twenty-day period (days $130-149$ ). 
Table 2.1: Model-specific parameters used in the submodels of water-limited and assimilation-limited stomatal conductance*

\begin{tabular}{|c|c|c|c|}
\hline Parameter & r Value & Units & Description \\
\hline \multicolumn{4}{|c|}{ Water-limited Submodel } \\
\hline$g_{o m}$ & $69.0(15.6)$ & $\mathrm{mmol} \mathrm{m}^{-2} \mathrm{~s}^{-1}$ & $\begin{array}{l}\text { Maximum stomatal conductance } \\
\text { in dark with saturated soil }\end{array}$ \\
\hline$k_{\psi}$ & $0.142(0.145)$ & $\mathrm{mmol} \mathrm{m} \mathrm{s}^{-2} \mathrm{kPa}^{-1}$ & Stomatal sensitivity to $\psi$ \\
\hline$k_{\alpha \beta}$ & $0.151(0.046)$ & $\mathrm{mmol} \mathrm{m} \mathrm{m}^{-2}\left(\mu \mathrm{mol} \mathrm{m} \mathrm{s}^{-2}\right)$ & Stomatal sensitivity to PAR \\
\hline$k_{\beta g}$ & $44.0(19.4)$ & $\mathrm{mmol} \mathrm{m} \mathrm{m}^{-2} \mathrm{~s}^{-1}\left(\mathrm{mb} \mathrm{mb}^{-1}\right)^{-1}$ & Stomatal sensitivity to $d_{v}$ \\
\hline \multicolumn{4}{|c|}{ Assimilation-limited Submodel } \\
\hline$V c_{\max 25}$ & $38.8(10.8)$ & $\mu \mathrm{mol} \mathrm{m} \mathrm{m}^{-2}$ & $\begin{array}{l}\text { Maximum carboxylation rate at } \\
25^{\circ} \mathrm{C}\end{array}$ \\
\hline$R_{d 25}$ & $0.46(1.8)$ & $\mu \mathrm{mol} \mathrm{m} \mathrm{s}^{-1}$ & $\begin{array}{l}\text { Daytime respiration rate at at } 25 \\
{ }^{\circ} \mathrm{C}\end{array}$ \\
\hline$m$ & $12.0(1.8)$ & unitless & $\begin{array}{l}\text { Slope of assimilation-limited } \\
\text { stomatal conductance }\end{array}$ \\
\hline$b$ & $0.015(0.012)$ & $\mathrm{mol} \mathrm{m} \mathrm{s}^{-2}$ & $\begin{array}{l}\text { Residual assimilation-limited } \\
\text { stomatal conductance }\end{array}$ \\
\hline
\end{tabular}

*Values are shown for rye, estimated in this study. Numbers in parentheses are distances to the $95 \%$ confidence limits. 
Table 2.2: Constants used for stomatal conductance submodels

\begin{tabular}{|c|c|c|c|}
\hline Constant & Value & Units & Description \\
\hline \multicolumn{4}{|c|}{ Photosynthesis submodel constants $^{1}$} \\
\hline$\left[\mathrm{O}_{2}\right]$ & 0.209 & $\mathrm{~mol} \mathrm{~mol}^{-1}$ & Ambient $\mathrm{O}_{2}$ concentration \\
\hline$a$ & 0.86 & $\mu \mathrm{mol} \mathrm{CO} 2(\mu \mathrm{E})^{-1}$ & Leaf absorbtance to $\mathrm{CO}_{2}$ \\
\hline$\alpha$ & 0.05 & unitless & Quantum efficiency \\
\hline$\tau_{25}$ & 2600 & unitless & $\mathrm{CO}_{2} / \mathrm{H}_{2} \mathrm{O}$ specificity ratio \\
\hline$k c_{25}$ & 296 & $\mu \mathrm{mol} \mathrm{mol}{ }^{-1}$ & Michaelis-Menten $\mathrm{CO}_{2}$ constant \\
\hline $\mathrm{ko}_{25}$ & 296 & $\mathrm{mmol} \mathrm{mol}^{-1}$ & Michaelis-Menten $\mathrm{O}_{2}$ constant \\
\hline Q10 $\tau$ & 0.57 & unitless & Temperature sensitivity for $\tau$ \\
\hline Q10 $k c$ & 2.1 & unitless & Temperature sensitivity for $k c$ \\
\hline Q10 $0_{\mathrm{ko}}$ & 1.2 & unitless & Temperature sensitivity for $k o$ \\
\hline$Q 10_{R d}$ & 2.0 & unitless & Temperature sensitivity for $R_{d}$ \\
\hline Q10 Vcmax & 2.4 & unitless & Temperature sensitivity for $V_{\text {cmax }}$ \\
\hline \multicolumn{4}{|c|}{ Field-specific constants } \\
\hline$P$ & 930 & $\mathrm{mb}$ & Atmospheric pressure \\
\hline$z$ & 3.5 & $\mathrm{~m}$ & Measurement height \\
\hline$h$ & 1 & $\mathrm{~m}$ & Canopy height (measured) \\
\hline$d_{o}$ & 0.6 & $\mathrm{~m}$ & Zero-plane displacement ${ }^{2}$ \\
\hline$z_{\text {om }}$ & 0.15 & $\mathrm{~m}$ & Roughness height for momentum ${ }^{3}$ \\
\hline$z_{o v}$ & 0.015 & $\mathrm{~m}$ & Roughness height for water vapor ${ }^{4}$ \\
\hline$u_{* \min }$ & 0.06 & $\mathrm{~ms}^{-1}$ & Friction velocity threshold \\
\hline$\psi_{\text {sat }}$ & 5.66 & $\mathrm{kPa}$ & Saturation water potential \\
\hline$b_{\psi}$ & 5.3 & unitless & Clapp-Hornberger parameter \\
\hline$n$ & 0.58 & $\mathrm{~m}^{3} \mathrm{~m}^{-3}$ & Porosity \\
\hline \multicolumn{4}{|c|}{ General constants } \\
\hline$g$ & 9.81 & $\mathrm{~m} \mathrm{~s}^{-2}$ & Gravitational acceleration \\
\hline$C_{p}$ & 1005 & $\mathrm{~J} \mathrm{~kg}^{-1} \mathrm{~K}^{-1}$ & Specific heat capacity of air \\
\hline$L v$ & $2.45 \times 10^{6}$ & $\mathrm{~J} \mathrm{~kg}^{-1}$ & Latent heat of vaporization \\
\hline$R$ & 8.314 & $\mathrm{~J} \mathrm{~mol}^{-1} \mathrm{~K}^{-1}$ & Ideal gas constant \\
\hline$\rho_{a}$ & 1.18 & $\mathrm{~kg} \mathrm{~m}^{-3}$ & Air density \\
\hline & 0.4 & unitless & von Kármán constant \\
\hline Phot & is submo & constants are fro & z et al. [1991]. ${ }^{2}$ [Baldocchi, 1997 \\
\hline
\end{tabular}

Sensitivity Analyses

We subjected the primary response variables, $g_{s-\min }$ and $\psi_{*}$, to sensitivity analyses to

determine the relative effect on our results of variability or uncertainty in the model 
parameters. For each of the eight model parameters, values were determined from the literature (Table 2.3), and sensitivity was evaluated over the range of each parameter (summarized as 'sensitivity range' in Table 2.4). Since measurements of $g_{s-E C}$ were available for comparison with modeled $g_{s-m i n}$, we used the behavioral mapping analysis of Hornberger and Spear [1981] to assess sensitivity of $g_{s-\min }$ to parameter values. The behavioral mapping analysis required a Monte Carlo simulation with 10,000 realizations. For each realization, values for each submodel parameter were sampled randomly from uniform distributions (i.e. sensitivity ranges) and were used to estimate $g_{s-\min }$ for the validation period. The correlation coefficient and regression slope between $g_{s-\min }$ and $g_{s-}$ $E C$ were used to assess goodness of fit between observed and simulated conductances, and to assign each parameter set to a category of those that met correlation and slope requirements (behavior) and those that did not (non-behavior). For each parameter, a two-sample Kolmogorov-Smirnov (K-S) test was used to compare cumulative distribution functions of behavior and non-behavior categories. The resulting K-S statistic measured the significance of $g_{s-\min }$ sensitivity to model parameters. 
Table 2.3: Parameter estimates from the literature for assimilation-limited stomatal conductance submodel ${ }^{*}$

\begin{tabular}{|c|c|c|c|c|c|c|c|c|}
\hline $\begin{array}{c}V c_{\max 25} \\
{\left[\mu \mathrm{mol} \mathrm{m}^{-2} \mathrm{~s}^{-1}\right]}\end{array}$ & $\begin{array}{c}\text { Species / } \\
\text { Description }\end{array}$ & $\begin{array}{c}R_{d 25} \\
{\left[\mu \mathrm{mol} \mathrm{m}^{-2} \mathrm{~s}^{-1}\right]} \\
\end{array}$ & $\begin{array}{c}\text { Species / } \\
\text { Description }\end{array}$ & $m$ & $\begin{array}{c}\text { Species / } \\
\text { Description }\end{array}$ & $\begin{array}{c}b \\
{\left[\mathrm{~mol} \mathrm{~m}^{-2} \mathrm{~s}^{-1}\right]}\end{array}$ & $\begin{array}{c}\text { Species / } \\
\text { Description }\end{array}$ & $\begin{array}{l}{ }^{*} \text { Data are organized by plant } \\
\text { functional type (broad- } \\
\text { leaves or needle-leaves) }\end{array}$ \\
\hline \multicolumn{9}{|c|}{ Needle-leaves } \\
\hline 50.4 & Maritime Pine $^{1}$ & 3.3 & P. strobus ${ }^{4}$ & 5.5 & P. taeda ${ }^{6}$ & 0.000 & P. taeda ${ }^{6}$ & \multirow{24}{*}{$\begin{array}{l}{ }^{1} \text { Delzon et al., 2005; } \\
{ }^{2} \text { Baldocchi and Meyers, } \\
\text { 1998; }{ }^{3} \text { Wang et al., 1996; } \\
{ }^{4} \text { Vose and Ryan, } 2002 \text { (18 } \\
\text { deg); }{ }^{5} \text { Gao et al., } 2003 ; \\
{ }^{6} \text { Katul et al. 2000; }{ }^{7} \text { Kosugi } \\
\text { et al., } 2003 \text { (mature leaves); } \\
{ }^{8} \text { Wilson et al., 2001; } \\
{ }^{9} \text { Dreyer et al., 2001; Bonan, } \\
{ }^{2002}{ }^{10}\end{array}$} \\
\hline 45.7 & Boreal Conifers ${ }^{2}$ & 2.3 & P. massoniana ${ }^{5}$ & 7.5 & Needle Forest $^{2}$ & & & \\
\hline 37.5 & P. sylvestris ${ }^{2}$ & 1.6 & P. elliottii ${ }^{5}$ & & & & & \\
\hline & & 2.3 & P. caribaea ${ }^{5}$ & & & & & \\
\hline & & 2.5 & Boreal Conifer $^{2}$ & & & & & \\
\hline & & 1.0 & P. sylvestris ${ }^{3}$ & & & & & \\
\hline \multicolumn{8}{|c|}{ Broad-leaves } & \\
\hline 39.7 & $\begin{array}{l}\text { Temp. Broad- } \\
\text { leaves }^{2}\end{array}$ & 0.7 & $\begin{array}{l}\text { Temp. Broad- } \\
\text { leaves }^{2}\end{array}$ & 9.0 & Non-needle Leaf ${ }^{10}$ & 0.010 & Deciduous Forest $^{8}$ & \\
\hline 47.8 & P. orientalis ${ }^{7}$ & 2.1 & A. pseudoplatanus ${ }^{9}$ & 9.5 & Deciduous Forest $^{2}$ & 0.061 & P. orientalis ${ }^{7}$ & \\
\hline 40.7 & L. tulipifera ${ }^{7}$ & 2.2 & B. pendula ${ }^{9}$ & 7.8 & Deciduous Forest $^{8}$ & 0.052 & L. tulipifera $^{7}$ & \\
\hline 51.9 & P. xyedoensis ${ }^{7}$ & 1.9 & F. sylvatica ${ }^{9}$ & 9.8 & P. orientalis ${ }^{7}$ & 0.094 & P. xyedoensis ${ }^{7}$ & \\
\hline 27.8 & C. japonicum ${ }^{7}$ & 2.1 & F. excelsior ${ }^{9}$ & 9.3 & L. tulipifera ${ }^{7}$ & 0.058 & C. japonicum ${ }^{7}$ & \\
\hline 60.0 & Q. alba ${ }^{8}$ & 1.9 & J. regia ${ }^{9}$ & 6.9 & P. xyedoensis ${ }^{7}$ & & & \\
\hline 63.1 & Q. prinus ${ }^{8}$ & 2.1 & Q. petraea ${ }^{9}$ & 5.8 & C. japonicum ${ }^{7}$ & & & \\
\hline 37.6 & A. rubrum $^{8}$ & 2.2 & Q. robur ${ }^{9}$ & & & & & \\
\hline 42.8 & A. saccharum ${ }^{8}$ & 2.1 & P. orientalis ${ }^{7}$ & & & & & \\
\hline 39.2 & $\begin{array}{l}\text { N. sylvatica } \\
\text { A. }\end{array}$ & 2.1 & L. tulipifera ${ }^{7}$ & & & & & \\
\hline 77.8 & pseudoplatanus $^{9}$ & 2.4 & P. xyedoensis ${ }^{7}$ & & & & & \\
\hline 70.5 & B. pendula ${ }^{9}$ & 2.2 & C. japonicum ${ }^{7}$ & & & & & \\
\hline 66.3 & F. sylvatica ${ }^{9}$ & & & & & & & \\
\hline 84.6 & F. excelsior ${ }^{9}$ & & & & & & & \\
\hline 63.6 & J. regia ${ }^{9}$ & & & & & & & \\
\hline 87.7 & Q. petraea ${ }^{9}$ & & & & & & & \\
\hline 90.5 & Q. robur ${ }^{9}$ & & & & & & & \\
\hline
\end{tabular}


The water stress threshold varied with soil properties and vegetation type, and also with changing environmental conditions (Equation 2.6). A general sensitivity analysis evaluated the sensitivity of $\psi_{*}$ to variability of parameters and micrometeorological conditions. Parameters were increased systematically and individually over the sensitivity ranges (Table 2.4 ) while others were held constant and $\psi_{*}$ was calculated from Equation 2.6 for combinations of relatively warm $\left(25^{\circ} \mathrm{C}\right)$ and $\operatorname{cool}\left(15^{\circ} \mathrm{C}\right)$ leaf temperatures and relatively humid (relative humidity, $R H=0.60)$ and dry $(R H=0.30)$ atmospheric conditions. PAR was held constant at a moderate level of $1000 \mu$ moles $\mathrm{m}^{-2}$ $\mathrm{s}^{-1}$ (approximately one-half full sunlight, $520 \mathrm{~W} \mathrm{~m}^{-2}$ ) for the entire analysis.

Table 2.4: Parameters used to represent vegetation functional types and ranges for each parameter used in sensitivity analysis ${ }^{*}$

\begin{tabular}{|c|c|c|c|c|}
\hline Parameter & Broad-leaves & Needle-leaves & Rye (This study) & Sensitivity Range \\
\hline \multicolumn{5}{|c|}{ Water-limited Submodel } \\
\hline$g_{\text {om }}$ & 251.31 & 213.45 & 69.0 & $63.2-456$ \\
\hline$k_{\psi}$ & 0.3099 & 0.1189 & 0.142 & $0.0145-0.534$ \\
\hline$k_{\alpha \beta}$ & 0.2244 & 0.3338 & 0.151 & $0.087-0.545$ \\
\hline$k_{\beta g}$ & 0 & 352.48 & 44.0 & $0-667$ \\
\hline \multicolumn{5}{|c|}{ Assimilation-limited Submodel } \\
\hline$V c_{\max 25}$ & 58.3 & 44.5 & 38.8 & $27.8-90.5$ \\
\hline$R_{d 25}$ & 1.99 & 2.17 & 0.46 & $0.71-3.27$ \\
\hline$m$ & 8.3 & 6.5 & 12.0 & $5.5-12$ \\
\hline$b$ & 0.055 & 0.000 & 0.015 & $0-0.094$ \\
\hline
\end{tabular}

*For water-limited submodel, values for broad-leaves, and needle-leaves are from Gao et al. [2002, 2003]. For the assimilation-limited submodel, values for broad-leaves and needle-leaves are averages from previous studies listed in Table 2.3. Parameters obtained from nonlinear regression on rye at Blandy Experimental Farm are used to represent grasses. For all parameters, the sensitivity range is the range of values reported across all functional types. 
Additionally, we simulated $\psi_{*}$ across ranges of environmental conditions and plant functional types. Parameters for the two submodels were collected from the literature and assembled in sets representing three plant functional types: grasses, broad-leaf trees, and needle-leaf trees. For each plant functional type, we evaluated variability of $\psi_{*}$ over simulated ranges of environmental conditions (PAR and $R H$ ) while holding temperature and $C_{a}$ constant.

We also used the linear relationships between leaf nitrogen and $A_{n}$ developed by Field and Mooney [1986] to demonstrate the effect of variable foliar nitrogen concentration on $\psi_{*}$ over changing environmental conditions ( $R H$ and Temperature). Specifically, we varied $V_{\text {Cmax }}$ in direct proportion to foliar nitrogen concentrations to demonstrate the potential influence of nutrient availability on the modeled water stress threshold. 


\section{Results and Discussion}

\section{Model Parameterization and Validation}

This modeling strategy yields a reasonable prediction of leaf-level stomatal conductance, $g_{\text {s-min, }}$ particularly when compared to individual submodel predictions (Figure 2.3).

Differences in regression slopes between the calibration period and validation period may be due, in part, to the assumption of constant $L A I$ for the entire experiment. In other words, if $L A I$ increases throughout the course of the validation period, simulated stomatal conductance may underestimate expected stomatal conductance by a factor proportional to $L A I$. In much the same manner, assuming static values for other parameters may adversely affect model fit at time scales of vegetation growth. For example, changes in biomass and biomass distribution during the course of a growing season (i.e. plant growth and aboveground versus belowground production) will likely affect not only $L A I$ but also plant hydraulic conductivity. In these cases, model fit may be improved by some knowledge of how these parameters vary through time, or by use of a submodel with more explicit definition of the relationships between processes and evolving vegetation.
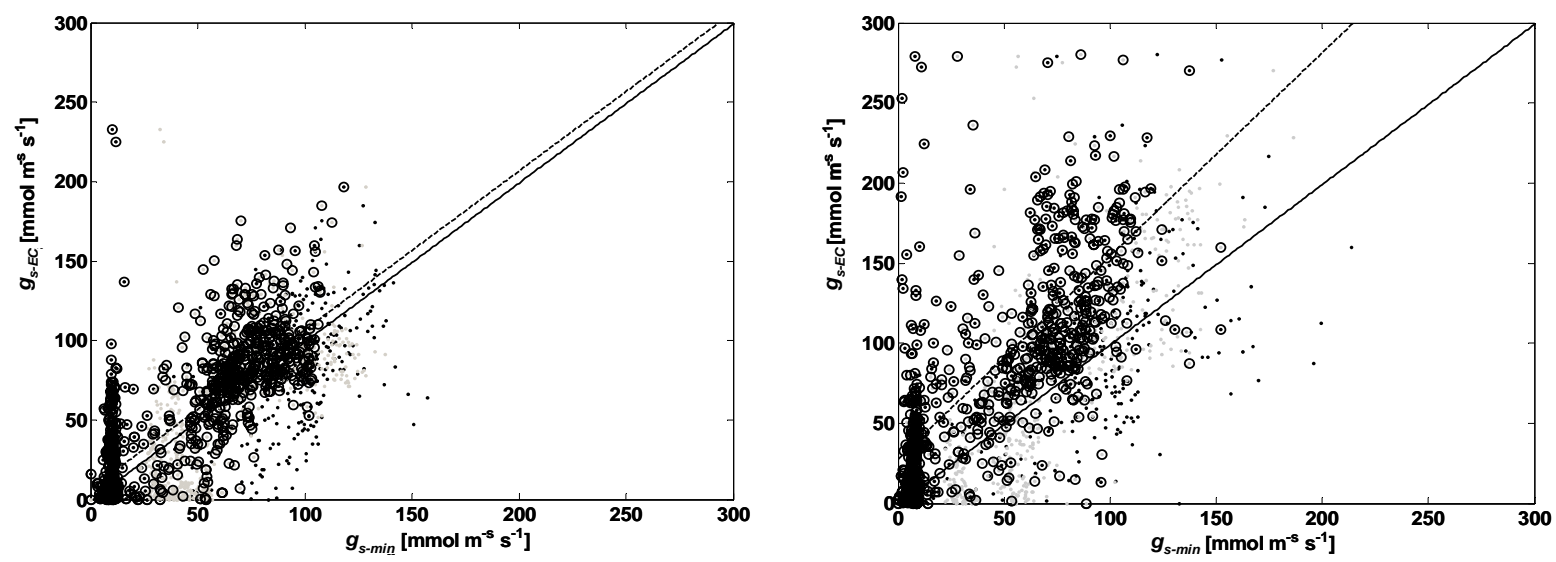

Figure 2.3: Simulated stomatal conductances $\left(g_{s-m i n}\right)$ versus eddy covariancederived stomatal conductances $\left(g_{s-E C}\right)$ for calibration period (a) and validation 
period (b). For the calibration period, $g_{s-\min }$ (open circles) has $\rho=0.77$ and slope $=1.01$. Submodel conductances $g_{s-A}$ (black dots, $\rho=0.48$ for calibration period) and $g_{s-W}$ (grey dots, $\rho=0.67$ for calibration period) are also shown. For the validation period, $g_{s-\min }$ has $\rho=0.70$ and slope $=1.27$ (for $g_{s-A}, \rho=0.59$ and for $\left.g_{s-W}, \rho=0.63\right)$. Regression slope shown as broken line, 1:1 shown as solid line.

Agreement between $g_{s-m i n}$ and $g_{s-E C}$ appears to be better during drier conditions than during wetter conditions (Figure 2.4); however, no significant relationship exists between the residual term $g_{s-E C}-g_{s-m i n}$ and soil moisture. Systematic underestimation of $g_{s-E C}$ between days 140 and 150 may result from the contribution of surface evaporation to ET following the precipitation events occurring between days 139 and 143. Based on Equation 2.9, any contribution of surface evaporation to measured ET results in an

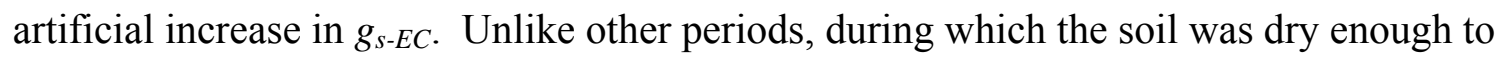
assume that ET consisted entirely of transpiration, wet conditions on these days likely violated this assumption.
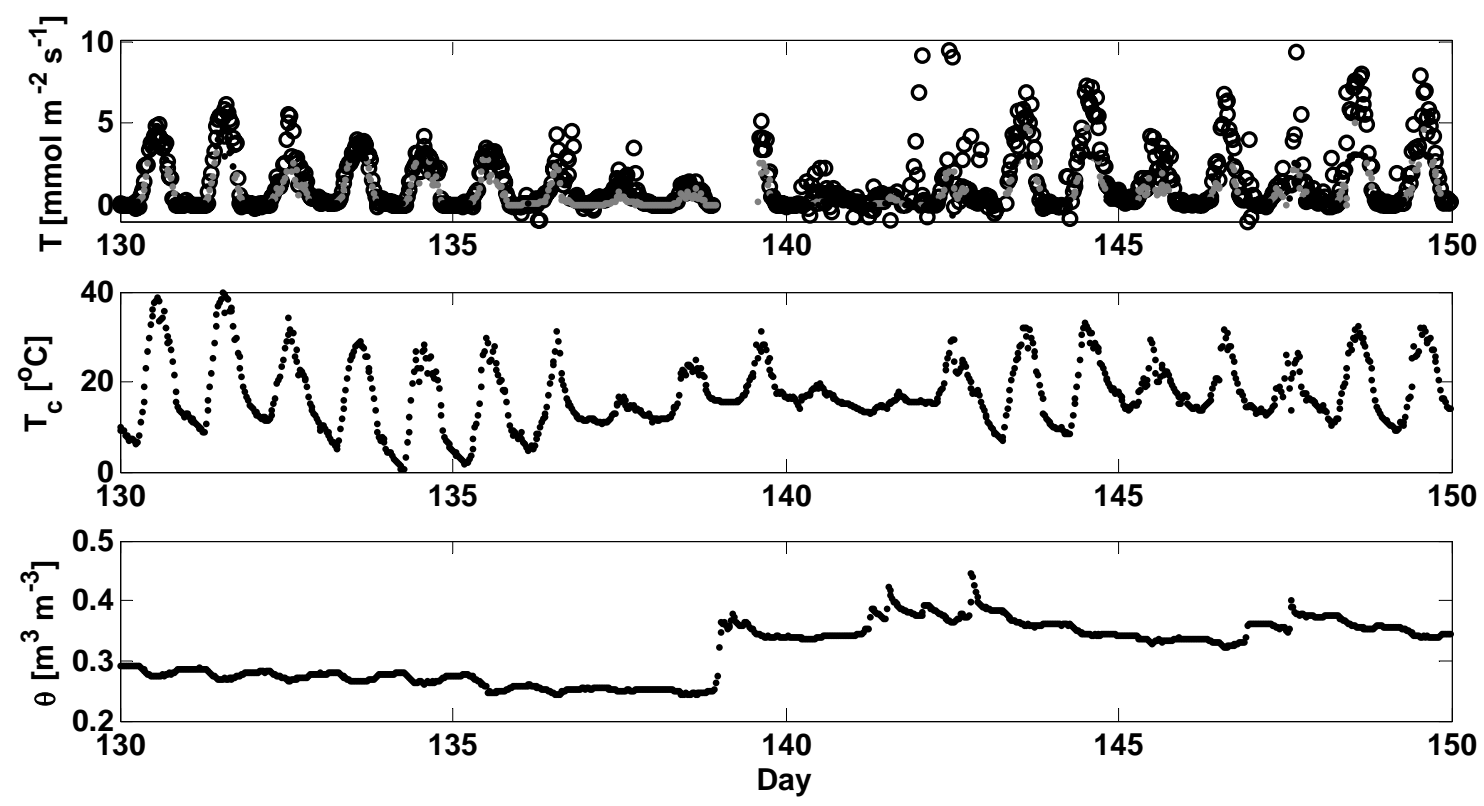
Figure 2.4: Predicted transpiration $\left(g_{s-\min } d_{v}\right)$ versus eddy covariance-derived evapotranspiration $\left(g_{s-E C} d_{v}\right)$ for the validation period (top panel). Open circles are eddy-covariance measurements and filled circles are predicted values of water-limited (grey) or assimilation-limited (black) transpiration. Also shown are canopy surface temperature $\left(T_{c}\right)$ and volumetric soil moisture $(\theta)$ during the validation period (middle and bottom panes).

\section{Sensitivity to Environmental Variables and Model Parameters}

Simulated $g_{s-\min }$ was sensitive to seven of the eight model parameters (Figure 2.5). Varying $R_{d 25}$ across ranges of published values did not significantly affect the model fit. This parameter is often considered a residual term for net photosynthesis, and is at least several times smaller than gross photosynthesis. The parameter that exerts the most influence on $g_{s-m i n}$ is $k_{\beta g}$, the sensitivity of stomatal conductance to $d_{v}$. Because of the close relationship between stomatal conductance and $d_{v}$ [Leuning, 1995; Oren et al. 1999; Gao et al. 2002], $k_{\beta g}$ is expected to have a strong impact on modeled stomatal conductance. Notice how the dependence of $g_{s-\min }$ on $d_{v}$ is in overall agreement with the empirical result by Oren et al. [1999] who found stomatal conductance to be proportional to $\left[1-\eta \log \left(d_{\mathrm{v}}\right)\right]$ with $\eta=0.53-0.60$. In fact, for relatively high values of $k_{\beta g}$ (needle leaves or rye, see Table 2.4) the right-hand side of Equation 2.4 is proportional to $1 / d_{\mathrm{v}}$ (waterlimited conditions), in agreement with the framework by Katul et al. [2003], whereas according to Equation 2.1 stomatal conductance is proportional to $d_{\mathrm{v}}^{-0.5}$ (assimilationlimited conditions). For $1 \mathrm{kPa}<d_{\mathrm{v}}<5 \mathrm{kPa}\left[1-\eta \log \left(d_{\mathrm{v}}\right)\right]$ can be approximated by $d_{\mathrm{v}}^{-1}$ [Katul et al., 2003] and falls between the two curves $d_{\mathrm{v}}{ }^{-1}$ and $d_{\mathrm{v}}{ }^{-0.5}$. 
Because the behavior analysis is conditioned upon field observations, this analysis is only directly applicable to the range of environmental conditions observed during the field observations. It is possible and altogether likely that behavior mapping of model responses to different vegetation or under different environmental conditions of light, temperature and humidity would result in different sensitivities of $g_{s-m i n}$. Furthermore, we note that, particularly when calibrated using ecosystem-level data, the physical significance of individual parameters is broadened to incorporate multiple factors and ecosystem processes including the potential effects of cavitation on xylem-water conductance and access to soil water based on rooting depth [e.g. Sperry et al., 2002]. 

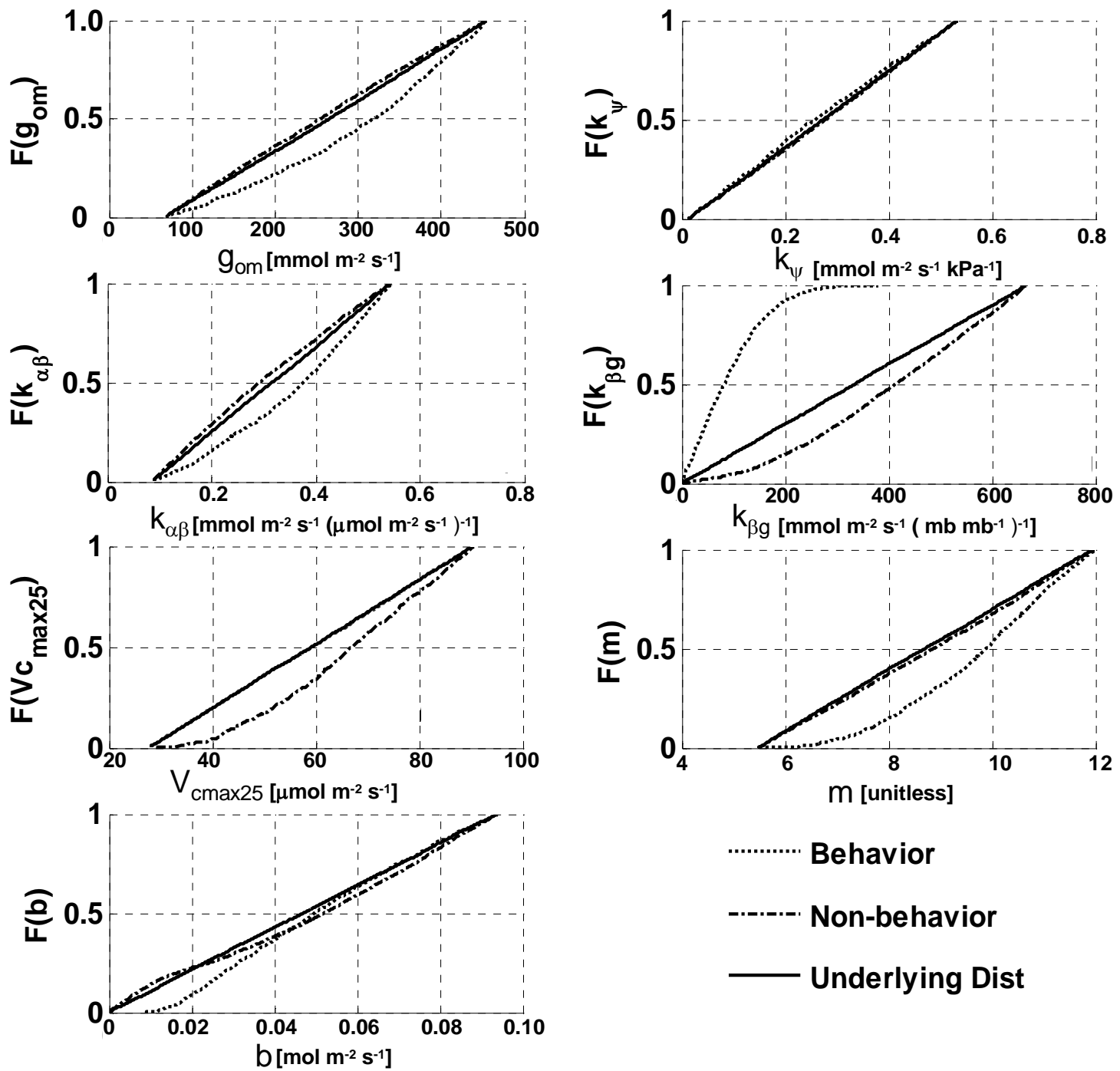

Behavior

\section{Non-behavior}

Underlying Dist

Figure 2.5: Behavior and non-behavior cumulative distribution functions for model parameters $g_{o m}(\mathrm{~K}-\mathrm{S}=0.18), k_{\psi}(\mathrm{K}-\mathrm{S}=0.05), k_{\alpha \beta}(\mathrm{K}-\mathrm{S}=0.19), k_{\beta g}(\mathrm{~K}-\mathrm{S}=$ $0.78), V c_{\max 25}(\mathrm{~K}-\mathrm{S}=0.20), m(\mathrm{~K}-\mathrm{S}=0.23)$, and $b(\mathrm{~K}-\mathrm{S}=0.16)$ during the study period. 
The second sensitivity analysis examined the sensitivity of $\psi_{*}$ to model parameters in different regimes of temperature and atmospheric humidity (Figure 2.6). Two important characteristics of $\psi_{*}$ are apparent from this sensitivity analysis:
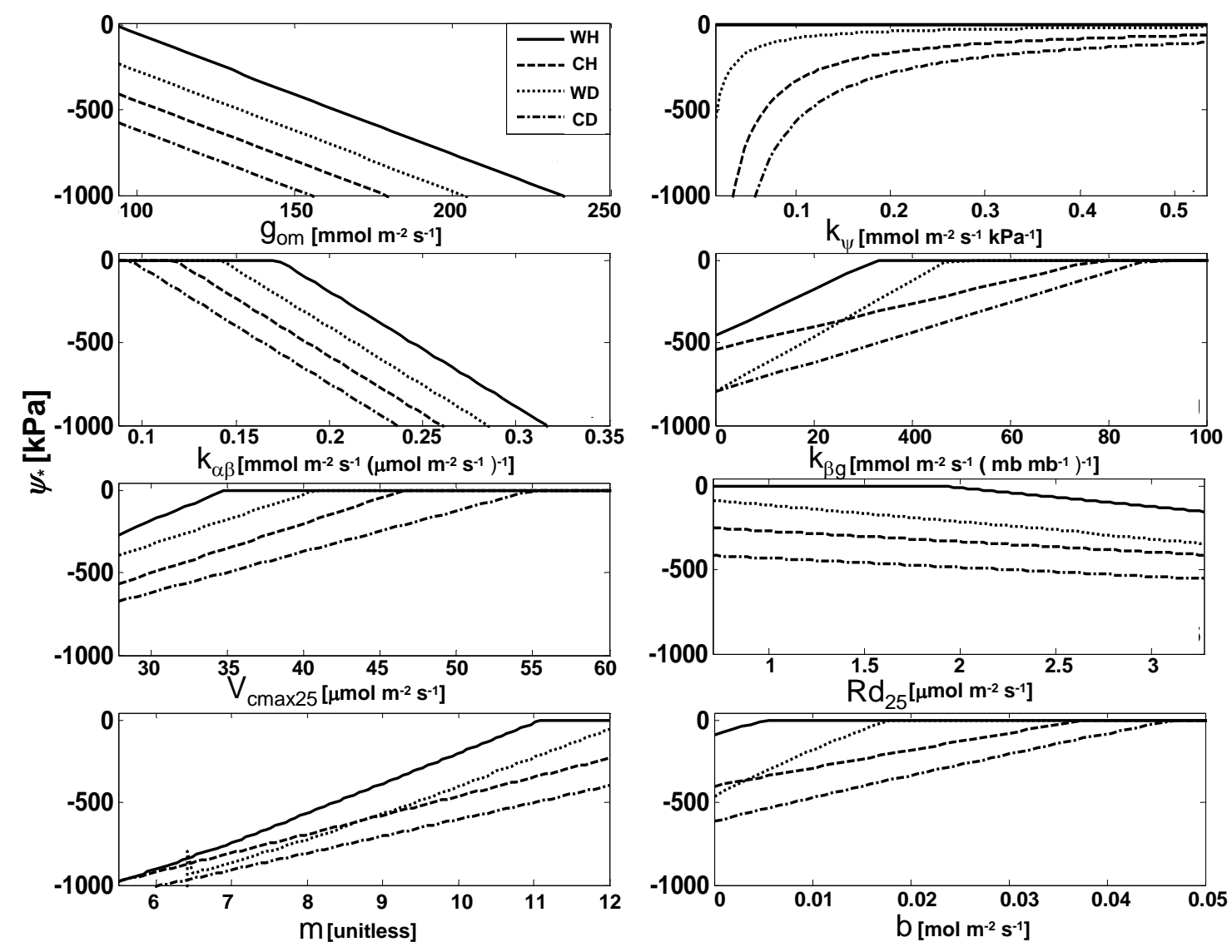

Figure 2.6: General sensitivity of $\psi *$ to relative humidity $(R H)$ and photosynthetically active radiation $(P A R)$ across ranges of $g_{o m}, k_{\psi}, k_{\alpha \beta}, k_{\beta g}$, $V c_{\max 25}, R d_{25}, m$, and $b . \mathrm{WH}$ represents warm, humid conditions $\left(T_{C}=25{ }^{\circ} \mathrm{C}, R H\right.$ $=0.60), \mathrm{CH}$ represents cool, humid conditions $\left(T_{C}=15{ }^{\circ} \mathrm{C}, R H=0.60\right), \mathrm{WD}$ represents warm, dry conditions $\left(T_{C}=25^{\circ} \mathrm{C}, R H=0.30\right)$, and $\mathrm{CD}$ represents cool, 
dry conditions $\left(T_{C}=15^{\circ} \mathrm{C}, R H=0.30\right) . P A R$ is held constant at $1000 \mu$ moles $\mathrm{m}^{-2}$ $\mathrm{S}^{-1}$

First, the general effect of increasing temperature or humidity is to increase $\psi_{*}$. Because temperature and humidity act on assimilation (temperature through Equation 2.3 and humidity through the iterative solution for $g_{s-A}$ and $A_{n}$ [see Collatz et al., 1991]) increasing either of these variables creates conditions favorable for plant photosynthetic activity. As conditions become more favorable for carbon assimilation, stomatal conductance required to maintain optimal rates of assimilation also increases. Consequently soil water potential required to support the stomatal conductance also increases; $\psi_{*}$ increases to reflect this requirement (i.e. more water is required to sustain high rates of assimilation). The relationship between temperature, humidity and $\psi_{*}$ is complicated by the effect of temperature on $d_{v}$ and subsequent interactions between $d_{v}$, ET and stomatal conductance (see Equations 2.9 and 2.10, and also Oren et al. [1999]). Increasing temperature but not humidity causes $d_{v}$ to increase. On one hand, increasing $d_{v}$ decreases $g_{s-A}\left(\right.$ through $D_{v}$ in Equation 2.1), and thereby decreases water stress indirectly by promoting stomatal closure. On the other hand, increasing $d_{v}$ directly increases $\psi_{*}$ by raising atmospheric demand for water (Equation 2.6). For the combination of parameters representing vegetation at Blandy Experimental Farm and used in the sensitivity analysis, the indirect effect of high $d_{\nu}$ to decrease $\psi_{*}$ through stomatal closure is masked by the direct influence of $d_{\nu}$ on $\psi_{*}$. 
We note that $\psi_{*}$ is not the wilting point; in other words plant activities do not cease at soil water potentials below $\psi_{*}$. Rather, $\psi_{*}$ indicates the point at which soil water availability can no longer support carbon assimilation at the optimal rate otherwise prescribed by environmental conditions. In this context $\psi_{*}$ may be interpreted as a measure of the likelihood of vegetation to experience water stress. If $\psi_{*}$ is very low relative to the distribution of soil moisture at a particular site, vegetation may rarely experience water stress [Ridolfi et al., 2000].

The second important characteristic of $\psi_{*}$, apparent from the sensitivity analysis is that soil moisture may always limit stomatal conductance and transpiration (Figure 2.6). In other words, for each parameter there exists some combination of environmental conditions and parameter values for which $\psi_{*}$ approaches or reaches its maximum value, 0. Under these conditions, $\psi_{s}<\psi_{*}$, meaning soil moisture limits stomatal conductance.

We also note that $\psi_{*}$ exhibits a positive response to some parameters and negative response to others. Parameters causing a positive response in $\psi_{*}\left(k_{\psi}, k_{\beta g}, V_{C \max }, m\right.$ and $\left.b\right)$ are those that reduce the sensitivity of water-limited stomatal conductance to changes in soil moisture $\left(k_{\psi}\right)$ or atmospheric humidity $\left(k_{\beta g}\right)$, or those that cause an increase in assimilation-limited stomatal conductance $\left(V_{C \max }, m\right.$ and $\left.b\right)$. Parameters causing a negative response in $\psi_{*}\left(g_{o m}, k_{\alpha \beta}\right.$ and $\left.R_{d 25}\right)$ increase water-limited stomatal conductance 
relative to assimilation-limited stomatal conductance, or in the case of $R_{d 25}$ decrease assimilation-limited stomatal conductance by decreasing $A_{n}$.

\section{Dependence of Water Stress Threshold on Environmental Conditions}

Transpiration derived from modeled stomatal conductance at Blandy Experimental Farm experienced periodic water stress because of changes in soil moisture and changes in other state variables used to calculate $\psi_{*}$. Beginning around day 130 , peak daily values of transpiration declined with falling soil moisture until by day 136, transpiration was constantly limited by soil moisture (Figure 2.4). On days 140 and 141, soil moisture increased in response to precipitation. On these days, transpiration was limited by assimilation (i.e. not limited by soil moisture). It is also likely that decreasing temperature and $P A R$ suppressed $A_{n}$, resulting in assimilation-limited stomatal conductance and transpiration. The shift from water-stressed to unstressed conditions following precipitation is expected; however, this modeling strategy explains the shift in terms of a combination of environmental factors and not soil moisture alone.

Another new aspect of this modeling framework is its ability to emulate the piecewiselinear function commonly used to scale stomatal conductance in response to water stress. Using parameters derived from Blandy Experimental Farm we simulated stomatal conductance at constant temperature and $P A R$ with varying $R H$ across a range of soil water potentials $(2.7)$. The wilting point $\left(g_{s-\min }=0 \mathrm{mmol} \mathrm{m} \mathrm{s}^{-1}\right)$ and the water-limited section of the function are defined by $g_{s-W}$ whereas the water-independent section of the 
function is defined by $g_{s-A} \cdot \psi_{*}$ is the point of intersection between these two segments, and varies as a function of atmospheric humidity.

As the atmosphere becomes more humid, the slope of the water-limited range of stomatal conductance increases. The equilibrium between root water uptake and transpiration in the Gao et al. [2002] model necessitates this changing slope. Additionally, assimilationlimited stomatal conductance increases with increasing atmospheric humidity as a result of the semi-empirical sensitivity of stomatal conductance to $D_{v}$ (Equation 2.1). Because of the independent responses of these two submodels to atmospheric humidity $\psi_{*}$ varies nonlinearly with atmospheric humidity. Submodels also vary independently with respect to light and temperature (directly for $g_{s-A}$ through temperature-dependent $A_{n}$ and indirectly for $g_{s-W}$ through the temperature-saturation vapor pressure relationship). 


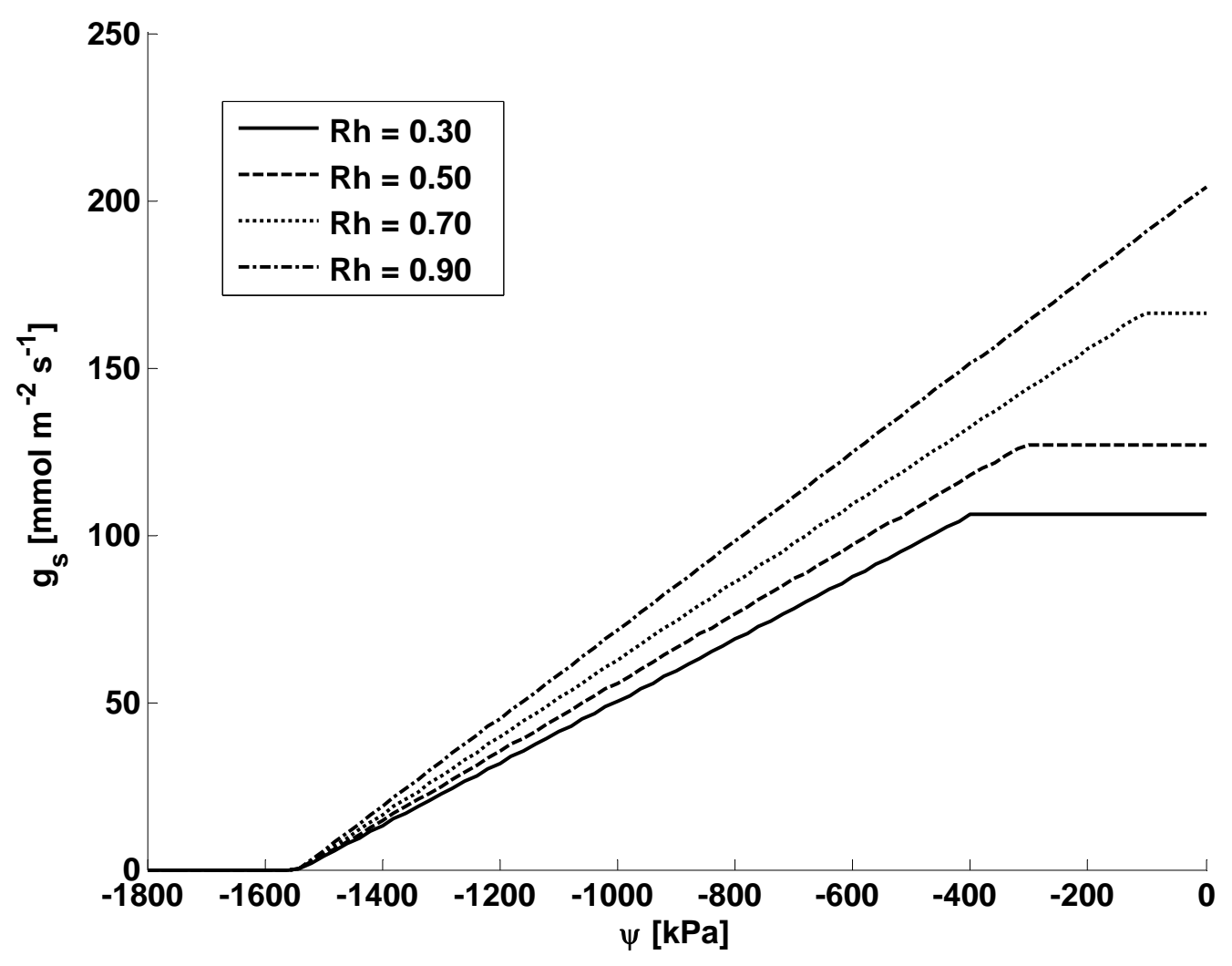

Figure 2.7 Simulated stomatal conductance $\left(g_{s-m i n}\right)$ over a range of soil water potentials at different relative humidities $(R H)$. Photosynthetically active radiation $(P A R)$ is held constant at $1000 \mu$ moles $\mathrm{m}^{-2} \mathrm{~s}^{-1}$ and temperature is held constant at $15{ }^{\circ} \mathrm{C}$.

\section{Comparing Water Stress Threshold Among Plant Functional Types}

Representative plant functional types included broad-leaf and needle leaf trees (Table 2.3) and grasses (represented by ryegrass at Blandy Experimental Farm). The $\psi_{*}$ response to $P A R$ and $R H$ (at a constant temperature) differed, not surprisingly, among the three plant functional types (Figure 2.8). 

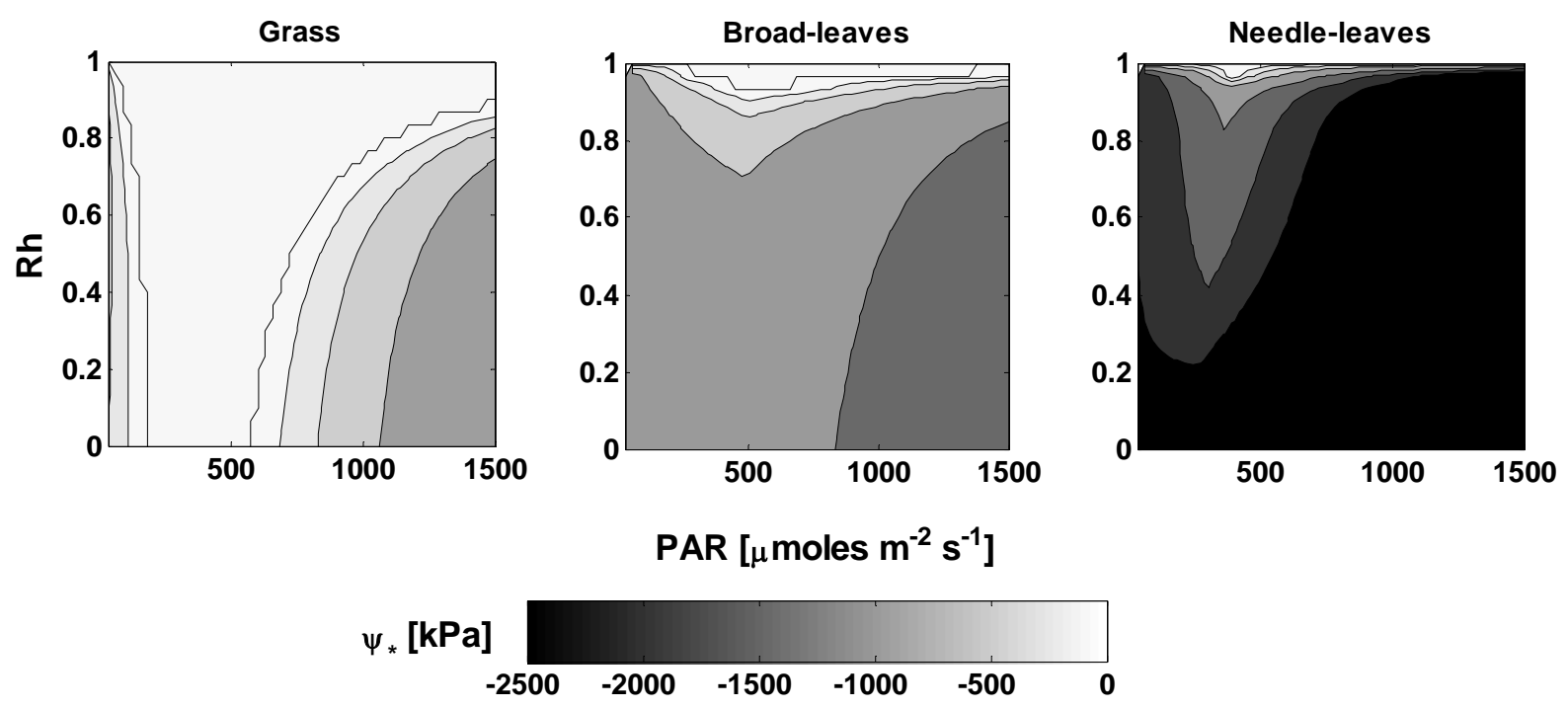

Figure 2.8: Water stress threshold $\left(\psi^{*}\right)$ for three plant functional types as a function of photosynthetically active radiation (PAR) and relative humidity $(\mathrm{RH})$. Temperature is held constant at $15^{\circ} \mathrm{C}$.

Based on the parameter sets used to represent each plant functional type, grasses have the highest $\psi_{*}$ values, or the greatest tendency to experience water stress (Figure 2.8). Across the $P A R-R H$ variable space, $\psi_{*}$ is frequently $0 \mathrm{kPa}$ for grasses, meaning that water is always limiting. Broad-leaves have lower $\psi_{*}$ values than grasses throughout most of the variable space, and needle leaves are only water-limited over a small range of $P A R$ and $R H$. These differences in $\psi_{*}$ among functional types suggest that grasses are most likely of the three functional types to experience water stress for wide ranges of $P A R$ and $R H$, broad-leaves are less likely to experiences water stress than grasses, and needle-leaves are least likely to experience water stress. Interestingly, Maherali et al. [2004] found a similar relationship between the vulnerabilities of broad-leaves and needle-leaves to water stress when comparing resistances to cavitation among plant types. 
In general, grasses are always water-stressed except for periods of low $R H$ and high PAR. Stomatal closure at low $R H\left(\right.$ high $\left.d_{v}\right)$ is expected, but reduced $\psi_{*}$ at high PAR is counterintuitive considering the important role of PAR in assimilation (Equation 2.3). Reduced $\psi_{*}$ despite increasing PAR may result from the light-sensitivity of water-limited stomatal conductance superseding the light-sensitivity of $A_{n}$ for small values of $g_{s-A}$ at low $R H$. Alternatively, $\psi_{*}$ may decrease with increasing $P A R$ because $g_{s-A}$ is already in the Rubisco-limited (PAR-independent) range of assimilation, whereas $g_{s-W}$ is still dependent on PAR. The ridge of $\psi_{*}$ (between 300 and $500 \mu$ moles $\mathrm{m}^{-2} \mathrm{~s}^{-1} P A R$ ) may correspond to the transition between light-limited $A_{n}$ and Rubisco-limited $A_{n}$ and the resulting effect on the PAR dependence of $g_{s-A}$.

We also examined the effect of nutrient availability on $\psi_{*}$ through the photosynthesis parameter $V c_{\max 25}$. Field and Mooney [1986] quantified, using linear regression, the positive relationship between Rubisco-limited assimilation $\left(V c_{\max }\right)$ and foliar nitrogen concentration. Using their regression equation for needle-leaves, we examined the effect of leaf nitrogen content on $\psi_{*}$ across a range of temperatures in needle-leaf trees at constant PAR (Figure 2.9). At low temperatures and leaf nitrogen levels, $A_{n}$ is low, resulting in reduced assimilation-limited stomatal conductance and thus a low likelihood of water stress. In general, $\psi_{*}$ increases with increasing leaf nitrogen, resulting in a higher likelihood of water stress as photosynthetic capacity increases and requires greater stomatal conductance to meet demands for $\mathrm{CO}_{2}$. 

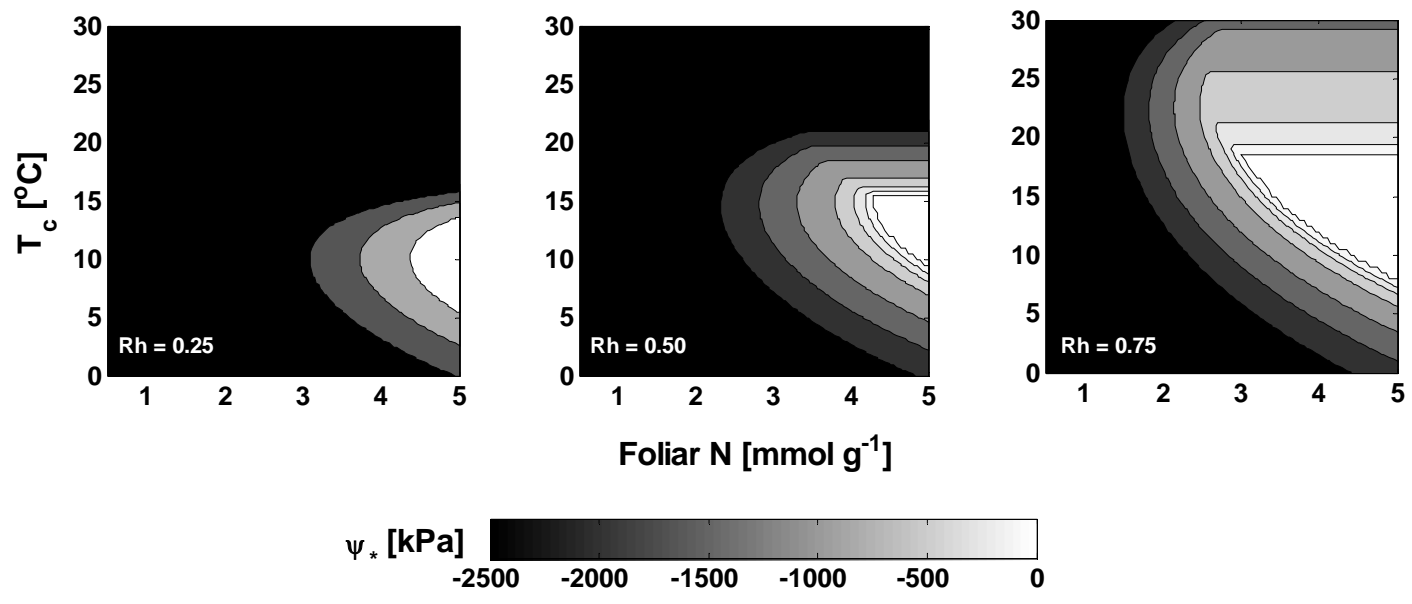

Figure 2.9: Water stress threshold $\left(\psi_{*}\right)$ as a function of temperature $\left(T_{c}\right)$ and foliar $\mathrm{N}$ concentration in needle-leaf plants. Relative humidity $(R H)$ varies from 0.25 (left pane) to 0.50 (center pane) to 0.75 (right pane).

Areas of maximized $\psi_{*}$ (Figure 2.9) are likely areas of maximized $A_{n}$ where temperature and foliar nitrogen are optimized for photosynthesis. Even though atmospheric demand for plant water decreases with increasing $R H, \psi_{*}$ increases with $R H$ because $\psi_{*}$ is calculated based on the competing requirement of water-limited stomatal conductance to maintain an adequate supply of $\mathrm{CO}_{2}$ for assimilation. Thus, as conditions become increasingly favorable for $\mathrm{CO}_{2}$ assimilation water-limited stomatal conductance required to maintain the $\mathrm{CO}_{2}$ supply increases, resulting in an increase in $\psi_{*}$. Because the pathway of assimilation and transpiration is shared, maintaining an optimal stomatal conductance for assimilation based on atmospheric conditions demands an adequate supply of water from the soil. 


\section{Conclusion}

Vegetation water stress is a dynamic phenomenon, varying with soil, vegetation and atmospheric conditions, and is an important control on terrestrial cycles of carbon and water. By combining two existing models of leaf-level stomatal conductance (assimilation-limited and water-limited), we have been able to (1) predict stomatal conductance (and transpiration) in the presence of alternating limitations by light, photosynthetic enzymes (through nitrogen) and soil moisture; (2) determine the critical soil water potential, $\psi_{*}$, marking the threshold between water-stressed and unstressed conditions; (3) assess the variability of this threshold with respect to dynamic environmental variables and different vegetation functional types; and (4) evaluate the sensitivity of $\psi_{*}$ to the environment across vegetation functional types represented by vegetation-specific model parameters.

We determined that $\psi_{*}$ varied substantially among vegetation functional types and also under various environmental conditions, suggesting that a constant value for the water stress threshold may not accurately represent stomatal response to water-stress through time or between plant functional types. As an alternative, we offer a quantitative framework for addressing the preexisting notion that many factors converge to influence vegetation water stress. 


\section{References}

Albertson JD, Kiely G (2001) "On the structure of soil moisture time series in the context of land surface models." Journal of Hydrology 243, 101-119.

Arya SP (2001) Introduction to Micrometeorology. Academic Press, San Diego. 420pp.

Avissar R, Pielke RA (1991) "The impact of plant stomatal control on mesoscale atmospheric circulations.” Agricultural and Forest Meteorology 54, 353-372.

Baldocchi D (1997) "Flux footprints within and over forest canopies." Boundary-Layer Meteorology 273-292.

Baldocchi D, Meyers T (1998) “On using eco-physiological, micrometeorological and biogeochemical theory to evaluate carbon dioxide, water vapor and trace gas fluxes over vegetation: a perspective." Agricultural and Forest Meteorology 90 1-25.

Ball JT, Woodrow IE, Berry JA (1987) “A model predicting stomatal conductance and its contribution to the control of photosynthesis under different environmental conditions." in Progress in Photosynthesis Research, Vol. IV. Biggens J (ed.) Martinus Nijhoff Publishers, Dordrecht, the Netherlands.

Begg JE, Turner NC (1976) " Crop water deficits.” Advances in Agronomy, (28) 161-218.

Bonan GB (2002) Ecological Climatology: Concepts and Applications. Cambridge University Press, Cambridge. 678pp.

Brutsaert W (1975) "The roughness length for water vapor, sensible heat and other scalars." Journal of the Atmospheric Sciences. 32, 2028-2031.

Brutsaert W (1982) Evaporation into the Atmosphere: Theory, History and Applications Kluwer Academic Publishers, Boston. 299pp.

Budyko MI (1958) Heat balance of the earth's surface. U.S. Weather Bureau, Washington, D.C.

Buckley TN, Mott KA, Farquhar GD (2003) “A hydromechanical and biochemical model of stomatal conductance." Plant Cell and Environment 26, 1767-1785.

Clapp RB, Hornberger GM (1978) "Empirical equations for some soil hydraulic properties." Water Resources Research 14, 601-604.

Collatz GJ, Ball JT, Grivet C, Berry JA (1991) "Physiological and environmental regulation of stomatal conductance, photosynthesis and transpiration: a model that includes a laminar boundary layer.” Agricultural and Forest Meteorology 54, 107-136. 
Cowan IR, Farquhar GD (1977) "Stomatal function in relation to leaf metabolism and environment." Symp. Soc. Exp. Biol. 31, 471-505.

Daly E, Porporato A, Rodriguez-Iturbe I (2004) "Coupled dynamics of photosynthesis, transpiration and soil water balance. Part I: Upscaling from hourly to daily level." Journal of Hydrometeorology 5, 546-558.

Dang QL, Margolis HA, Coyea MR, Sy M, Collatz GJ (1997) "Regulation of branchlevel gas exchange of boreal trees: roles of shoot water potential and vapor pressure difference." Tree Physiology 17, 521535.

Delzon S, Bosc A, Cantet L, Loustau D (2005) "Variation of the photosynthetic capacity across a chronosequence of maritime pine correlates with needle phosphorus concentration." Annals of Forest Science 62 537-543.

Dewar RC (2002) "The Ball-Berry-Leuning and Tardieu-Davies stomatal models: synthesis and extension within a spatially aggregated picture of guard cell function." Plant, Cell and Environment 25(11) 1383-1398.

Dreyer E, Le Roux X, Montpied P, Daudet FA, Masson F (2001) “Temperature response of leaf photosynthetic capacity in seedlings from seven temperate tree species." Tree Physiology 21 223-232.

Eagleson PS (1982). "Ecological optimality in water-limited natural soil-vegetation systems. 1. Theory and hypothesis" Water Resources Research 18(2) 325-340.

Emanuel RE, Albertson JD, Epstein HE, Williams CA (2006) "Carbon dioxide exchange and early old-field succession.” Journal of Geophysical Research 111, G01011.

Evans JR (1989) "Photosynthesis and nitrogen relationships in leaves of $\mathrm{C}_{3}$ plants." Oecologia 78, 9-19.

Farquhar GD, von Caemmerer S, Berry JA (1980) "A biochemical model of photosynthetic $\mathrm{CO}_{2}$ in leaves of $\mathrm{C}_{3}$ species." Planta 149, 78-90.

Fernandez-Illescas CP, Porporato A, Laio F, Rodriguez-Iturbe I (2001) “The ecohydrological role of soil texture in a water-limited ecosystem." Water Resources Research 37(12) 2863-2872.

Field C, Mooney HA (1986) "The photosynthesis-nitrogen relationship in wild plants." in On the economy of plant form and function. Givnish T (ed) Cambridge University Press, Cambridge. 
Gao Q, Xhao P, Zeng X, Cai X, Shen W (2002) “A model of stomatal conductance to quantify the relationship between between leaf transpiration, microclimate, and soil water stress." Plant Cell and Environment 25, 1373-1381.

Gao Q, Peng S, Zhao P, Zeng X, Cai X, Yu M, Shen W, Liu Y (2003) “Explanation of vegetation succession in subtropical southern China based on ecophysiological characteristics of plant species.” Tree Physiology 23, 641-648.

Gollan T, Munns R, Passioura JB (1986) "Soil water status affects the stomatal conductance of fully turgid wheat and sunflower leaves." Australian J. Plant Physiology $13,459-464$.

Gu L, Falge EM, Boden T, Baldocchi DD, Black TA, Saleska SR, Suni T, Verma SB, Vesala T, Wofsy SC, Xu L (2005) “Objective threshold determination for nighttime eddy flux filtering." Agricultural and Forest Meteorology 128 179-197.

Harley PC, Weber JA, Gates DM (1985) "Interactive effects of light, leaf temperature, $\mathrm{CO}_{2}$ and $\mathrm{O}_{2}$ on photosynthesis in soybean." Planta 165 249-263.

Hornberger GM, Spear RC (1981) "An approach to the preliminary analysis of environmental systems.” Journal of Environmental Management 12 7-18.

Jacquemin B, Noilhan J (1990) "Sensitivity study and validation of a land surface parameterization using the HAPEX-MOBILHY data set." Boundary-Layer Meteorology 52, 93-134.

Jarvis PG (1976) "The interpretation of the variations in leaf water potential and stomatal conductance found in canopies in the field." Phil. Trans. R. Soc. Lond. B 273 593-610.

Jones MM, Turner NC (1978) "Osmotic adjustment in leaves of sorghum in response to water deficits.” Plant Physiology 61(1) 122-126.

Jones HG (1999) "Use of thermography for quantitative studies of spatial and temporal variation of stomatal conductance over leaf surfaces." Plant, Cell and Environment 22, 1043-1055.

Katul GG, Ellsworth DS, Lai C-T (2000) "Modelling assimilation and intercellular $\mathrm{CO}_{2}$ from measured conductance: a synthesis of approaches." Plant, Cell and Environment 23 1313-1328.

Katul GG, Leuning R, Oren R (2003) "Relationship between plant hydraulic and biochemical properties derived from a steady-state coupled water and carbon transport model." Plant, Cell and Environment 26, 339-350. 
Kosugi Y, Shibata S, Kobashi S (2003) "Parameterization of the $\mathrm{CO}_{2}$ and $\mathrm{H}_{2} \mathrm{O}$ gas exchange of several temperate deciduous broad-leaved trees at the leaf scale considering seasonal changes." Plant, Cell and Environment 26, 285-301.

Lange OL, Kappen L, Shulze ED, Eds. (1976) Water and Plant Life, Springer-Verlag, New York.

Leuning R (1995) “A critical appraisal of a combined stomatal-photosynthesis model for $\mathrm{C}_{3}$ plants." Plant, Cell and Environment 18, 339-355.

Maherali H, Pockman WT, Jackson RB (2004) "Adaptive variation in the vulnerability of woody plants to xylem cavitation.” Ecology 85(8) 2184-2199.

Meir P, Kruijt B, Broamedow M, Barbosa E, Kull O, Carswell F, Nobre A, Jarvis P (2002) "Acclimation of photosynthetic capacity to irradiance in tree canopies in relation to leaf nitrogen concentration and leaf mass per unit area." Plant, Cell and Environment $25,343-357$.

Monteith JL (1973) Principles of Environmental Physics, Elsevier, New York 241pp.

Morgan JM (1984) "Osmoregulation and water stress in higher plants." Annual Review of Plant Physiology 35 299-319.

Oren R, Sperry JS, Katul GG, Pataki DE, Ewers BE, Phillips N, Schäfer KVR (1999) "Survey and synthesis of intra- and interspecific variation in stomatal sensitivity to vapor pressure deficit” Plant, Cell and Environment 22, 1515-1526.

Passioura JB (1988) "Root signals control leaf expansion in wheat seedlings growing in drying soil.” Australian Journal of Plant Physiology 15(5) 687-693.

Pelleschi S, Rocher J-P, Prioul J-L (1997) "Effect of water restriction on carbohydrate metabolism and photosynthesis in mature maize leaves." Plant, Cell and Environment 20 493-503.

Porporato A, Laio F, Ridolfi L, Rodriguez-Iturbe I (2001) "Plants in water-controlled ecosystems: active role in hydrologic processes and response to water stress - III Vegetation water stress." Advances in Water Research 24, 725-744.

1.1.1. Ridolfi L, D’Odorico P, Porporato A Rodriguez-Iturbe I (2000). "Duration and frequency of water stress in vegetation: an analytical model." Water Resources Research, 36(8), 2297-2307.

Richards, JM (1971) "Simple expression for the saturation vapor pressure of water in the range -50 degrees to 140 degrees" Journal of Applied Physics 4: LI5-8 
Rodríguez-Iturbe I, D’Odorico P, Porporato A, Ridolfi L (1999) “On the spatial and temporal links between vegetation, climate, and soil moisture." Water Resources Research 35(12), 3709-3722.

Saab IN, Sharp RE, Pritchard J, Voetberg GS (1990) "Increased endogenous abscisic acid maintains primary root growth and inhibits shoot growth of maize seedlings at low water potentials." Plant Physiology 93 1329-1336.

Soil Conservation Service (1982) Soil Survey of Clarke County Virginia. USDA.

Sperry JS (2000) "Hydraulic constraints on plant gas exchange." Agricultural and Forest Meteorology 104, 13-23.

Sperry JS, Hacke UG, Oren R, Comstock JP (2002) "Water deficits and hydraulic limits to leaf water supply." Plant, Cell and Environment 25 251-263.

Thornthwaite CW, Mather JR (1955). "The water balance." in: Publications in Climatology, Drexel Institute of Technology, 8(1), 1-104.

Vose JM, Ryan MG (2002) "Seasonal respiration of foliage, fine roots and woody tissue in relation to growth, tissue N and photosynthesis." Global Change Biology 8, 182-193.

Wang K-Y, Kellomäki S, Laitinen K (1996) "Acclimation of photosynthetic parameters in Scots pine after three years exposure to elevated temperature and $\mathrm{CO}_{2}$." Agricultural and Forest Meteorology 82, 195-217.

Wilson KB, Baldocchi DD, Hanson PJ (2001) "Leaf age affects the seasonal pattern of photosynthetic capacity and net ecosystem exchange of carbon in a deciduous forest." Plant, Cell and Environment 24, 571-583.

Zelitch I, Waggoner PE (1967) "Effect of chemical control of stomata on transpiration and photosynthesis." Proceedings of the National Academy of Sciences 48(7) 1101-1108. 


\title{
Chapter 3: Spatial and Temporal Influences of Soil Moisture on the Ecophysiology of a Montane Conifer Forest
}

\author{
Abstract \\ The northern Rocky Mountains provide a unique opportunity to evaluate the role of water \\ stress in determining leaf-level fluxes of carbon dioxide and water vapor due to strong \\ spatial gradients and seasonality of soil water availability. We explore the role of water \\ stress in controlling leaf-level photosynthesis, transpiration and stomatal conductance in \\ the context of two northern Rocky Mountain ecosystems. Specifically, we examine leaf- \\ level responses across changes in elevation, aspect, and seasonality in a small montane \\ watershed containing forest and meadow ecosystems. Although soil moisture varied \\ significantly across these environmental gradients, significant changes in \\ ecophysiological responses occurred that were largely unrelated to changes in soil \\ moisture. The dynamic threshold of vegetation water stress is a variable derived from \\ ecophysiological models and provides additional context for evaluating the relative \\ importance of soil water content in determining leaf-level fluxes, and we use this variable \\ to explain ecophysiological responses relative to soil water content and atmospheric \\ conditions. In this way, we demonstrate the importance of atmospheric conditions and \\ vegetation type in considering the effects of soil moisture on carbon dioxide assimilation, \\ transpiration, and stomatal conductance.
}




\section{Introduction}

Soil water availability may present significant limitations to plant growth and activity. This is particularly true for environments having otherwise favorable conditions, including abundant light, moderate temperatures and adequate nutrients. In these environments, soil moisture may serve as the first order control not only on plant growth and activity, but also on the distribution of vegetation across ecosystems and landscapes [Rodriguez-Iturbe, et al., 2001]. Historically, studies of water-limitation to vegetation activity and distribution in terrestrial ecosystems have focused primarily on arid or semiarid landscapes where soil moisture limitation in some form is ubiquitous [Noy-Meir, 1973; Sala and Lauenroth, 1982; Scholes and Walker, 1993; Breshears and Barnes, 1999; Caylor, et al., 2006]. A number of other studies have focused on water-limitation to crop production [Begg and Turner, 1976; Saab, et al., 1990; Pelleschi, et al., 1997]. Less attention has been given to water-limited vegetation activity in temperate ecosystems, particularly those for which water is not always the most limiting resource. These ecosystems may include temperate forests, various agricultural landscapes, or other systems subject to alternating stresses from water, nutrients, or other environmental factors. The previous chapter presents an ecophysiological framework for conceptualizing water stress in the presence of such variable limitation and also suggests that water stress across an ecosystem may be heterogeneous in response to variability in soil and vegetation properties, soil water content and meteorological conditions.

Montane forest ecosystems of the western United States are prime examples of systems where vegetation activity may be limited by any of a number of environmental factors, 
including, most notably, temperature and water availability [Nemani, et al., 2003; Boisvenue and Running, 2006]. Temperature and precipitation may vary widely throughout the year in these ecosystems; for example, air temperature extremes recorded at a representative weather station in the northern Rocky Mountains during the 2006 water year (October 2005 through September 2006) ranged from a minimum of $-30{ }^{\circ} \mathrm{C}$ in February to a maximum of $29{ }^{\circ} \mathrm{C}$ in July [Natural Resources Conservation Service, 2006]. This same site received $874 \mathrm{~mm}$ of precipitation during the 2006 water year with approximately 70\% arriving as snow between November and May [Natural Resources Conservation Service, 2006].

Seasonal trends in temperature and precipitation interact in such a way that precipitation may be stored as snow during periods of limited vegetation activity due to cold and then made available for vegetation use during warmer, active periods following snow melt. In this way, temperature limits vegetation activity most of the year in northern Rocky Mountain forests, and following a brief period of optimal temperature and moisture conditions, water limits vegetation activity until cold weather returns in the fall. Furthermore, topographical properties such as aspect and elevation may play an important role in alternating water and temperature limitation in these ecosystems. Temperature is affected by aspect, with north-facing slopes generally receiving less radiative input than south-facing slopes [van Cleve, et al., 1983; Bonan, 1991; Wilson and Gallant, 2000]. In fact, vegetation responses to changes in elevation and aspect have been studied for a range of ecosystems (see [Van de Water, et al., 2002] and references therein), although not explicitly in the context of alternating limitation to vegetation 
activity. Topography and micrometeorology both affect the spatial distribution of soil moisture [Western, et al., 1999; Albertson and Kiely, 2001; D'Odorico and Porporato, 2004; Lin, et al., 2006], and also affect the seasonal drying of soils in montane forest ecosystems [Reynolds and Knight, 1973; Bales, et al., 2006]. The soil moisture response to topography and micrometeorology has been studied in many systems and may be driven by vertical and lateral drainage, plant water uptake and soil surface evaporation as functions of temperature, humidity and net radiation. Of particular interest to this study is the interplay between soil moisture and the ecophysiological activity of vegetation.

How these ecosystems function in response to alternating limitations has important implications for research across the environmental sciences. For example, recent studies have highlighted the important role of montane forest ecosystems in the sequestration of atmospheric carbon dioxide [Falge, et al., 2002; Bowling, et al., 2005]. Bowling et al. [2005] attribute relatively high measured rates of carbon uptake in these ecosystems to water availability in the form of snowfall at higher elevations (i.e. a lack of water limitation at higher altitudes for at least some part of the year). Another recent study has linked the timing of water limitation brought on by snowmelt to fire risk in montane forests of the western United States [Westerling, et al., 2006]. Limitations to vegetation activity are heterogeneous and may vary across environmental gradients and through time, and these studies illustrate the wide-ranging implications for the interplay between temperature and water limitations. 
The purpose of this study is to evaluate the influence of water limitation on vegetation activity by examining relationships between soil water availability and plant ecophysiology across spatial gradients and also through the course of a growing season in a montane, conifer forest. Of primary interest are spatial effects including elevation and aspect (together topography), and temporal effects that primarily include the seasonal decline in soil moisture following snowmelt and accompanying semiarid conditions. Specifically, the objective of this study is to quantify and compare the effects of topography and seasonality on soil water availability, and to assess the impact of spatially and temporally variable water status on the ecophysiology of dominant plant types in a typical northern Rocky Mountain watershed. Based on the dynamic water stress framework introduced in the previous chapter, we hypothesize that spatial and temporal variability in moisture and atmospheric conditions create conditions of water stress that correlate with plant ecophysiological variables. 


\section{Methods}

\section{Site Description}

This study was conducted in a forested, mountain watershed dominated by lodgepole pine (Pinus contorta) within the U. S. Forest Service Tenderfoot Creek Experimental Forest (Montana, USA). Topographic and vegetation distribution data were derived from airborne light detection and ranging (lidar) measurements collected by the National Center for Airborne Laser Mapping (NCALM) in September 2005. Lidar-based digital elevation and vegetation height models were coarsened from $1 \mathrm{~m}$ x $1 \mathrm{~m}$ to $10 \mathrm{~m}$ x $10 \mathrm{~m}$ horizontal resolution for this study. The study watershed, Stringer Creek (SC), covers approximately 550 ha with elevations ranging from $1980 \mathrm{~m}$ to $2430 \mathrm{~m}$ (Figure 3.1).

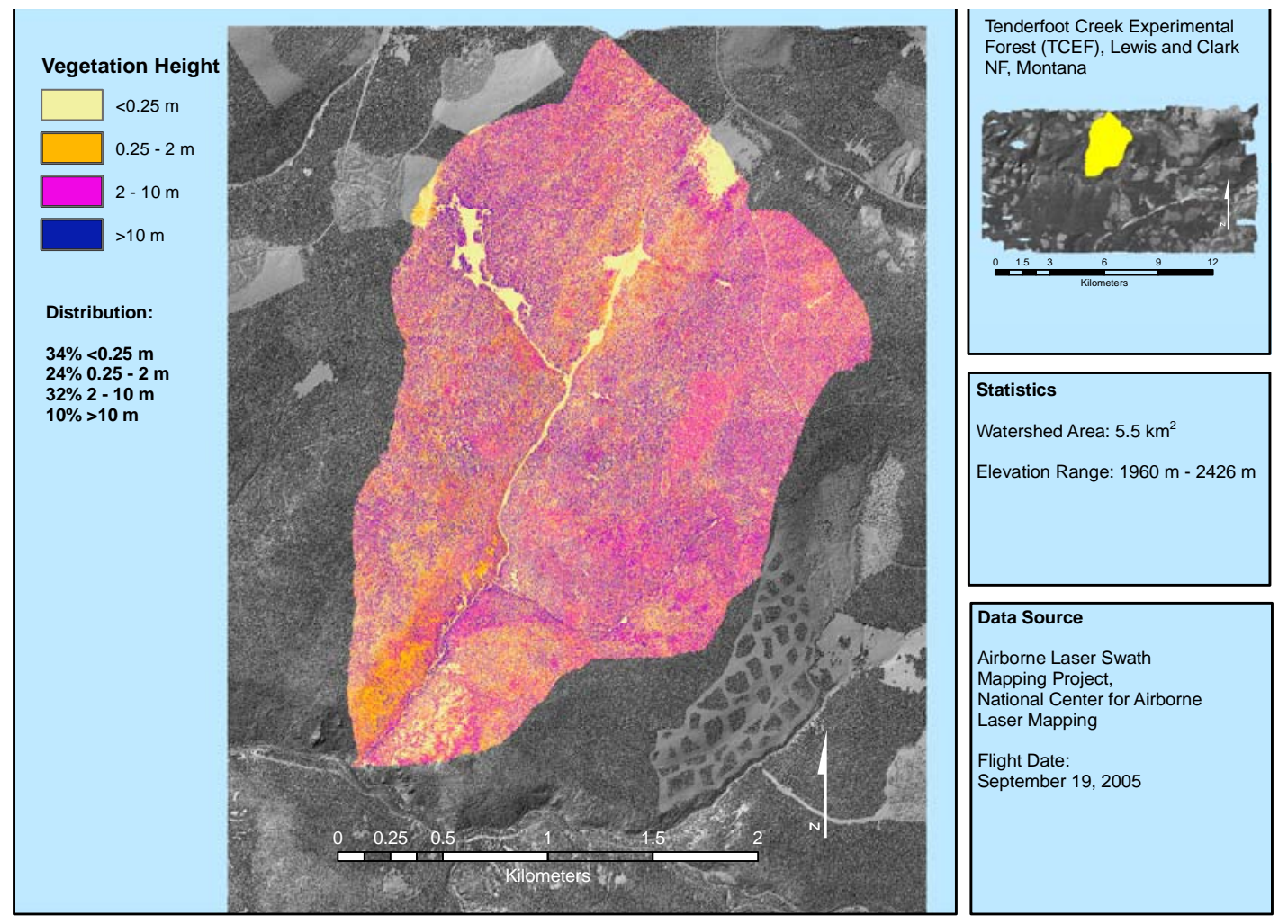

Figure 3.1: Lidar-derived shaded relief of the Stringer Creek watershed with an overlay of $1 \mathrm{~m}$ x $1 \mathrm{~m}$ vegetation heights. 
From a biogeographical perspective, vegetation within SC is typical of the conifer forests found below the treeline throughout the northern Rocky Mountains [Richardson and Rundel, 1998]. These conifer forests cover approximately 500 ha (91\%) of SC. Lodgepole pine is the dominant forest species, with limber pine (Pinus flexilis), subalpine fir (Abies lasiocarpa) and Engelmann spruce (Picea engelmannii) also present throughout the watershed, primarily in the understory. The remaining 9\% of SC is comprised primarily of wet meadows containing grasses and forbs, confined mainly to riparian corridors flanking Stringer Creek and its tributaries. A high elevation dry meadow also contributes to a small fraction $(<1 \%)$ of the watershed area. In general, however, SC may be characterized by even-aged, low diversity lodgepole forest [Mincemoyer and Birdsall, 2006].

Lodgepole stands in this area are not considered climax vegetation; rather, they are early colonizers following disturbance (in this case, fire) of a fir/spruce ecosystem [Richardson and Rundel, 1998]. A few specimens of old growth fir and spruce remain in the watershed, but they constitute a very small percentage of the watershed. Vegetation activity within SC is limited by cold temperatures during much of the year, interrupted by a brief warm period (two to three months) during which snow melts, and grasses and other deciduous plants are productive [McCaughey, 1996].

Stringer Creek flows northeast to southwest with west-facing hillslopes (32\%) covering a majority of the watershed. However, there are also significant portions of forested 
hillslopes facing southeast (21\%), south (16\%) and northwest (12\%). The majority of land covered by meadows faced southwest, with the exception of the dry meadow, which faces primarily west. Although a comparison of north- and south-facing slopes may best capture the effects of aspect on the surface energy balance, a general lack of north-facing slopes ( $1 \%$ of watershed area) and lack of south-facing slopes at lower watershed elevations precluded their use in this analysis. By establishing study sites on northwestand southeast-facing slopes at high and low elevations, we were able to test the effects of aspect and elevation on soil water limitation and subsequent effects on leaf-level responses within the lodgepole-dominated forest. Similarly, by establishing study sites at different elevations in the meadows, we were able to test the effect of elevation on water limitation for this vegetation type.

In June 2006, we established five study sites in SC to test elevation and aspect effects across the lodgepole forest and meadows. These sites contained meteorological instruments augmenting two previously established flux tower sites and bringing the total number of study sites to seven. Four of these sites were located in the lodgepole forest, identified by elevation and aspect as high elevation, southeast aspect - HS; high elevation, northwest aspect - HN; low elevation, southeast aspect - LS; and low elevation, northwest aspect - LN. Three sites were located in meadows, identified as dry meadow - DM; high elevation meadow - HM; and low elevation meadow - LM. Each study site was defined as a $30 \mathrm{~m}$ x $30 \mathrm{~m}$ square within which micrometeorological and ecophysiological data were collected during a single growing season between June 2006 and September 2006 (referred to hereafter simply as the growing season). 
Micrometeorological and Ecophysiological Measurements

Micrometeorological data were collected at each of the seven study sites from an array of instruments. In addition to energy and mass flux measurements not considered in this study, the two flux towers (located at HS and HM) measured air temperature and relative humidity 2 m above the ground using a combination probe (model HMP45C Campbell Scientific, Logan, UT). Volumetric soil moisture was measured at each flux tower site using three time domain reflectometry probes (model CS616, Campbell Scientific) surrounding each tower and taking a vertical average of soil moisture from 0 to $30 \mathrm{~cm}$ depth. Data were recorded at 30-minute intervals using a CR23X datalogger (Campbell Scientific).

At the five remaining study sites, air temperature and relative humidity were measured 1 $\mathrm{m}$ above the ground using a combination probe (Temperature/RH Smart Sensor, Onset Computer Corporation, Bourne, MA). Volumetric soil moisture was measured at each site using one capacitance-type probe (Soil Moisture Smart Sensor, Onset Computer Corporation) measuring vertically averaged soil moisture between 0 and $20 \mathrm{~cm}$ depth. Data at these five sites were recorded at 30-minute intervals using a HOBO Micro Station datalogger (Onset Computer Corporation). Precipitation was measured at five of the seven sites using a tipping bucket (model TE525, Texas Electronics, Dallas Texas). In addition, two snowpack telemetry (SNOTEL) stations operated by the Natural Resources Conservation Service are located within $10 \mathrm{~km}$ of the seven study sites and provided reference measurements of total snow depth, snow water equivalent and air temperature [Natural Resources Conservation Service, 2006]. 
Leaf-chamber measurements of ecophysiological responses including photosynthesis rate, transpiration rate and stomatal conductance were collected from vegetation at each site during the growing season using a portable photosynthesis analyzer (model LI-6400, Licor Biosciences, Lincoln, NE). For each chamber measurement, a single layer of needles (for conifers), or single leaves (for grasses) were arranged within a $6 \mathrm{~cm}^{2}$ cleartop leaf chamber. For conifers, one-sided needle area within the chamber averaged 3.0 to $5.4 \mathrm{~cm}^{2}$ depending on species. For grasses and other herbaceous plants, one-sided leaf area within the chamber averaged 4.0 to $6.0 \mathrm{~cm}^{2}$ depending on species. Chamber measurements included ecophysiological responses to manipulated $\mathrm{CO}_{2}$ as well as surveys of plant responses to ambient environmental conditions. Among all sites, more than 100 response curves were collected throughout the growing season containing an aggregate total of more than 1000 individual chamber measurements. More than 2000 individual survey measurements were collected among all sites during the growing season as well. Of 3157 total chamber measurements only lodgepole or limber pine (1325), or the dominant grass species in each meadow (802) considered in this analysis. Most chamber measurements were accompanied by a measurement of volumetric soil moisture integrated through the top $20 \mathrm{~cm}$ of soil using a hand held time domain reflectometry probe (Hydrosense, Campbell Scientific). Soil moisture measurements were converted to soil water potential for modeling using the textural-based conversion of Clapp and Hornberger [Clapp and Hornberger, 1978].

Carbon dioxide response curves measured net photosynthesis (gross photosynthesis less photorespiration) across a broad range of chamber $\mathrm{CO}_{2}$ concentrations while holding 
other environmental conditions (i.e. light, temperature, humidity) constant [Norman, et al., 2006]. Response curves were collected both at saturating and sub-saturating light conditions, where light was measured using a photosynthetically active radiation (PAR) detector mounted within the leaf chamber. Response curve and survey measurements were collected using a mixer to supply steady and predetermined reference concentrations of $\mathrm{CO}_{2}$ to the leaf chamber following the methods of Norman et al. [2006]. For response curves, temperature and relative humidity within the chamber were controlled by modulating flow rate, desiccant use and instrument block temperature. For these measurements, we set target ranges of 18 to $20{ }^{\circ} \mathrm{C}$ for temperature and 50 to $70 \%$ for relative humidity. By contrast, survey measurements were collected at ambient temperature and relative humidity (i.e. no temperature or humidity control) using a constant flow rate of $400 \mu \mathrm{mol} \mathrm{s}$ s. $^{-1}$.

Several $\mathrm{CO}_{2}$ response curves were collected at each site during two periods of the 2006 growing season: late June through mid-July and late August through early September. These periods were designed to correspond with early and late growing season conditions based on historical patterns of temperature, water availability and observed vegetation activity. Survey measurements were collected at regular intervals during the entire growing season (late June through early September).

\section{Modeling Water Stress}

Because the degree to which vegetation experiences water stress is a combination of soil properties, micrometeorology and ecophysiology [Rodriguez-Iturbe, et al., 1999], 
ecophysiological processes (assimilation, transpiration and stomatal conductance) were simulated by combining a biochemical model of photosynthesis and stomatal conductance [Farquhar, et al., 1980; Collatz, et al., 1991; Leuning, 1995] with a hydrodynamic model of stomatal conductance [Gao, et al., 2002]. The development of this model is discussed in the previous chapter. Ecophysiological model parameters were estimated by aggregating chamber measurements separately for vegetation types, and separately for early and late season measurements. These parameter values were estimated using nonlinear least squares regression of $\mathrm{CO}_{2}$ response curve measurements for the photosynthesis submodel parameters and survey measurements for the hydrodynamic submodel parameters. Survey measurements and chamber measurements were used to derive parameters for the Ball et al. [Ball, et al., 1987] stomatal conductance submodel. Chamber measurements were filtered to eliminate measurements collected under unsteady instrument of biophysical conditions. $\mathrm{CO}_{2}$ response measurements were filtered to eliminate extremes of temperature and humidity, and survey measurements were filtered to eliminate very small values of calculated intrastomatal $\left[\mathrm{CO}_{2}\right]$, or $C_{i}$. Eliminating these values decreased the size of the ecophysiological dataset, but ensured that the remaining data were of very high quality. 


\section{Results and Discussion}

\section{Soil Moisture and Ecophysiological Measurements}

Soil moisture and ecophysiological measurements are subject to a high degree of natural variability, and as such, the behavior of the entire data distribution is of interest to this study. Field measurements are thus presented using the empirical cumulative distribution function

$$
F(x)=1-\frac{r_{x}-1}{N}
$$

where $r_{x}$ is the rank, in descending order, of each unique value of $x$ in a sample of size $N$.

Because all of the data have nonparametric frequency distributions, the two-sample Kolmogorov-Smirnov (KS) test was used to assess the magnitude and significance of differences between groups of measurements based on comparisons of their cumulative distribution functions. Test results are presented in Table 3.1 for distributions of soil moisture $(\theta)$, photosynthetic assimilation $(A)$, transpiration $(T)$ and stomatal conductance $\left(G_{s}\right)$. For forest sites 131 separate measurements were analyzed for each group (elevation, aspect and season), with individual cohorts containing 51 measurements (high elevation), 80 measurements (low elevation), 83 measurements (southeast aspect), 48 measurements (northwest aspect), 67 measurements (early season) and 64 measurements (late season). For meadow sites 76 separate measurements were analyzed for each group (elevation and season), with individual cohorts containing 43 measurements (high elevation), 33 measurements (low elevation), 34 measurements (early season) and 42 measurements (late season). 
Table 3.1: Kolmogorov-Smirnov Statistics for Site Comparisons

\begin{tabular}{cccc} 
Forest $(\mathbf{N}=\mathbf{1 3 1})$ & Elevation & Aspect & Season \\
\hline$\theta$ & 0.14 & 0.26 & 0.60 \\
$A$ & 0.31 & 0.36 & $0.21^{*}$ \\
$T$ & 0.28 & 0.35 & 0.31 \\
$G_{s}$ & 0.28 & 0.31 & 0.27 \\
Meadow $(\mathbf{N}=\mathbf{1 3 1})$ & Elevation & Aspect & Season \\
\hline$\theta$ & 0.58 & - & 0.27 \\
$A$ & $0.13^{*}$ & - & 0.46 \\
$T$ & 0.40 & - & $0.20^{*}$ \\
$G_{s}$ & $0.25^{*}$ & - & $0.19^{*}$ \\
\multicolumn{4}{c}{ * Not significant $(\mathbf{P}>\mathbf{0 . 0 5})$}
\end{tabular}

For the forest sites cumulative frequency distributions of handheld soil moisture measurements vary significantly with aspect and elevation, and also through time during the 2006 growing season (Figure 3.2, Table 3.1). The dominant trend is a decrease in soil moisture between early growing season (June-July) and late growing season (AugustSeptember). Among forest sites, the greatest change in soil moisture distribution was observed between early and late season, with median soil moisture decreasing from 0.10 to $0.06 \mathrm{~m}^{3} \mathrm{~m}^{-3}$ between the early and late growing season.
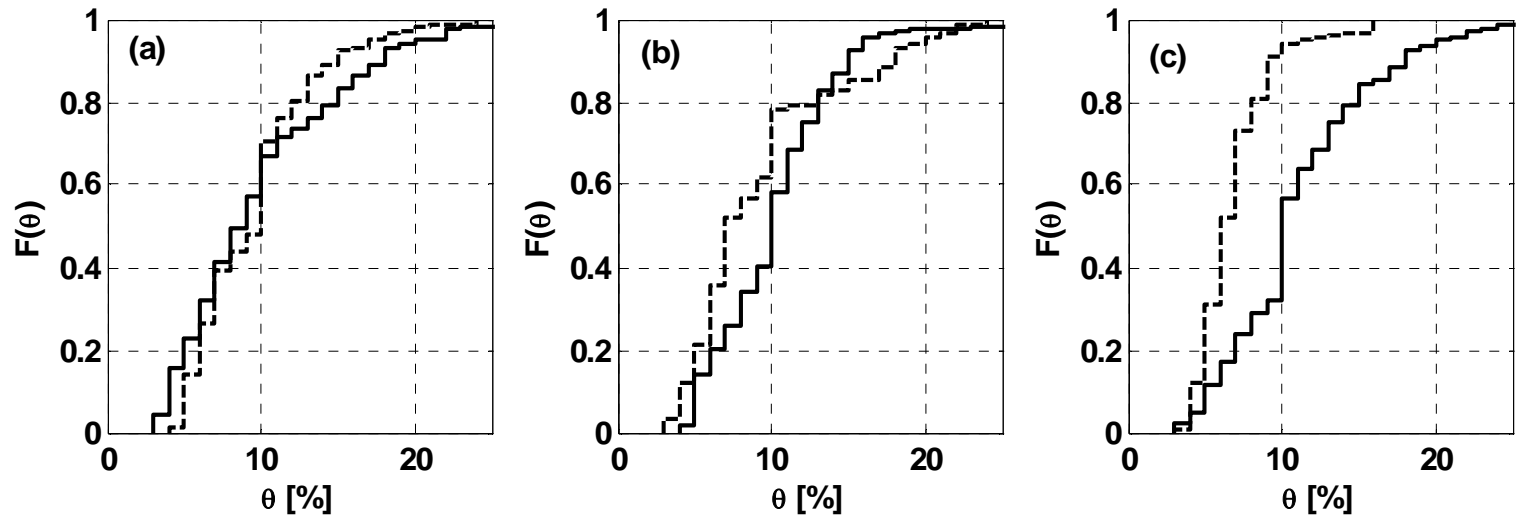

Figure 3.2: Cumulative distribution functions of volumetric soil moisture at forested sites for (a) high elevation (solid) versus low elevation (dashed) sites, (b) 
southeast (solid) versus northwest (dashed) sites and (c) early (solid) versus late (dashed) growing season periods.

Among meadow sites, changes in elevation were more important than seasonal changes to the distribution of soil moisture. As expected, the high elevation meadow site was consistently drier than the low elevation meadows, suggesting that wet areas tended to remain wet through the growing season whereas drier areas tended to remain dry (Figure 3.3, Table 3.1). In SC, the high elevation meadow occupies a topographic saddle on a watershed divide, meaning that soil water and groundwater are likely to flow away from the meadow. The low elevation meadows occupy topographic convergences near or along the stream corridor, resulting in a higher likelihood of increased soil moisture in these areas. The high elevation meadows of SC, also known as 'parks,' differ from low elevation meadows in species composition [Mincemoyer and Birdsall, 2006], perhaps as a result of these characteristic, topography-driven soil moisture conditions.
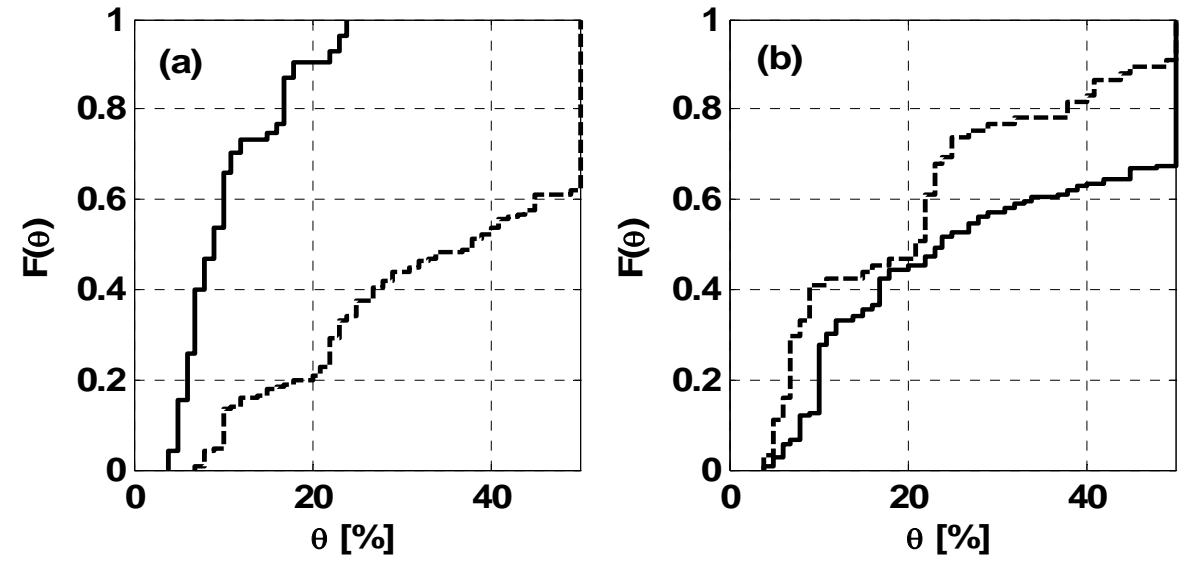

Figure 3.3: Same as Figure 3.2 but for (a) elevation and (b) seasonal effects in meadow ecosystems. 
At forest sites, most frequency distributions of ecophysiological measurements differed significantly among sites grouped by topography, and between early and late season measurements (Figure 3.4). Distributions of photosynthesis differed among groups of elevation and aspect, but not between the early and late growing season. Median photosynthesis increased from high elevation to low elevation and from northwest aspect to southeast aspect. Transpiration differed significantly for all effects, increasing from high elevation to low elevation and from northwest aspect to southeast aspect. Although median transpiration did not change significantly between the early and late growing season, the distribution of transpiration shifted between these periods, with higher levels of transpiration ( $\mathrm{T}>3 \mathrm{mmol} \mathrm{m} \mathrm{m}^{-2}$ ) occurring much more frequently during the late growing season. As with photosynthesis and transpiration, median stomatal conductance increased from high elevation to low elevation and from northwest aspect to southeast aspect. As with transpiration, higher levels of stomatal conductance $\left(G_{\mathrm{s}}>0.2 \mathrm{~mol} \mathrm{~m}^{-2} \mathrm{~s}^{-}\right.$ ${ }^{1}$ ) occurred more frequently during the late growing season than during the early season. 

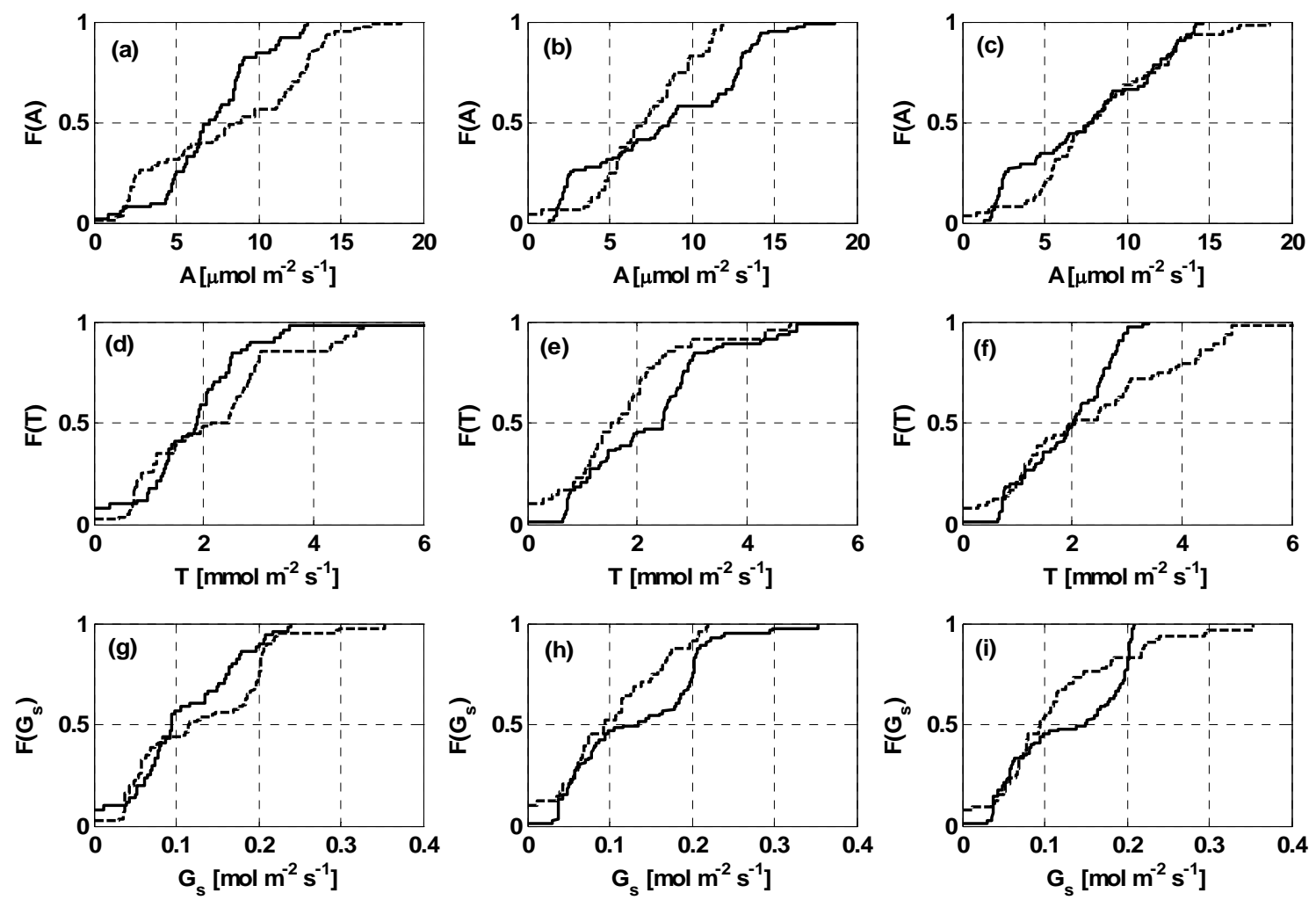

Figure 3.4: Cumulative frequency distributions of photosynthesis (a-c), transpiration (d-f) and stomatal conductance (g-i) grouped by elevation (first column), aspect (second column) and seasonality (third column). Line styles are the same as Figure 3.2.

Distributions of ecophysiological variables for meadow sites are shown in Figure 3.5. The frequency distributions of photosynthesis did not differ significantly between high elevation and low elevation meadows. However, the distribution of photosynthesis changed significantly from the early to the late growing season. Median photosynthesis declined from 11.4 to $7.2 \mu \mathrm{mol} \mathrm{m} \mathrm{m}^{-2} \mathrm{~s}^{-2}$ between these periods. The distribution of transpiration, while not changing significantly from early to late growing season, differed significantly between high elevation and low elevation meadows. Median transpiration 
was significantly less for low elevation meadows than for high elevation meadows.

Distributions of stomatal conductance did not change significantly from high elevation to low elevation meadows, or from the early growing season to the late growing season.
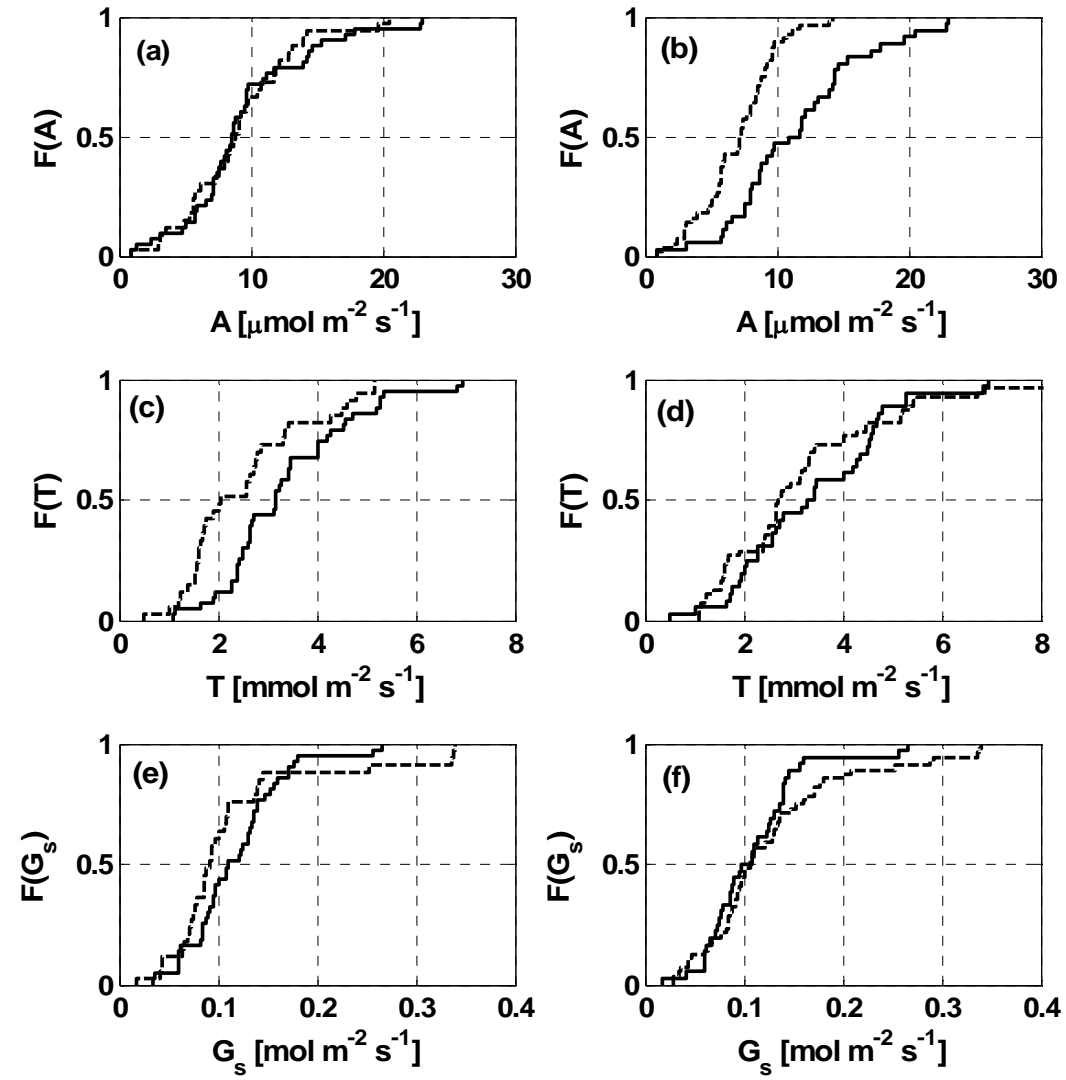

Figure 3.5: Same as Figure 3.4, but for meadow sites grouped by elevation (first column) and seasonality (second column).

Meteorological data from the study period is shown for two of the seven study sites, HS and LM (Figure 3.6). The forest site is, in general, cooler and less humid than the meadow site, and although LM normally has wetter soil than HS, both sites show the gradual drying of soils through the course of the growing season. Because LM is situated along a riparian corridor, the proximity to flowing water and abundance of low- 
growing grasses and other herbaceous vegetation likely influenced relative humidity at this site. Additionally, exposure to direct sunlight during much of the day and lack of an overlying tree canopy resulted in higher temperatures and greater diurnal variability of temperature at LM than at HS. As temperature, humidity and sunlight vary through the course of the growing season, the photosynthetic demand for carbon and the atmospheric demand for water vapor fluctuate and may affect levels of stomatal conductance. As soil moisture declines through the growing season, plants may sense the decline in soil water potential and initiate feedbacks [Passioura, 1988; Gollan, et al., 1992] with stomatal conductance that, in conjunction with the biological and atmospheric requirements for stomatal conductance, may result in conditions of water stress. To further explain this phenomenon in the context of the northern Rocky Mountains, the following sections calculate the dynamic threshold of vegetation water stress from ecophysiological model parameters, and demonstrate its relationship to ecophysiological observations. 

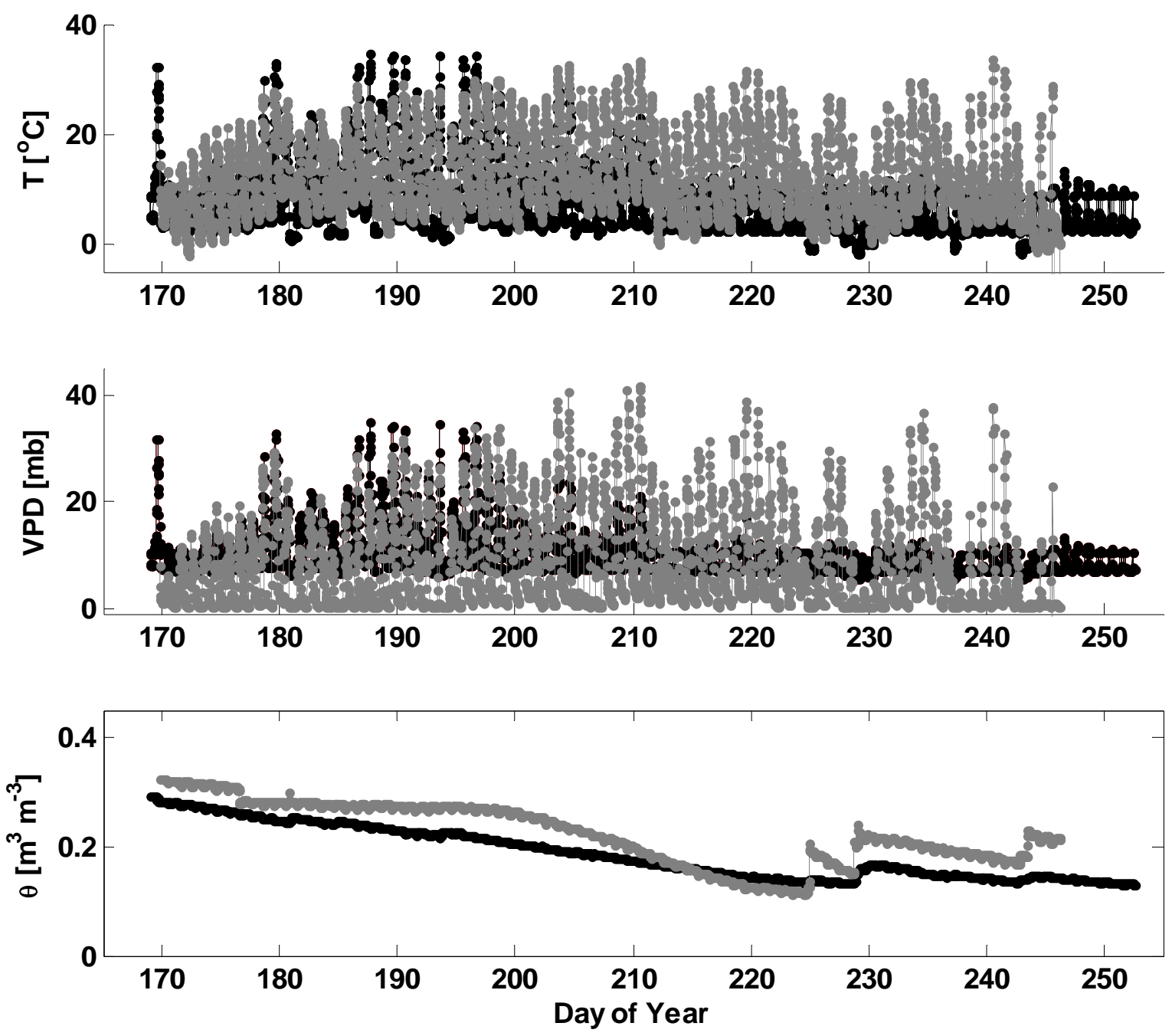

Figure 3.6: Meteorology for HS (gray) and LM (black) including (top panel) temperature, (middle panel) relative humidity and (lower panel) volumetric soil moisture.

\section{Ecophysiological Modeling}

Nonlinear regressions of ecophysiological measurements versus chamber micrometeorological conditions (and complementary soil moisture measurements) were used to estimate parameters for biochemical- and water-limited models of stomatal 
conductance (Table 3.2). These parameters were necessary to compute the dynamic threshold of vegetation water stress, $\psi_{*}$. Parameter estimates did not differ significantly among spatial groups, or from early season to late season. We use these modeled values of $\psi *$ in conjunction with measurements of soil moisture to assess the impact of vegetation water stress on observed ecophysiology, namely photosynthetic assimilation, transpiration and stomatal conductance.

Table 3.2: Ecophysiological Model Parameters Used to Calculate $\psi *$.

\begin{tabular}{cccc} 
Parameter & Units & Forest & Meadow \\
\hline$g_{o m}$ & $\mathrm{mmol} \mathrm{m}^{-2} \mathrm{~s}^{-1}$ & 387 & 168 \\
$k_{\psi}$ & $\mathrm{mmol} \mathrm{m}^{-2} \mathrm{~s}^{-1} \mathrm{kPa}^{-1}$ & 0.142 & 0.002 \\
$k_{\alpha \beta}$ & $\mathrm{mmol} \mathrm{m}^{-2} \mathrm{~s}^{-1}\left(\mu \mathrm{mol} \mathrm{m}^{-2} \mathrm{~s}^{-1}\right)^{-1}$ & 0.065 & 0.028 \\
$k_{\beta g}$ & $\mathrm{mmol} \mathrm{m}^{-2} \mathrm{~s}^{-1}\left(\mathrm{mb} \mathrm{mb}^{-1}\right)^{-1}$ & 140 & 20.1 \\
$V c_{\max 25}$ & $\mu \mathrm{mol} \mathrm{m}^{-2} \mathrm{~s}^{-1}$ & 38.7 & 51.0 \\
$R_{d 25}$ & $\mu \mathrm{mol} \mathrm{m}^{-2} \mathrm{~s}^{-1}$ & 2.00 & 2.00 \\
$m$ & $u n i t l e s s$ & 11.4 & 2.00 \\
$b$ & $\mathrm{~mol} \mathrm{~m}^{-2} \mathrm{~s}^{-1}$ & 0.01 & 0.01
\end{tabular}

For forest sites, frequency distributions of $\psi *$ only differed significantly between the early growing season and the late growing season (Figure 3.7). Frequency distributions of $\psi *$ for the meadow sites differed significantly by elevation and growing season (Figure 3.8); however, $\psi *$ is so low that water stress is very unlikely. Meadow sites are likely to experience phenological senescence at the end of the growing season rather than a reduction in ecophysiological activity due to water stress. However, interactions between phenology and water stress are beyond the scope of this study. 

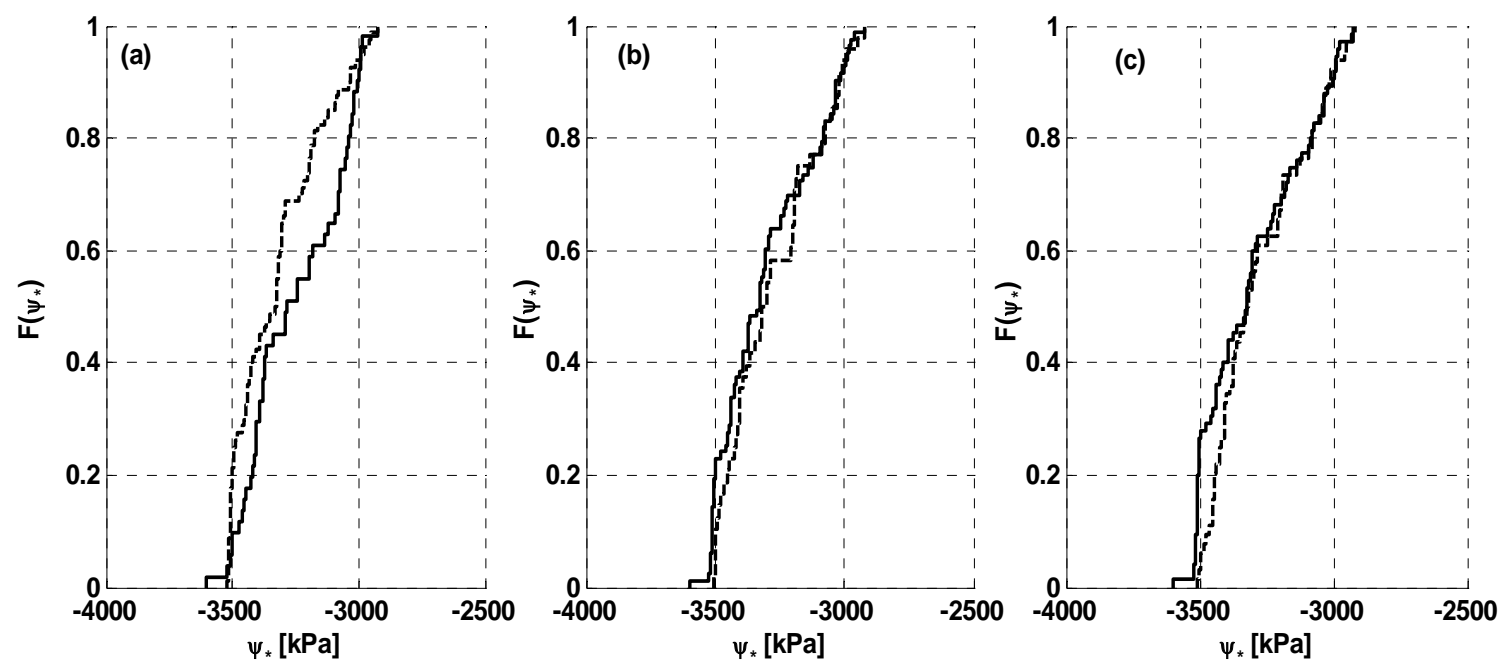

Figure 3.7: Frequency distributions of $\psi *$ for forested sites grouped by (a) high elevation (solid) and low elevation (dashed), (b) southeast aspect (solid) and northwest aspect (dashed) and (c) early season (solid) and late season (dashed).
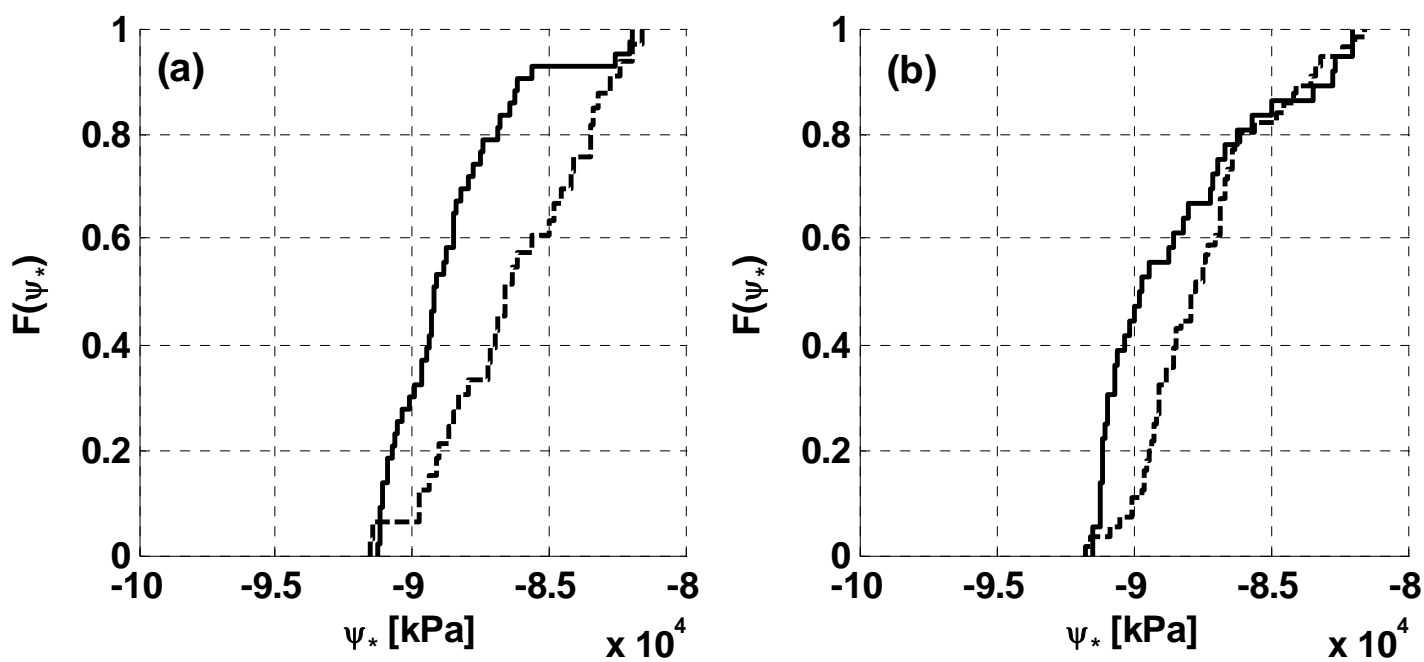

Figure 3.8: Same as Figure 3.7 but for meadow (a) elevation and (b) seasonality.

As an indicator of the biophysical (vegetation and atmospheric) demand for water, the threshold of water stress may be correlated either positively or negatively with 
ecophysiological variables; however, we found only a few of these correlations to be significant (Table 3.3). The significant negative correlations are found in the lowmoisture cohorts of their respective groupings (Figures 2 and 3), suggesting that for periods of reduced moisture (i.e. periods where water stress is likely), vegetation may be sensitive to changes in $\psi *$. However, it is also possible that covariance between ecophysiological activity and senescence may be reflected in negative correlations for meadow sites.

Table 3.3: Rank Correlation for $\psi *$ versus Ecophysiological Variables

\begin{tabular}{|c|c|c|c|c|c|c|}
\hline Forest & \multicolumn{2}{|c|}{ Elevation } & \multicolumn{2}{|c|}{ Aspect } & \multicolumn{2}{|c|}{ Season } \\
\hline & $H I$ & $L O$ & $S E$ & $N W$ & Early & Late \\
\hline A & -0.36 & $0.11^{*}$ & $-0.02 *$ & $-0.25 *$ & $0.15^{*}$ & -0.39 \\
\hline$T$ & $0.19 *$ & $0.06^{*}$ & $0.13^{*}$ & $0.02 *$ & 0.34 & $-0.15^{*}$ \\
\hline$G_{s}$ & $0.11^{*}$ & $0.21 *$ & $0.10 *$ & $0.21 *$ & 0.36 & $-0.10^{*}$ \\
\hline Meadow & \multicolumn{2}{|c|}{ Elevation } & \multicolumn{2}{|c|}{ Aspect } & \multicolumn{2}{|c|}{ Season } \\
\hline & $H I$ & $L O$ & $S E$ & $N W$ & Early & Late \\
\hline$A$ & -0.34 & $-0.02 *$ & - & - & $-0.02 *$ & $-0.15^{*}$ \\
\hline$T$ & -0.39 & $0.21 *$ & - & - & $-0.24 *$ & -0.34 \\
\hline$G_{s}$ & $-0.20 *$ & $0.25 *$ & - & - & $-0.17^{*}$ & $-0.02 *$ \\
\hline
\end{tabular}

For forest sites, $\psi *$ provides a quantitative, though relative, measure of water stress. The next section describes calculation of actual water stress from $\psi *$ and evaluates its effects on the ecophysiology of forest sites.

\section{Ecophysiology and Water Stress}

Vegetation water stress arises from an imbalance between atmospheric and biological demand for water and soil available water (Figure 3.9). Frequency distributions of water stress differ significantly among several groups of elevation, aspect and seasonality 
(Table 3.3). As a result of water stress, ecophysiological activity (photosynthesis, transpiration, stomatal conductance) may decline as a plant attempts to conserve water. If water stress affects the ecophysiological response of plants, then declines in photosynthesis, transpiration and stomatal conductance across spatial gradients and through time may be correlated to some measure of water stress.

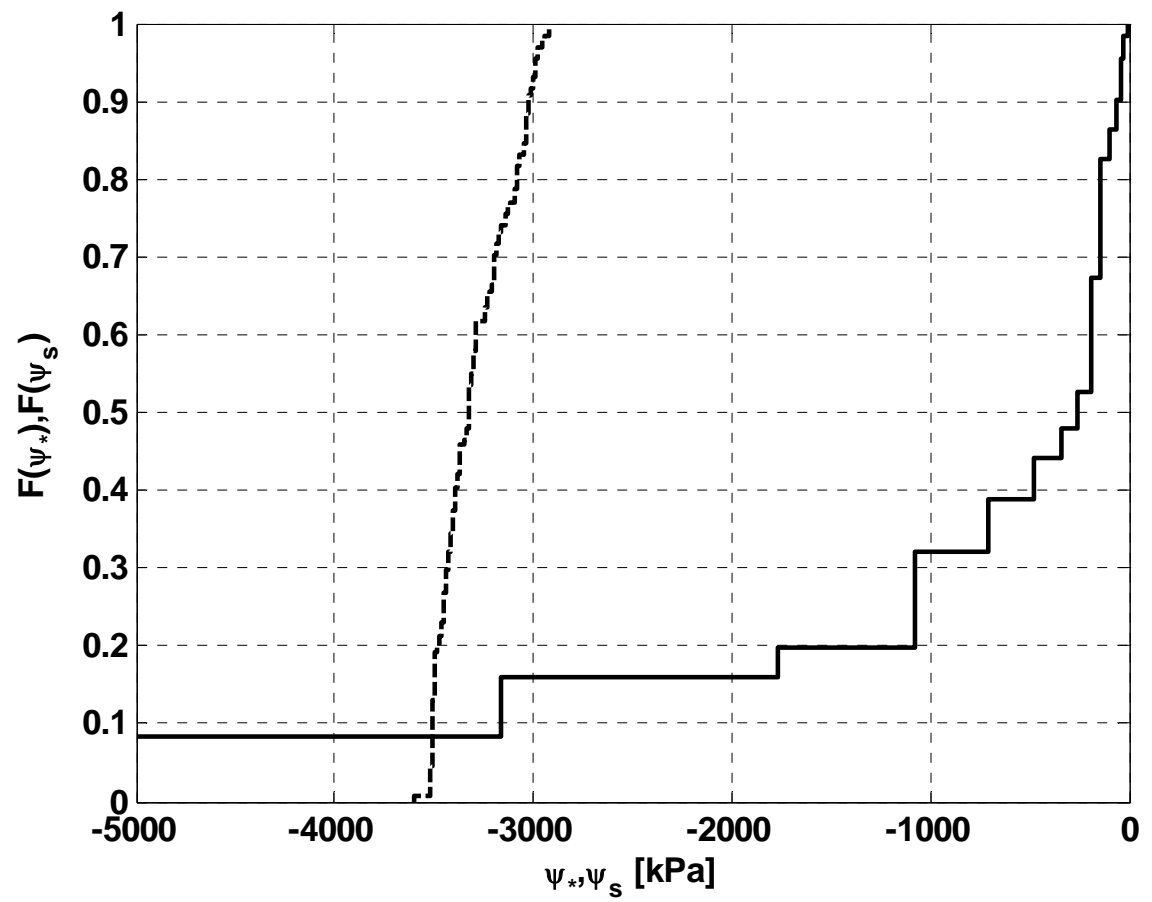

Figure 3.9: Frequency distributions of $\psi_{\mathrm{s}}$ (solid) and $\psi *$ (dashed) for forest sites.

Table 3.4: KS Statistics for Water Stress at Forest and Meadow Sites

\begin{tabular}{cccc} 
Forest & Elevation & Aspect & Season \\
\hline$\psi_{*}^{*}$ & 0.24 & $0.30 *$ & 0.24 \\
$\psi_{\mathrm{s}}-\psi_{*}$ & 0.24 & 0.52 & 0.88 \\
Meadow & Elevation & Aspect & Season \\
\hline$\psi_{*}^{*}$ & 0.46 & - & 0.42 \\
$\psi_{\mathrm{s}}-\psi_{*}^{*}$ & 0.32 & - & $0.19 *$ \\
& $*$ Not significant $(\mathbf{P}>\mathbf{0 . 0 5})$
\end{tabular}


For forest sites, changes in ecophysiological response variables (photosynthesis and transpiration) are shown as bivariate frequency distributions (Figure 3.10). Between high and low elevations, the most frequent region of photosynthesis and transpiration shifts to reduced photosynthesis and transpiration. Similar shifts occur in the locations of modes for aspect and seasonal changes. It is possible that water stress affects these shifts in ecophysiology. Changes in actual water stress (defined as soil water potential minus $\psi *$ ) are shown between cohorts of elevation, aspect and seasonality (Figure 3.11).

Correlations between maximum changes in water stress and changes in the frequency space of photosynthesis and transpiration are not significant; however, collocation of these regions suggests that water stress may play a role in changing spatial patterns of ecophysiological variables such as assimilation and transpiration. There were also no significant relationships between regions of maximum change in stomatal conductance and maximum change in water stress. 

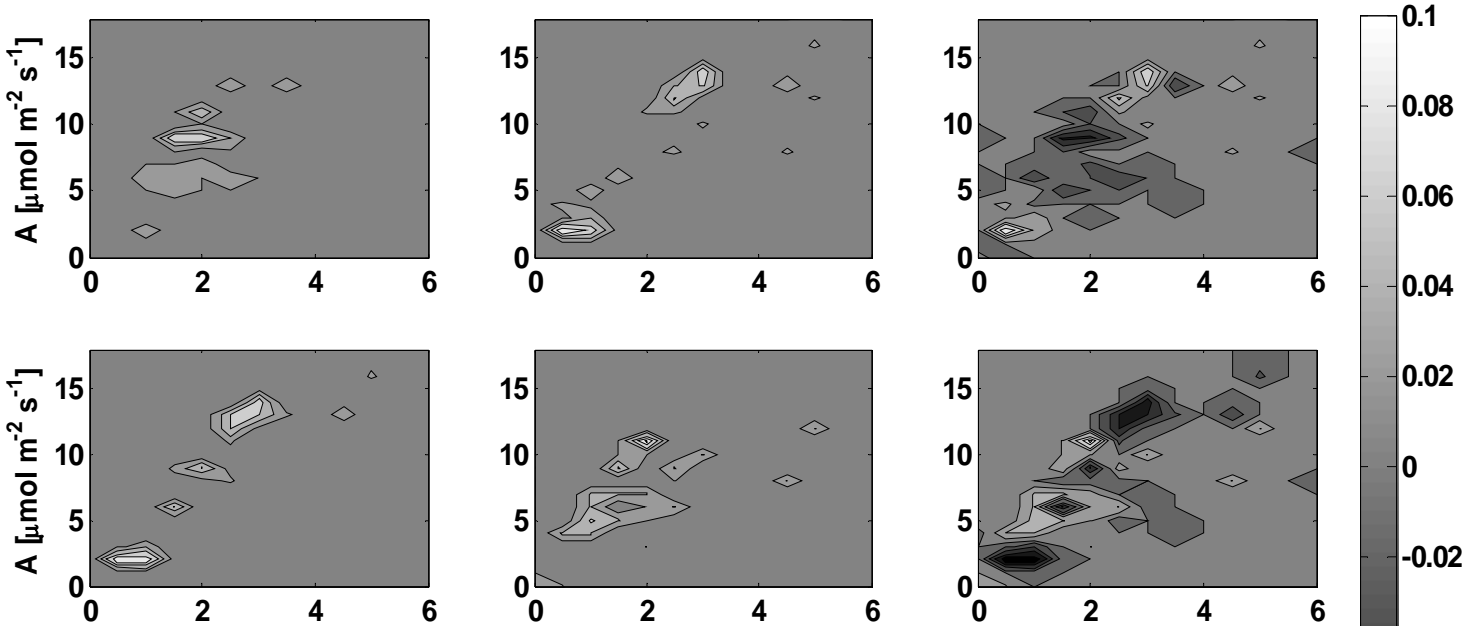

0.02

$-0$

$-0.02$
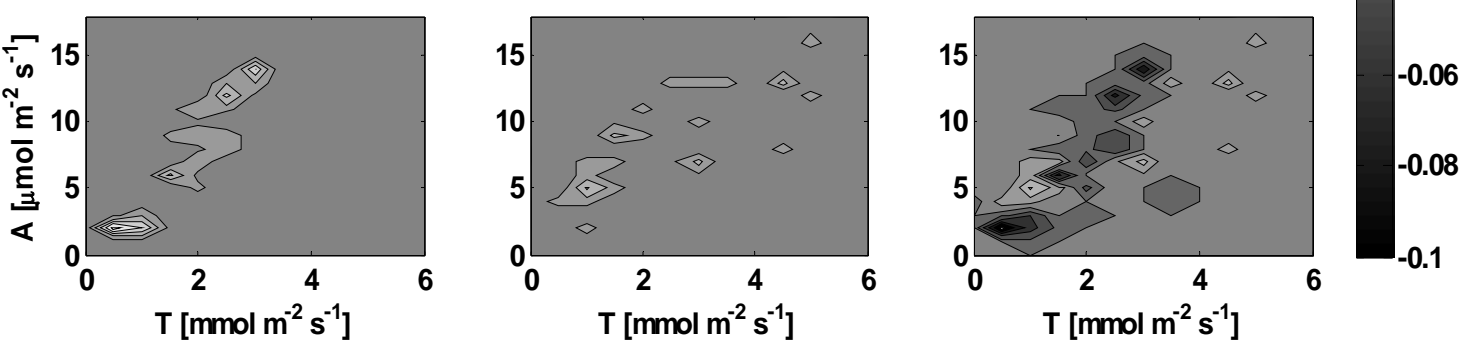

Figure 3.10: Normalized, bivariate frequency distributions of photosynthesis (A) and transpiration ( $\mathrm{T}$ ) for changes in elevation (top row), aspect (middle row) and seasonality (bottom row) at forest sites, where first column is high elevation, southeast aspect and early season for each row, respectively. Second column is low elevation, northwest aspect and late season for each row, respectively. Third column is the difference between the second column and the first column. 

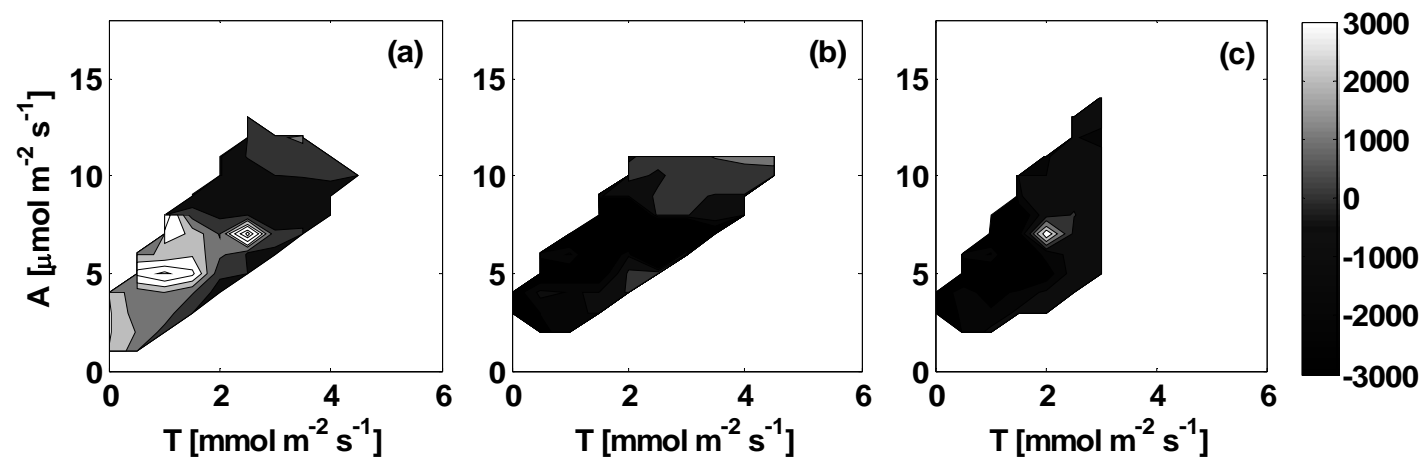

Figure 3.11: Changes in actual water stress across groups of (a) elevation, (b) aspect and (c) seasonality.

Although no significant relationships were found between changes in ecophysiological variables and changes in water stress, significant differences were found in the distributions both of soil moisture and ecophysiological response among elevation, aspect and seasonal groupings. To determine the degree to which shifts in these distributions were related, we examined: 1) correlations between individual ecophysiological responses $(A, T$, and $G)$ and soil moisture within each cohort of each group (Table 3.5) and 2) how these correlations were organized in the bivariate space of each response variable versus soil water content (Figures 3.12 and 3.13).

\section{Table 3.5: Rank Correlation Coefficients Between Volumetric Soil Moisture Ecophysiological Response Variables}

\begin{tabular}{ccccccc} 
Forest & \multicolumn{2}{c}{ Elevation } & \multicolumn{2}{c}{ Aspect } & \multicolumn{2}{c}{ Season } \\
\hline & $H I$ & $L O$ & $S E$ & $N W$ & Early & Late \\
$A$ & $-0.24^{*}$ & $-0.04^{*}$ & $-0.09^{*}$ & 0.32 & 0.30 & $0.04^{*}$ \\
$T$ & 0.42 & $-0.19^{*}$ & -0.24 & 0.42 & 0.29 & $0.15^{*}$ \\
$G_{S}$ & 0.60 & $-0.03^{*}$ & $-0.09^{*}$ & 0.54 & 0.40 & $0.02^{*}$ \\
Meadow & \multicolumn{2}{c}{ Elevation } & \multicolumn{2}{c}{ Aspect } & \multicolumn{2}{c}{ Season } \\
\hline \multicolumn{1}{c}{ HI } & LO & \multicolumn{2}{c}{ SE } & NW & Early & Late \\
$T$ & $-0.02^{*}$ & $-0.08^{*}$ & - & - & $-0.26^{*}$ & $-0.02^{*}$ \\
$G_{S}$ & $0.10^{*}$ & 0.02 & - & - & -0.42 & $-0.21^{*}$ \\
& $-0.11^{*}$ & $-0.28^{*}$ & - & - & $-0.22^{*}$ & $-0.16^{*}$
\end{tabular}

* Not significant $(\mathrm{P}>0.05)$ 

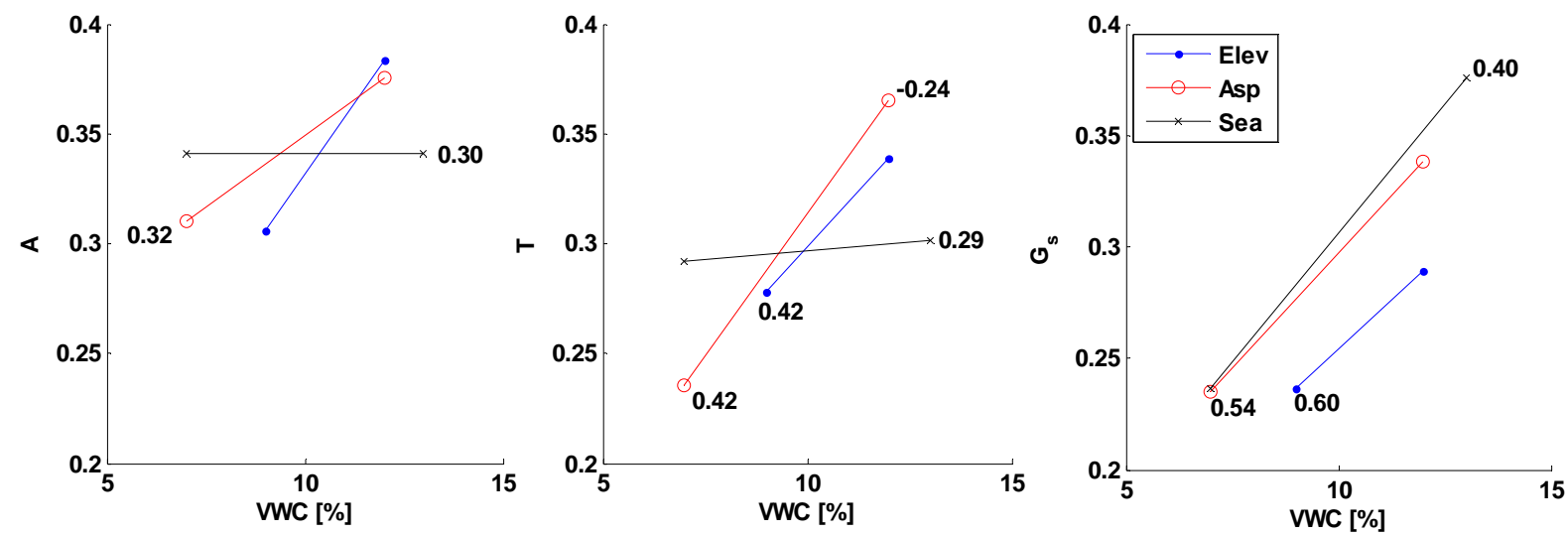

Figure 3.12: Significant correlation coefficients for forest sites mapped to median cohort values in the photosynthesis (A) versus soil water content phase space (left), the transpiration (T) versus soil water content phase space (center), and the stomatal conductance $\left(\mathrm{G}_{\mathrm{s}}\right)$ versus soil water content phase space (right).

Ecophysiological responses are unitless, having been normalized by the total range in observed values. Legend shows groups.
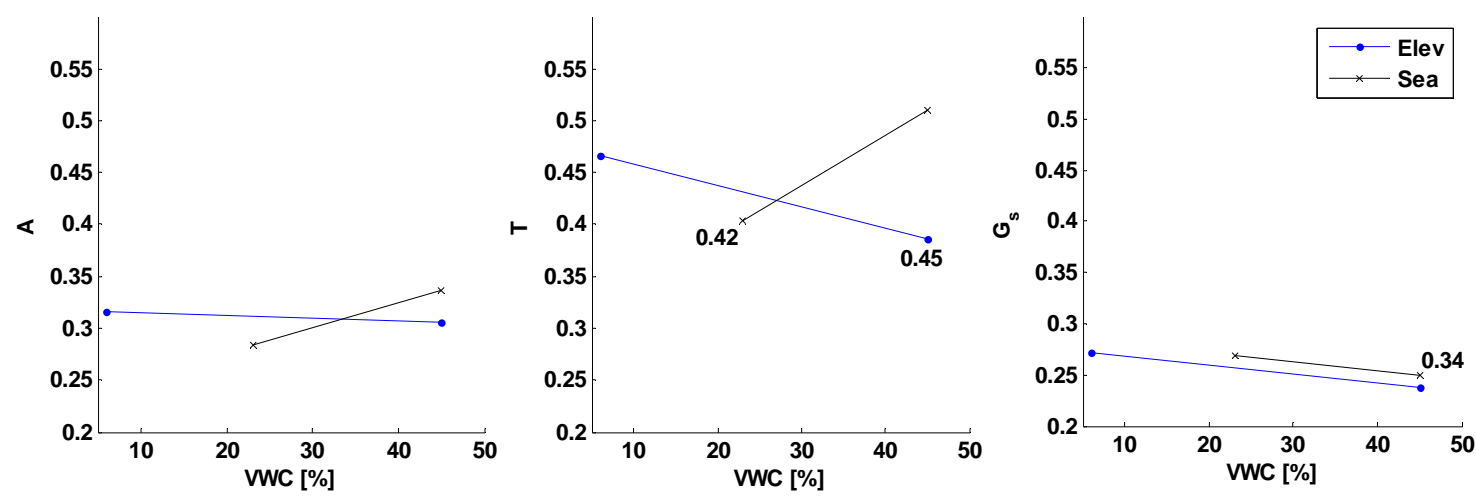

Figure 3.13: Significant correlation coefficients for forest sites mapped to median cohort values in the photosynthesis (A) versus soil water content phase space (left), the transpiration (T) versus soil water content phase space (center), and the stomatal conductance (Gs) versus soil water content phase space (right). 
Ecophysiological responses are unitless, having been normalized by the total range in observed values. Legend shows groups.

When significant correlations are mapped onto median cohort values within the respective response variable versus soil moisture phase spaces for forest sites, a pattern emerges that suggests control of ecophysiological variables by soil moisture. For forests, nearly all distributions of soil moisture and ecophysiological responses declined across groups of elevation, aspect and season (Table 3.2); the positive slopes of the lines in Figure 3.12 reinforce this point. (The only non-positive slope coincides with the only insignificant difference in photosynthesis.) This pattern of declining response with declining moisture suggests some control of vegetation activity by soil moisture and provides further evidence of water stress. Additionally, as soil moisture and ecophysiology decline for each group (elevation, aspect or seasonality), the correlations between photosynthesis, transpiration and stomatal conductance increase, moving from insignificant to significant, or negative to positive. Thus, at lower moisture levels, there is, in general, a stronger relationship between each ecophysiological response and soil moisture.

Negative correlations within wetter cohorts suggest also that despite controlled ranges of temperature, atmospheric humidity and light during leaf chamber measurements, conditions existed during wetter conditions wherein photosynthesis, transpiration and stomatal conductance decreased with increasing soil moisture. These decreases may be due to reduced atmospheric demand for water vapor or reduced photosynthetic demand during cool or cloudy conditions associated with increasing soil moisture [Emanuel et al. 
2007]. For forest ecosystems at this site, these correlations and their relationship to median values of soil moisture and ecophysiological response variables indicate that, regardless of the means by which soil moisture varies (whether by elevation, aspect or seasonality), the control of ecophysiology by soil moisture increases as soils dry.

For meadows, there exist few significant correlations between ecophysiology and soil moisture. In these systems, soil moisture controls may be less important that species differences between dry and wet meadows, and the effect of senescence on early versus late season ecophysiology. The observed decline in median photosynthesis from early to late growing season may correspond to senescence, which itself may be related to soil moisture, temperature, or other phenological factors. Further evidence for senescence as the cause of reduced photosynthesis through the growing season is provide by the distribution of transpiration, which does not decrease significantly through the course of the growing season (Table 3.2). A change in photosynthesis and not transpiration (or stomatal conductance) suggests the reduction in photosynthesis may result from translocation of photosynthetic chemicals rather than from water limitation. Thus, for meadow ecosystems, other factors including species differences and phenology are more important than water stress in affecting physiological activity at this site.

These observed patterns in the relationships (or lack thereof) between control of ecophysiology by soil moisture and level of soil moisture suggest that in areas such as the northern Rocky Mountains, trees may be subject to greater control by soil moisture than the grasses and forbs that occupy wet and dry meadows. The same tree species occupy 
areas of both wet and dry soils, meaning that trees in drier areas, or areas that may become dry during the course of the growing season, may be subject to water stress. By contrast, different herbaceous species occupy wet versus dry meadows, and soils in these areas remain relatively wet or dry during the growing season. That vegetation in neither wet nor dry meadows is subject to detectable control by soil moisture may be evidence of adaptation of these herbaceous species to their respective moisture regimes.

The concept of moisture-sensitive forests and moisture-insensitive meadows is an interesting contrast to the framework of tree-grass ecohydrology characterized by semiarid sites such as the Kalahari Transect (KT) in southern Africa [e.g. Scholes et al., 2002]. In semiarid systems such as the KT, short term variability in vegetation activity is driven largely by the response of herbaceous species to water stress, whereas trees in these systems exhibit steadier growing season vegetation activity. Scanlon and Albertson [2002] demonstrated this response of herbaceous vegetation to water stress along the KT by determining a relationship between grass cover and water stress from year to year. By contrast, and at the scale of a single growing season, these roles are reversed in the northern Rocky Mountains, albeit for different mechanistic reasons, with trees exhibiting ecophysiological response to water stress, and herbaceous plants exhibiting none. 


\section{Conclusions}

Photosynthesis, transpiration and stomatal conductance varied predictably across spatial gradients of elevation and aspect, and through the course of a growing season. Responses in these variables differed for forest and meadow sites, and these sites were also characterized by soil moisture states that differed among sites and through the course of a growing season.

This study, conducted at a site typical of the northern Rocky Mountains, illustrates several important concepts of plant-water relations that have implications for many systems subjected to spatial and temporal environmental gradients. By controlling certain micrometeorological conditions during chamber-based measurements of ecophysiological response, we demonstrated that significant differences exist in plant physiological processes, namely photosynthesis, transpiration and stomatal conductance, both across spatial gradients and through time. For a given ecosystem (forest versus meadow), these differences were not related to phenotypic differences in the vegetation, that is to say model parameters representing ecophysiological processes did not vary significantly in response to spatial heterogeneity of the landscape, or to seasonal changes. Rather, we presented evidence for control of ecophysiological response variables by vegetation water stress, which may, itself, vary spatially and temporally with soil, atmospheric, and vegetation conditions.

These results suggest that, at least for systems such as the montane forests of the northern Rockies, factors contributing to water stress, namely soil moisture, and atmospheric 
conditions, may be more important than differences in vegetation within a given plant type for determining the heterogeneity of carbon assimilation and transpiration.

Furthermore, this study suggests that in montane forests, trees may experience a greater degree of control by soil moisture than grasses, resulting in a greater seasonal variability in the physiological activity of forest vegetation than in the physiological activity of meadow vegetation.

By contrast, different grass species were found in the high and low meadows, and soil moisture was not found to be a strong control on physiological activity at these sites. That neither high nor low meadows were significantly affected by water stress suggests that the species present at each elevation cohort may be adapted to the soil moisture regime of their meadow ecosystems. Though subjected to similar meteorological conditions through the course of a growing season, forest and meadow ecosystems in the northern Rocky Mountains are distinctive in their ecophysiological responses of assimilation, transpiration and stomatal conductance to soil and atmospheric conditions. 


\section{References}

Albertson, J. D., and G. Kiely (2001), On the structure of soil moisture time series in the context of land surface models, Journal of Hydrology, 243, 101.

Bales, R. C., N. P. Molotch, T. H. Painter, M. D. Dettinger, R. Rice, and J. Dozier (2006), Mountain hydrology of the western United States, Water Resources Research, 42.

Ball, J. T., I. E. Woodrow, and J. A. Berry (1987), A model predicting stomatal conductance and its contribution to the control of photosynthesis under different environmental conditions, Progress in Photosynthesis Research, 4, 221-224.

Begg, J. E., and N. C. Turner (1976), Crop water deficits, Adv. Agron, 28, 161-217.

Boisvenue, C., and S. W. Running (2006), Impacts of climate change on natural forest productivity - evidence since the middle of the 20th century, Global Change Biology, 12, 862-882.

Bonan, G. B. (1991), A Biophysical Surface Energy Budget Analysis of Soil Temperature in the Boreal Forests of Interior Alaska, Water Resources Research, 27, 767-781.

Bowling, D. R., S. P. Burns, T. J. Conway, R. K. Monson, and J. W. C. White (2005), Extensive observations of CO 2 carbon isotope content in and above a high-elevation subalpine forest, Global Biogeochemical Cycles, 19.

Breshears, D. D., and F. J. Barnes (1999), Interrelationships between plant functional types and soil moisture heterogeneity for semiarid landscapes within the grassland/forest continuum: a unified conceptual model, Landscape Ecology, V14, 465.

Caylor, K. K., P. D'Odorico, and I. Rodriguez-Iturbe (2006), On the ecohydrology of structurally heterogeneous semiarid landscapes, Water Resources Research, 42.

Clapp, R. B., and G. M. Hornberger (1978), Empirical Equations for Some Soil Hydraulic Properties, Water Resources Research, 14.

Collatz, G. J., J. T. Ball, C. Grivet, and J. A. Berry (1991), Physiological and environmental regulation of stomatal conductance, photosynthesis and transpiration: a model that includes a laminar boundary layer, Agricultural and Forest Meteorology, 54, 107-136.

D'Odorico, P., and A. Porporato (2004), Preferential states in soil moisture and climate dynamics, Proceedings of the National Academy of Sciences, 101, 8848-8851. 
Emanuel R. E., D’Odorico P., and Epstein H. E. (2007) Evidence for optimal water use across a range of North American Ecosystems, Geophysical Research Letters, 34, L07401, doi:10.1029/2006GL028909.

Falge, E., J. Tenhunen, D. Baldocchi, M. Aubinet, P. Bakwin, P. Berbigier, C. Bernhofer, J. M. Bonnefond, G. Burba, and R. Clement (2002), Phase and amplitude of ecosystem carbon release and uptake potentials as derived from FLUXNET measurements, Agricultural and Forest Meteorology, 113, 75-95.

Farquhar, G. D., S. Von Caemmerer, and J. A. Berry (1980), A biochemical model of photosynthetic CO2 in leaves of C3 species., Planta, 149, 78-90.

Gao, Q., P. Zhao, X. Zeng, X. Cai, and W. Shen (2002), A model of stomatal conductance to quantify the relationship between leaf transpiration, microclimate and soil water stress, Plant, Cell and Environment, 25, 1373-1381.

Gollan, T., U. Schurr, and E. D. Schulze (1992), Stomatal response to drying soil in relation to changes in the xylem sap composition of Helianthus annuus. I. The concentration of cations, anions, amino acids in, and $\mathrm{pH}$ of, the xylem sap, Plant, Cell and Environment, 15, 551-559.

Leuning, R. (1995), A critical appraisal of a combined stomatal-photosynthesis model for C3 plants, Plant, Cell and Environment, 18, 339-355.

Lin, H. S., W. Kogelmann, C. Walker, and M. A. Bruns (2006), Soil moisture patterns in a forested catchment: A hydropedological perspective, Geoderma, 131, 345-368.

McCaughey, W. W. (1996), Tenderfoot Creek Experimental Forest, in Experimental Forests, Ranges, and Watersheds in the Northern Rocky Mountains: A compendium of Outdoor Laboratories in Utah, Idaho, and Montana, edited by W. C. Schmidt and J. L. Friede, United States Department of Agriculture, Forest Service.

Mincemoyer, S. A., and J. L. Birdsall (2006), Vascular flora of the Tenderfoot Creek Experimental Forest, Little Belt Mountains, Montana, Madroño, 53, 211-222.

Natural Resources Conservation Service (2006)

http://www.wcc.nrcs.usda.gov/snotel/snotel.pl?sitenum=1008\&state=mt

Nemani, R. R., C. D. Keeling, H. Hashimoto, W. M. Jolly, S. C. Piper, C. J. Tucker, R. B. Myneni, and S. W. Running (2003), Climate-Driven Increases in Global Terrestrial Net Primary Production from 1982 to 1999, Science, 300, 1560-1563.

Norman, J. M., J. M. Welles, and D. K. McDermitt (2006), Estimating Canopy Light-use And Transpiration Efficiencies From Leaf Measurements (Application Note 105), Licor Biosciences, Incorporated. 
Noy-Meir, I. (1973), Desert Ecosystems: Environment and Producers, Annual Review of Ecology and Systematics, 4, 25-51.

Passioura, J. B. (1988), Root Signals Control Leaf Expansion in Wheat Seedlings Growing in Drying Soil, Australian Journal Of Plant Physiology, 15, 687-693.

Pelleschi, S., J. P. Rocher, and J. L. Prioul (1997), Effect of water restriction on carbohydrate metabolism and photosynthesis in mature maize leaves, Plant, Cell and Environment, 20, 493-503.

Reynolds, J. F., and D. H. Knight (1973), The magnitude of snowmelt and rainfall interception by litter in lodgepole pine and spruce-fir forests in Wyoming, Northwest Science, 47, 50-60.

Richardson, D. M., and P. W. Rundel (1998), Ecology and Biogeography of Pinus: an Introduction, in Ecology and biogeography of Pinus, edited by D. M. Richardson, pp. 346, Cambridge University Press, Cambridge.

Rodriguez-Iturbe, I., P. D'Odorico, A. Porporato, and L. Ridolfi (1999), On the spatial and temporal links between vegetation, climate, and soil moisture, Water Resources Research, 35, 3709-3722.

Rodriguez-Iturbe, I., A. Porporato, F. Laio, and L. Ridolfi (2001), Plants in watercontrolled ecosystems: active role in hydrologic processes and response to water stress I. Scope and general outline, Advances in Water Resources, 24, 695-705.

Saab, I. N., R. E. Sharp, J. Pritchard, and G. S. Voetberg (1990), Increased Endogenous Abscisic Acid Maintains Primary Root Growth and Inhibits Shoot Growth of Maize Seedlings at Low Water Potentials 1, Plant Physiology, 93, 1329-1336.

Sala, O. E., and W. K. Lauenroth (1982), Small rainfall events: An ecological role in semiarid regions, Oecologia, V53, 301.

Scanlon, T. M., and J. D. Albertson (2002), Inferred controls on tree/grass composition in a savanna ecosystem: Combining 16-year normalized difference vegetation index data with a dynamic soil moisture model, Water Resources Research, 39, 1224, doi:10.1029/2002WR001881.

Scholes, R. J., Dowty, P. R., Caylor, K., Parsons D. A. B., Frost P. G. H., and H. H. Shugart (2002), Trends in savanna structure and composition along an aridity gradient in the Kalahari, Journal of Vegetation Science, 13, 419-428. 
van Cleve, K., L. Oliver, R. Schlentner, L. A. Viereck, and C. T. Dyrness (1983), Productivity and nutrient cycling in taiga forest ecosystems, Can. Journal of Forest Research, 13, 747-766.

Van de Water, P. K., S. W. Leavitt, and J. L. Betancourt (2002), Leaf d13C variability with elevation, slope aspect, and precipitation in the southwest United States, Oecologia, V132, 332.

Westerling, A. L., H. G. Hidalgo, D. R. Cayan, and T. W. Swetnam (2006), Warming and Earlier Spring Increases Western U. S. Forest Wildfire Activity, Science, 1128834.

Western, A. W., R. B. Grayson, G. Bloschl, G. R. Willgoose, and T. A. McMahon (1999), Observed spatial organization of soil moisture and its relation to terrain indices, Water Resources Research, 35, 797-810.

Wilson, J. P., and J. C. Gallant (2000), Secondary topographic attributes, in Terrain Analysis: Principles and Applications, edited by J. P. Wilson and J. C. Gallant, p. 479, John Wiley and Sons, Inc., New York. 


\title{
Chapter 4: Modeling Vegetation Water Stress and its Effects on Land-
} Atmosphere Exchange in a Northern Rocky Mountain Watershed

\begin{abstract}
We examine the spatial and temporal heterogeneity of vegetation water stress in a forested, subalpine watershed in the northern Rocky Mountains by integrating a model of vegetation water stress into a spatially distributed soil-vegetation-atmosphere transfer model. Using one growing season of meteorological measurements collected from several stations and interpolated over a 300 ha watershed, we simulated soil moisture, stomatal conductance, evapotranspiration, and the dynamic threshold of vegetation water stress. We show that spatially-averaged, catchment-scale water stress varies diurnally with meteorology (photosynthetically active radiation and vapor pressure deficit), and also varies seasonally with the dry-down in soil moisture characteristic of snowmeltdominated hydrological environments. Additionally, we demonstrate the spatial control of water stress within the catchment by topography and vegetation, and the subsequent effects on spatially distributed evapotranspiration. By systematically varying temperature and atmospheric vapor pressure, we also demonstrated the sensitivity of evapotranspiration in certain areas of the watershed to changes in meteorology. Finally, by varying the distribution of vegetation height within the watershed we illustrate effects of vegetation height on temporal patterns of water stress, and briefly discuss implications for ecological optimality.
\end{abstract}




\section{Introduction}

The dynamics of carbon dioxide and water vapor exchange in terrestrial ecosystems are driven by complex interactions among natural and anthropogenic factors that include, among others, climate, land cover, and the allocation of water resources [Houghton, et al., 1999; Nemani, et al., 2003; Palmer, et al., 2004; Boisvenue and Running, 2006]. These factors converge to influence a number of other environmental variables, one of the most important being soil moisture. As a key determinant of carbon and water exchange rates in many terrestrial ecosystems [Noy-Meir, 1973; Eagleson, 1978; Hale and Orchutt, 1987; Rodriguez-Iturbe, et al., 1999; D'Odorico and Porporato, 2006; Emanuel, et al., 2007] soil moisture and its influences on vegetation have received considerable treatment at the plant level [Reich and Hinckley, 1989; Passioura, 2002], the canopy level [Oren, et al., 1998], and also at broader spatial scales [Dickinson, et al., 2002; D'Odorico and Porporato, 2004; Koster, et al., 2004].

Not only does soil moisture status affect vegetation activity, but soil moisture is itself affected by vegetation processes, namely root uptake, canopy interception and transpiration. In terms of the mass balance of soil moisture $(\theta)$ integrated to depth $z$,

$$
z \frac{\partial \theta}{\partial t}=P-E-T-Q
$$

where $P$ is infiltrated precipitation, $E$ is evaporation and $Q$ is drainage, transpiration $(T)$ may represent a significant loss of water from the system and may strongly influence temporal patterns of soil moisture [Albertson and Kiely, 2001] and fluxes of mass and energy [Katul, et al., 2001]. Evidence also exists for vegetation effects on soil moisture 
and water availability in general at broader spatial scales [e.g. Rodriguez-Iturbe, et al., 1991; Brubaker and Entekhabi, 1996; D'Odorico and Porporato, 2004; Jackson, et al., 2005]. As a result, the interactions between soil moisture and vegetation are complex and interdependent across a range of temporal and spatial scales, and have broad implications for terrestrial budgets of carbon, water and energy.

At the spatial scale of a single plant or plant canopy the relationship between soil moisture and transpiration may be represented in terms of vegetation water stress - the degree to which plant physiological activity is limited by the ability to transport water through the so-called soil-plant-atmosphere continuum [Albertson and Kiely, 2001; Porporato, et al., 2001; Daly, et al., 2004; Guswa, 2005; Detto, et al., 2006; Emanuel, et al., 2007, among others]. At larger spatial scales, hydrometeorological conditions (primarily soil moisture and atmospheric vapor pressure deficit, VPD) are commonly used to asses water stress as the long-term balance between hydrologic supply (soil moisture) and demand (VPD) [Nemani, et al., 2003; Mu, et al., 2007]. Across all scales, the relationship between soil moisture and transpiration is commonly characterized as a flux driven by the balance between water supply (soil moisture) and environmental requirements (either vegetation productivity or atmospheric demand, i.e. VPD and wind speed).

The transpiration flux of water vapor from any vegetated land surface to the atmosphere is not simply a linear function of the gradient of water through the soil-plant-atmosphere continuum; rather, the rate of transpiration is sensitive to a number of environmental 
parameters that address the surface energy balance [e.g. Katul, et al., 2001], the biophysical requirements of photosynthesis [Katul, et al., 2003], and other factors in addition to the state of soil moisture. Furthermore, not only is transpiration dependent upon soil moisture status (Equation 4.1), but transpiration itself affects the status of soil moisture, in a similar fashion to the manner in which infiltration both affects and is affected by soil moisture status [e.g. Green and Ampt, 1911]. Similar complexities are encountered in the processes affecting bare soil evaporation [Dingman, 2002] such that evapotranspiration (evaporation plus transpiration) becomes a highly nonlinear function of soil moisture across the full range of natural variability in environmental controls.

Several modeling frameworks exist for the purpose of representing the functional dependence of transpiration on soil moisture. Some of these models base their first principles on the biochemistry of photosynthesis and include a phenomenological rather than process-based response to soil moisture [e.g. Jarvis, 1976; Collatz, et al., 1991; Leuning, 1995]. Other models are structured around the hydrodynamics of the soil-plant atmosphere continuum [e.g. Gao, et al., 2002; Buckley, et al., 2003; Katul, et al., 2003], or the surface energy balance [e.g. Kustas and Norman, 1999; Katul, et al., 2001]. All of these frameworks recognize the key role of stomatal conductance in regulating rates of transpiration. Nevertheless, significant uncertainty remains concerning the actual mechanisms by which soil moisture modulates stomatal conductance [Jarvis, 1976; Gollan, et al., 1986; Saab, et al., 1990; Passioura, 2002; Pataki and Oren, 2003; Buckley, 2005]. Top-down models, typically used to estimate evapotranspiration from remotely sensed surface or atmosphere conditions, are subject to the same uncertainties in 
the relationship between soil moisture and stomatal conductance or its proxy [Schmugge, et al., 2002; Ivanov, et al., 2004].

A combination of the biophysical and hydrodynamic constraints on stomatal conductance forms the basis of a framework to quantify vegetation water stress proposed in Chapter 2 . This framework proposes that vegetation water stress arises as an imbalance between soil water availability and the rate of water vapor flux through the plant stomata imposed by an environmentally-determined level of photosynthesis, and it was formulated initially as a combination of existing leaf-level ecophysiological models. Here we extend this framework to address vegetation water stress at broader spatial scales, since it is still not clear how the emergence of water stress conditions varies across a complex landscape. Additionally, it is uncertain how spatial variability in water stress affects the hydrologic balance at the watershed scale in the presence of additional or contributing heterogeneities that may include topography, distribution of vegetation and meteorology.

Therefore, the purpose of this study is to provide a critical appraisal of the role played by water stress in limiting rates of catchment-scale evapotranspiration through the course of a growing season in a forested, subalpine watershed. We combine ecological and hydrological models to quantify vegetation water stress, spatially distributed and simulated through time, for the purposes of exploring 1) the degree to which environmental state variables (e.g. temperature, atmospheric vapor pressure) and catchment-scale processes (e.g. redistribution of soil water through the catchment) interact with vegetation to control conditions of water stress, 2) the effects of water stress 
on vegetation activity (namely evapotranspiration) at the catchment scale, and 3) the effects of spatially and temporally heterogeneous water stress on the catchment-scale water balance. We discuss these results and their implications in the context of the seasonal water balance in the northern Rocky Mountains. 


\section{Methods}

We used hydrometeorological observations from the 2006 growing season to force a spatially distributed model of land-atmosphere exchange coupled with a topographydependent, spatially distributed soil water balance and our framework for estimating the dynamic threshold for vegetation water stress. Spatially distributed topographic and vegetation information were obtained from high resolution lidar imagery. Using the dynamic threshold of vegetation water stress we defined actual water stress and studied both the controls on water stress and the controls on the watershed hydrologic balance during a growing season in the northern Rocky Mountains.

\section{Site Description}

We collected data during the 2006 growing season (72 days between June 2006 and September 2006) within the upper Stringer Creek watershed (USC), a heavilyinstrumented, 300 ha sub-catchment of the 550 ha Stringer Creek study watershed, located in the Tenderfoot Creek Experimental Forest (TCEF, Montana, USA). The study site is a steep, subalpine watershed dominated by lodgepole pine but also containing small areas of wet and dry meadows (Figure 4.1). The soil is predominantly a sandy loam. The biogeography of this watershed is typical of the northern Rocky Mountains, as described in Chapter 3. Stringer Creek receives a majority of its annual precipitation $(>70 \%)$ as snow [McCaughey, 1996], and experiences a relatively steady drying of soils throughout the growing season [Woods, et al., 2006; Riveros-Iregui, et al., In Review]. Snow melt ended approximately three weeks before the study period began. Long-term measurements at this site include snow-depth, snow-water equivalent and streamflow 
[McCaughey, 1996; Woods, et al., 2006], and more recently tower-based measurements of ecosystem fluxes and micrometeorology over the lodgepole forest (measured at $30 \mathrm{~m}$ ) and separately over a riparian meadow (measured at $1.5 \mathrm{~m}$ ) [Muth et al., In Preparation].

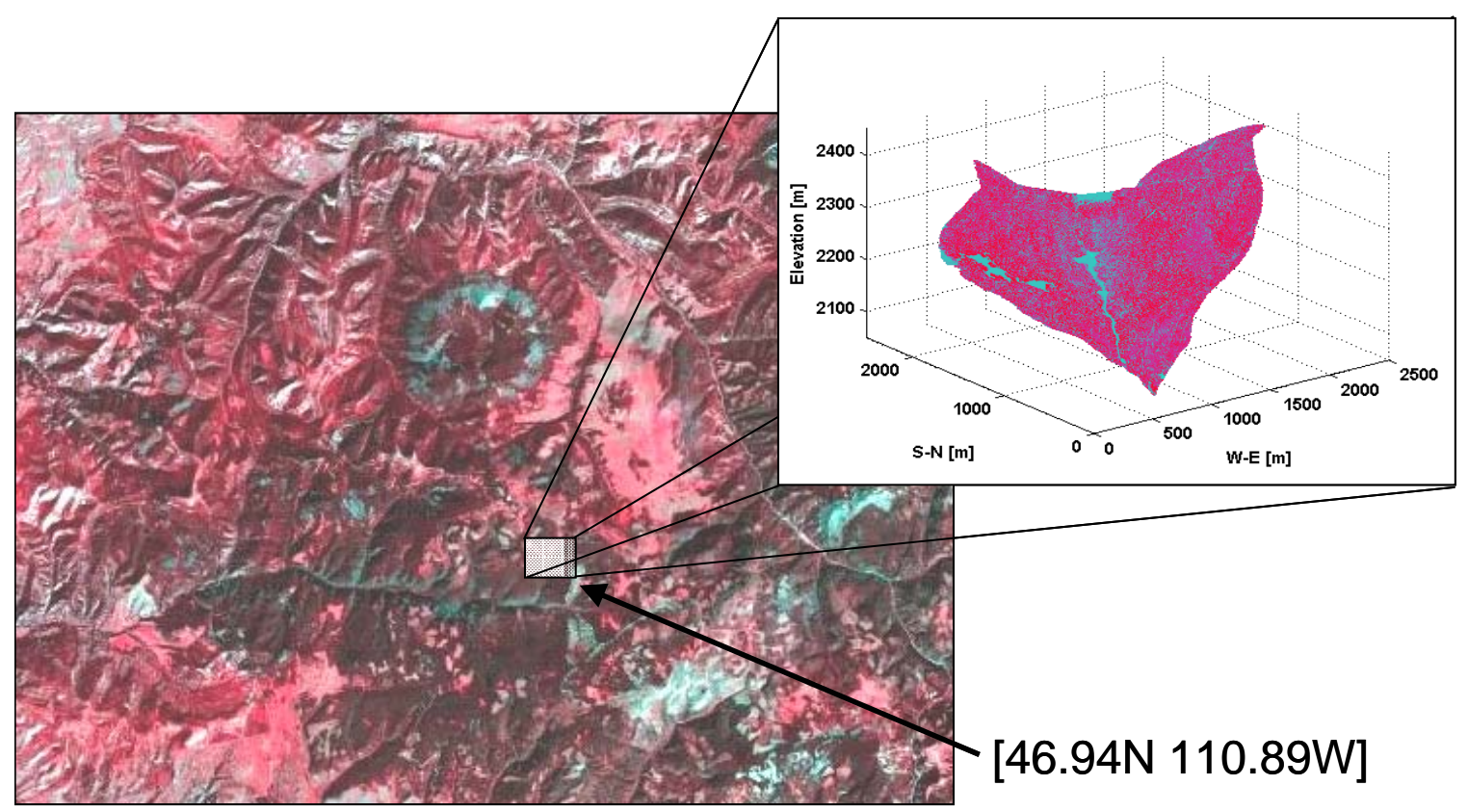

Figure 4.1: ASTER false-color infrared image of Little Belt Mountains, Montana, with inset showing Upper Stringer Creek watershed. Coordinates are shown for watershed outlet.

At the beginning of the growing season (June 2006), five weather stations (HOBO Micro Station, Onset Computer Corporation, Bourne, MA) were installed in USC to supplement meteorological data collected from the two flux towers (Figure 4.2), and to provide necessary atmospheric input for a spatially distributed model of land-atmosphere exchange. These weather stations measured air temperature and relative humidity at $1 \mathrm{~m}$ above the ground surface. Two of the five weather stations measured precipitation, which was also measured at the two flux towers. Flux towers and weather stations 
collected data at 30-minute intervals. Meteorological variables of interest to this study included photosynthetically active radiation (PAR), net radiation, air temperature, relative humidity, precipitation, and horizontal wind speed. In addition to tower-based measurements, we collected leaf-level ecophysiological data at regular intervals using a portable photosynthesis system (LI6400, Licor Biosciences, Lincoln, NE). Each ecophysiological measurement was accompanied by a measurement of volumetric soil moisture integrated from 0 to $20 \mathrm{~cm}$ (Hydrosense, Campbell Scientific, Logan, UT). These measurements are described in Chapter 3. For this study, we used these ecophysiological measurements to estimate leaf-level ecological parameters for the two dominant vegetation types in the watershed, namely conifers and grasses/forbs.
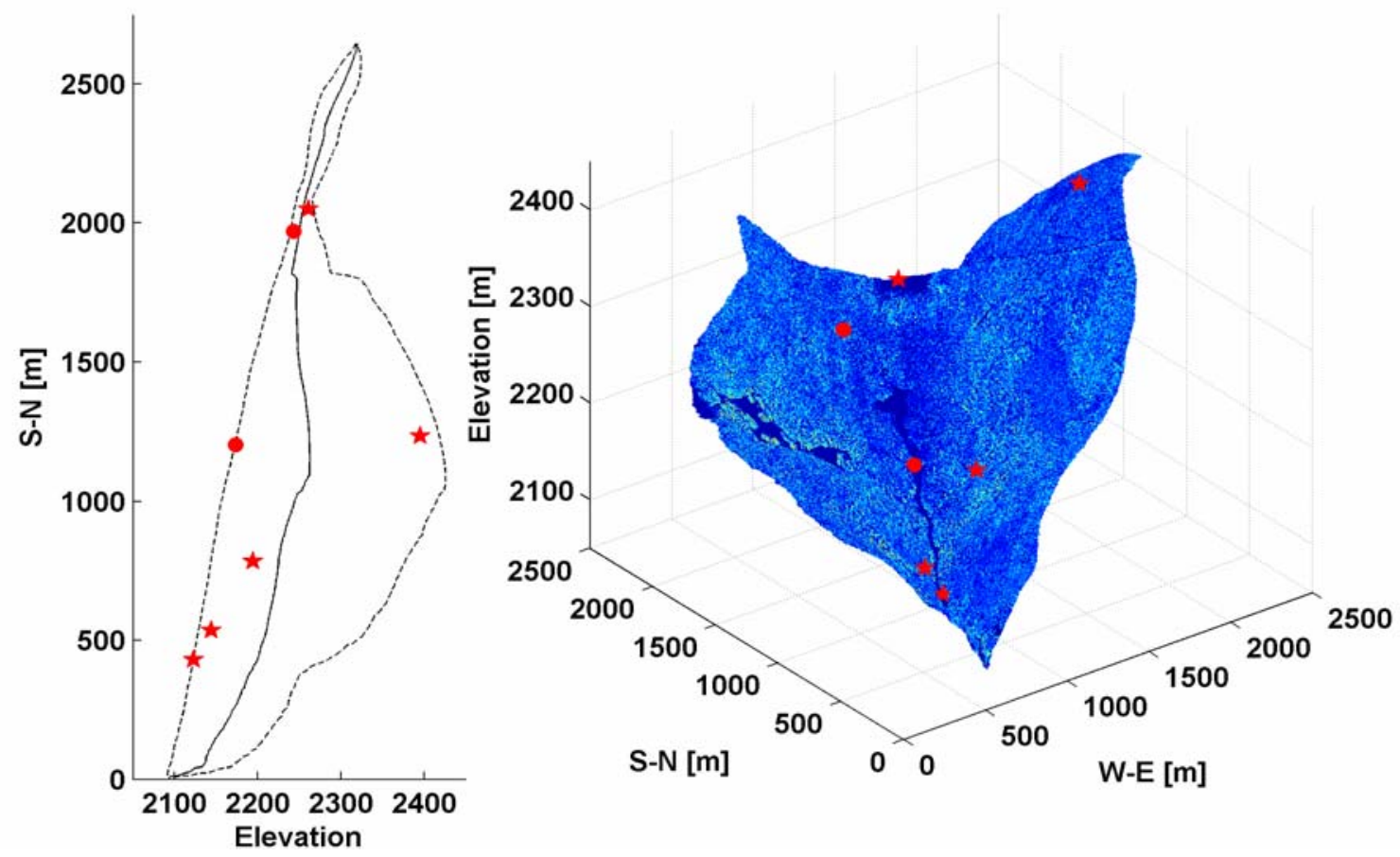

Figure 4.2: Location of flux towers (circles) and ancillary meteorological stations (stars) within Upper Stringer Creek, Montana, shown along an elevation profile 
(left) with mean (solid), minimum and maximum (dashed) elevations shown, and from a three-dimensional perspective (right).

\section{Remote Sensing of Topography and Vegetation}

In September 2005, airborne light detection and ranging (lidar) measurements (ALSMLidar, National Center for Airborne Laser Mapping, Berkeley, CA) were collected over approximately $50 \mathrm{~km}^{2}$ of TCEF, including USC. Elevations of first return (canopy top) and last return (ground surface) of emitted light were recorded at high spatial resolution $\left(<1 \mathrm{~m}^{2}\right)$ and interpolated to a $1 \mathrm{~m}^{2}$ grid in post-processing, producing a dataset typically described as small-footprint lidar [Lefsky, et al., 2002].

Two useful indices were derived from the lidar data: a topographic index and an index of vegetation height. The topographic index, TI (Figure 4.3), was calculated from a digital elevation model (DEM) derived from the last return lidar data. The digital elevation model was coarsened from $1 \mathrm{~m}^{2}$ to $5 \mathrm{~m}^{2}$ horizontal resolution using bilinear interpolation, and $T I$ was computed as

$$
T I=\ln \left(\frac{a}{D I}\right)
$$

where $a$ is the specific area contributing to flow through a point in the watershed computed following the algorithm introduced by Seibert and McGlynn [Seibert and McGlynn, 2007] and DI is the downstream index, an alternative to the local slope that considers topographic concavity downslope of each point [Hjerdt, et al., 2004]. In this system, use of $D I$ has advantages over local slope that include the ability to use a high 
resolution DEM to simulate hydraulic gradients that contain detailed topographic information, but are not as sensitive to microtopography as the local slope. Thus, DI provides an improved representation of topographic influences on flow in this watershed over the local slope.
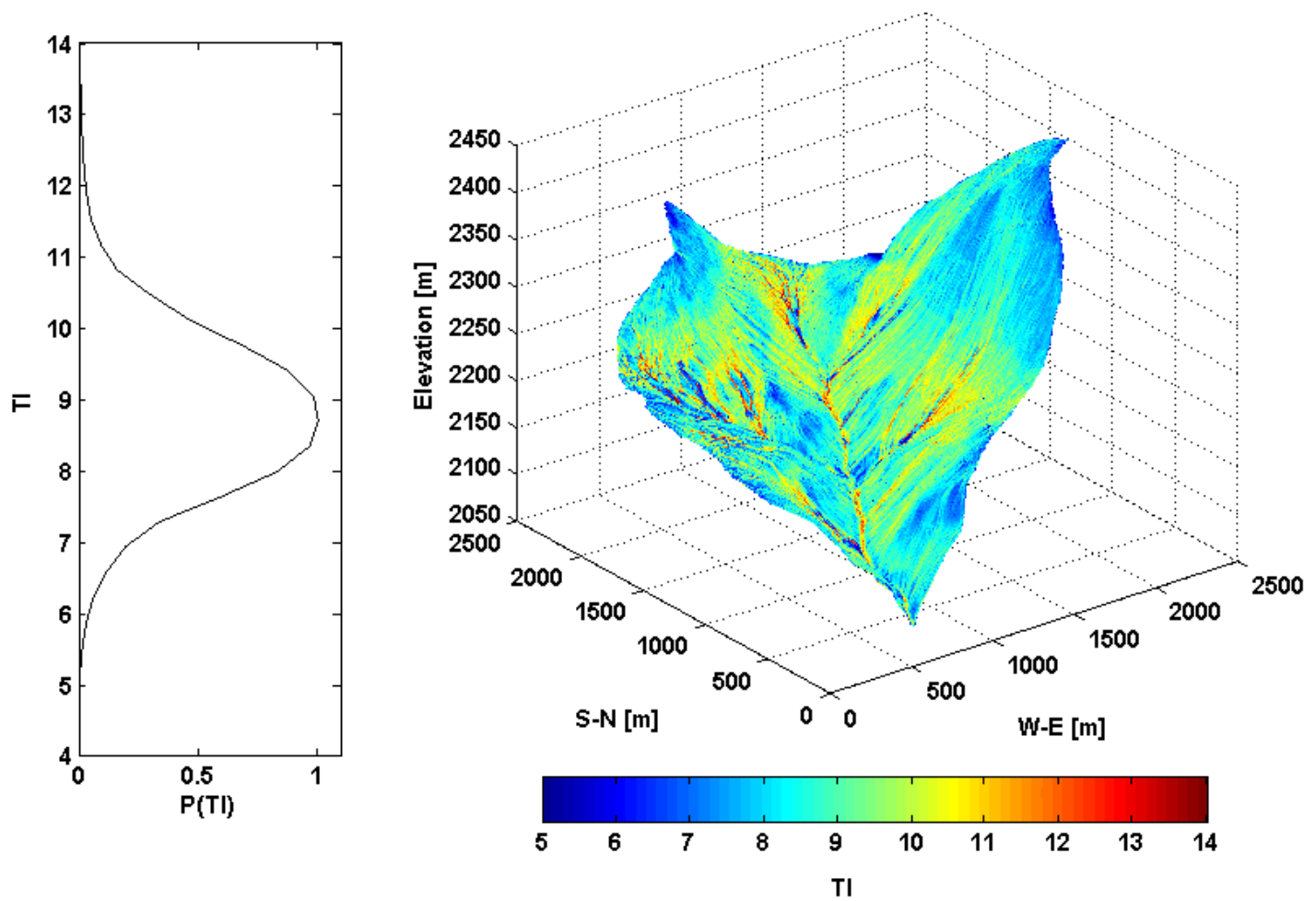

Figure 4.3: Lidar-derived topographic index (TI) for upper Stringer Creek, MT, showing probability distribution of $T I$ (left) and spatial distribution of $T I$.

In addition to $T I$, an index of vegetation height, $Z_{\text {veg }}$ (Figure 4.4), was calculated as the difference in elevation between the first and last returns of the lidar data (i.e. the difference between the canopy top elevation and the ground surface elevation) averaged from $1 \mathrm{~m}^{2}$ to $5 \mathrm{~m}^{2}$ using bilinear interpolation. Similar lidar-derived vegetation height indices have been shown to correlate well with ground-based estimates of vegetation 
height [Dubayah and Drake, 2000; Lefsky, et al., 2002]. We used this index to estimate leaf area index (LAI), a necessary model input, from an empirically-derived relationship between $Z_{v e g}$ and LAI using site-specific allometric data collected by Keane et al. [Keane, et al., 2005]. For grass/forb pixels, we estimated LAI to be $1.0 \mathrm{~m}^{2} \mathrm{~m}^{-2}$. We treated LAI as static through the model simulation period.

Vegetation height was also used to classify vegetation as either needle-leaf trees or grasses/forbs by evaluating $Z_{v e g}$ at each $5 \mathrm{~m}^{2}$ grid cell. Grid cells having $Z_{v e g}>1 \mathrm{~m}$ were classified as needle-leaf trees and $Z_{v e g} \leq 1 \mathrm{~m}$ were classified as grasses/forbs.
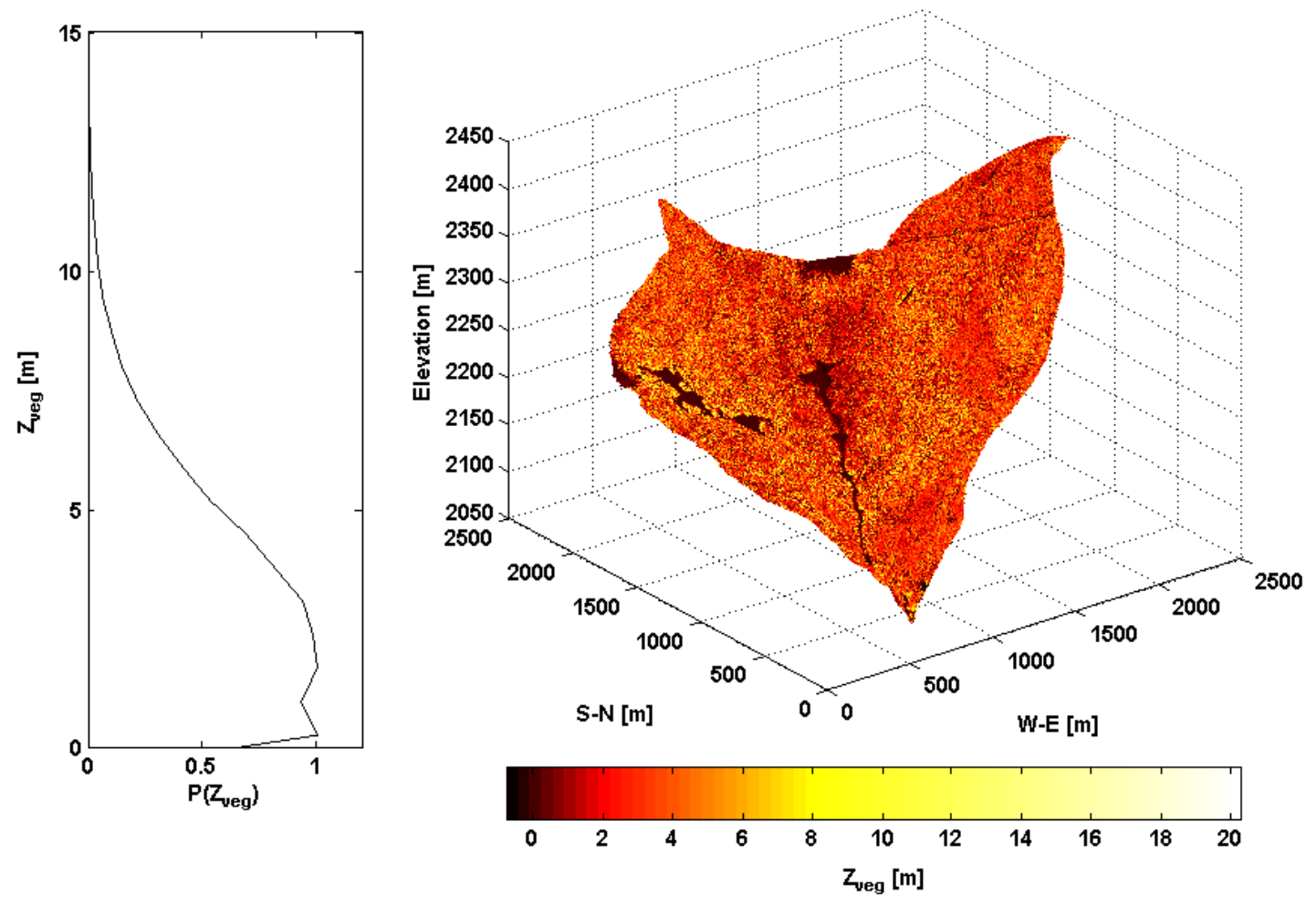

Figure 4.4: Lidar-derived vegetation height index $\left(Z_{v e g}\right)$, for upper Stringer Creek, Montana, showing probability distribution of $Z_{\text {veg }}(\mathrm{left})$ and spatial distribution of $Z_{\text {veg }}$ (right). 


\section{Hydrological and Ecological Modeling Strategy}

The purpose of our land-atmosphere exchange model was to simulate vegetation water stress, through time, as a function of spatially heterogeneous soil, vegetation, and atmospheric conditions. As such, our modeling strategy may be broadly classified as a soil-vegetation-atmosphere transfer or SVAT model, a type of land surface model that has received broad application in recent years (see [Famiglietti and Wood, 1994; Houser, et al., 1998; Olioso, et al., 1999; Boegh, et al., 2004; Scanlon, et al., 2005; Detto, et al., 2006]). Although the model simulated fluxes of water from the catchment that include evapotranspiration and runoff, estimation of these fluxes was not our primary objective. Rather, we used modeled evapotranspiration and runoff to assess the validity of the model (as described in the next section).

Our model included a version of TOPMODEL [Beven and Kirkby, 1979] integrated into a SVAT model [Scanlon, et al., 2005] that was modified further to include calculations of vegetation stomatal conductance and transpiration based on a framework for modeling the dynamic threshold for water stress presented in Chapter 2. Calculating the dynamic threshold for water stress requires that stomatal conductance be modeled as two separate processes, a soil moisture-independent process where stomatal conductance is a function of the biochemical demand for carbon, and a soil moisture-dependent process where stomatal conductance responds to plant hydrodynamics. These bottom-up calculations of conductance and evapotranspiration replace the top-down Priestly-Taylor calculation of 
evapotranspiration [Priestley and Taylor, 1972] used by Scanlon et al. [2005] in conjunction with a commonly used piecewise-linear 'water stress' function.

We derived a moisture-independent, or biochemical, model of stomatal conductance following the standard practice of combining a Farquhar [Farquhar, et al., 1980] -type photosynthesis model [Collatz, et al., 1991] with a modified Ball-Woodrow-Berry [Ball, et al., 1987] model of stomatal conductance [Leuning, 1995]. This model assumes similarity among biochemical processes of $\mathrm{C}_{3}$ plants, and is also based on a semiempirical relationship between photosynthetic assimilation rate and stomatal conductance. The direct proportionality between photosynthesis and stomatal conductance results in a model of stomatal conductance that is extremely sensitive to changes in the rate of photosynthesis, which was our primary reason for selecting this model.

For the hydrodynamic model of stomatal conductance, we selected a steady-state model of soil-plant water transfer with four physiological parameters [Gao, et al., 2002]. This model considers transpiration as the steady-state balance between two Fickian diffusion processes; transpiration is expressed as diffusion of water vapor between the watersaturated stomatal cavity and the atmosphere, and soil to leaf water flux is expressed as a laminar flow driven by water potential gradients between the soil and leaf. Leaf water potential is related to stomatal conductance by assuming a linear (elastic) dependence of guard cell deformation on leaf water potential, where osmotic potential is expressed as a semi-empirical function of PAR [see Gao, et al., 2002; Buckley, et al., 2003, Chapter 2]. 
Although this semi-empirical relationship between PAR and conductance has been criticized for lack of causality [Buckley, et al., 2003], the model is parsimonious compared to other hydrodynamic models of stomatal conductance (which may include 20 or more parameters), and captures the main factors and processes that determine moisture limitations to stomatal conductance.

The soil moisture model simulates volumetric soil water content in the root zone (estimated to be $60 \mathrm{~cm}$ deep) by solving the mass balance of Equation 4.1 at a 30 -minute time step. Given atmospheric inputs and initial states of root zone soil water content and catchment discharge (estimated from field observations of soil moisture and discharge), the model estimates transpiration and discharge (groundwater, root zone and overland) using the previously described ecological and hydrological modeling schemes, and also estimates evaporation of interception and litter moisture (from a lumped storage term) using a radiation-driven estimate of potential evapotranspiration.

In addition to the standard assumptions of the hydrological and ecological model subcomponents, we make several assumptions and simplifications for the sake of accommodating the computational requirements of distributing this model over a watershed partitioned into more than $2.4 \times 10^{5}$ grid cells. These assumptions have implications for evaluating point-scale model results. First, assuming homogeneous soil texture and depth influences the modeled relationship between volumetric soil water content and soil water potential (e.g. [Clapp and Hornberger, 1978]). This assumption and the corollary assumption of homogeneous rooting depth affect modeled soil moisture, 
and hence plant hydrodynamics for individual points. Second, by assuming static ecological structure (e.g. no biomass accumulation, litterfall, nutrient cycling), we ignore seasonal changes as plants allocate carbon to new growth or experience senescence. This assumption is reasonable based on the short length of this study (76 days) relative to the slow growth of lodgepole pines in subalpine ecosystems (viz. [Ryan and Waring, 1992]). Finally, evapotranspiration rates modeled at any individual point are subject to uncertainty because we assume simple canopy aerodynamics (canopy boundary layer resistance to water vapor and aerodynamic resistance to water vapor based on spatial interpolation of wind velocity measurements over complex terrain).

\section{Atmospheric Model Inputs}

We framed this model in a spatially explicit fashion, meaning that all atmospheric, soil, topographic and vegetation inputs were distributed over the entire watershed at $5 \mathrm{~m}^{2}$ resolution, and model algorithms were evaluated for each grid cell rather than for bins of similar grid cells. Others [Famiglietti and Wood, 1994; Houser, et al., 1998] have adopted this approach in the past when considering spatial heterogeneity of multiple environmental factors. Precipitation, air temperature, relative humidity and horizontal wind speed measurements from the flux towers and weather stations were interpolated to a $10 \mathrm{~m}^{2}$ grid using the Spatial Observation Gridding System (SOGS) [Jolly, et al., 2005]. These grid cells were then subdivided to match the resolution of the $5 \mathrm{~m}^{2}$ topographic and vegetation inputs. This interpolation scheme was designed to be independent of the spatial scale of the input data, and it was found to have an absolute uncertainty of less 
than $2.0{ }^{0} \mathrm{C}$ for temperature and less than $3 \mathrm{mb}$ for atmospheric vapor pressure for continental-scale measurements interpolated to a few kilometers [Jolly, et al., 2005].

Photosynthetically active radiation and net radiation were assumed spatially homogeneous at the top of the vegetation canopy; however, we approximated the effects of topography on these variables using a terrain-based hillshading algorithm [Kumar, et al., 1997; Pierce, et al., 2005] to scale radiation and account for differential topographic shading during morning and afternoon hours. We also used a simplified two big-leaf approximation [Dai, et al., 2004] based on lidar-derived vegetation height to simulate the effects of shading and attenuation on radiation vertically within the canopy.

We simplified the complex relationship between surface heat fluxes, air temperature and canopy temperature [Campbell and Norman, 1998] after comparing measurements of air temperature to canopy surface skin temperature taken at the forest and meadow flux towers with temperature-corrected infrared thermometers (IRTS-P, Campbell Scientific / Apogee Instruments, Logan, UT). For both sites, regression slopes between air and surface temperatures were statistically indistinguishable from unity $(\mathrm{P}<0.05)$, and regression intercepts were statistically indistinguishable from $0(\mathrm{P}<0.05$, Figure 4.5). For this reason, we used air temperature to represent average canopy temperature for each half hour of the study period. We considered the horizontal variability of catchmentscale micrometeorology to be a primary control on the spatial heterogeneity of the SVAT model. For this reason, we did not explicitly consider the vertical variability of 
micrometeorological conditions within the canopy other than the effects of light attenuation.

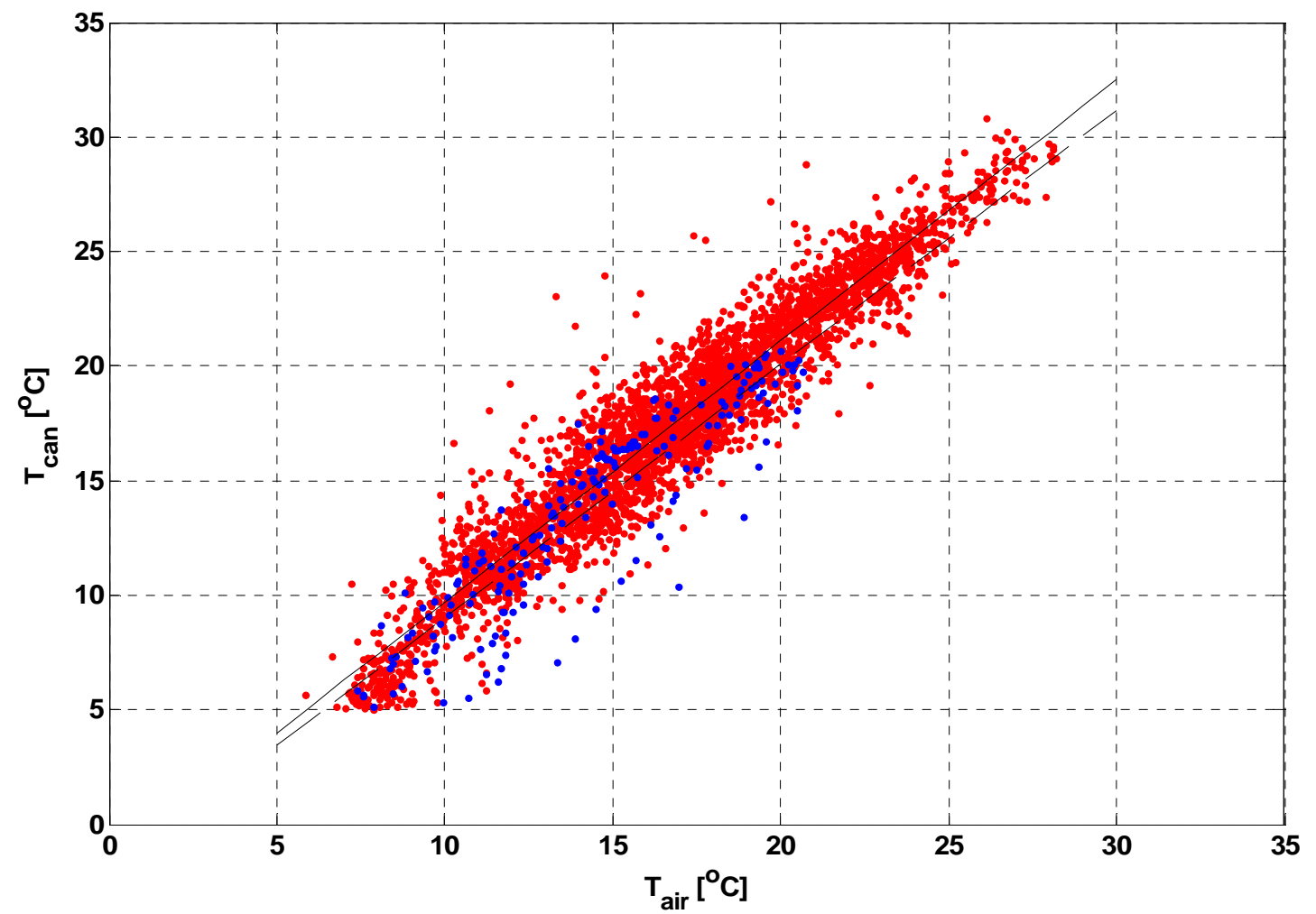

Figure 4.5: Canopy surface temperature versus air temperature for forest (red) and meadow (blue). Linear least-squares regession lines are shown for both forest (solid line, $\mathrm{R}^{2}=0.91$ ) and meadow (dashed line, $\mathrm{R}^{2}=0.82$ ) sites.

We used friction velocity $(u *)$, derived from turbulence measurements at the forest flux tower to estimate the canopy boundary-layer resistance to water vapor $\left(r_{b}\right)$ following Hicks et al. [1987] and Fuentes et al. [1994] as

$$
r_{b}=\frac{2}{k u_{*}}\left(\frac{S c}{P_{r}}\right)^{2 / 3}
$$


where $k$ is the von Kármán number, $S c$ is the Schmidt number for water vapor in air, and $\operatorname{Pr}$ is the Prandtl number. Aerodynamic resistance to water vapor transfer was calculated by applying flux tower-based stability corrections to the logarithmic wind profile to neutrally-stable wind profiles computed from interpolated wind speed data (see Chapter 2).

Nuances of this SVAT model include 1) calculation and incorporation of a dynamic threshold for vegetation water stress, 2) exclusive use of lidar-derived topographical and vegetation structure information, 3) use of the downstream index in the calculation of $T I$ (Equation 4.2), and 4) spatial interpolation of point-based meteorological variables using SOGS. This modeling strategy makes a number of common assumptions and simplifications, yet assimilates a wide range of spatially and temporally detailed environmental data to characterize the response of vegetation water stress to a range of meteorological, hydrological, and ecological conditions.

\section{Model Performance and Application}

Since no method exists for measuring vegetation water stress directly at the spatial or temporal scales represented by the model, we assessed the validity of the model using simulated components of the hydrologic balance that could be measured directly, and we also considered these validation results to represent the model's ability to track vegetation water stress. We validated the model at two time scales using three different approaches, each utilizing independent measures of hydrologic conditions within USC. At the 30 minute time scale, we compared the whole-catchment model estimate of 
evapotranspiration $(E T)$ to $E T$ measured by eddy covariance above the lodgepole forest. This validation method assumes that the flux footprint of the tower is large enough to represent the variability of ET across USC. A conservative estimate of the upwind extent of the flux footprint of $3 \mathrm{~km}$ based on an instrument height of $30 \mathrm{~m}$ and a general southerly wind direction suggests that, in general, the area contributing to the measured flux is an area that contains the study site and similar forested areas. This method tests the ability of the model to capture the short-term response of vegetation to fluctuations in atmospheric and soil conditions. Also at the 30 minute time scale, we compared simulated soil moisture in the root zone $(0$ to $60 \mathrm{~cm})$ to actual measurements of root zone soil moisture collected from three time-domain reflectometry probes (CS616, Campbell Scientific, Logan, UT) buried near the forest flux tower at depths of $5 \mathrm{~cm}, 20 \mathrm{~cm}$ and 50 $\mathrm{cm}$. For each set of observed, $O$, and simulated, $S$, variables, we used two measures of model performance. First, the mean absolute error, or MAE, was calculated for the time series of length $N$ as

$$
\text { MAE }=N^{-1} \sum_{i=1}^{N}\left|O_{i}-S_{i}\right|
$$

following Legates and McCabe [Legates and McCabe, 1999]. This measure provides an estimate of model performance in absolute units that have relevance to the system under consideration. Second, a comparative measure of model performance, the adjusted coefficient of efficiency, $E_{1}^{\prime}$ was calculated as 


$$
E_{1}^{\prime}=1-\frac{\sum_{i=1}^{N}\left|O_{i}-S_{i}\right|}{\sum_{i=1}^{N}\left|O_{i}-\overline{O^{\prime}}\right|}
$$

where $\overline{O^{\prime}}$ may be either the mean of observations or a time trend of observations (which could also be another model simulation) with confidence intervals derived from bootstrapping [Legates and McCabe, 1999]. A value of 0 for $E_{1}^{\prime}$ means that the model performed equally as well (i.e. explained as much variation) as $\overline{O^{\prime}}$. Positive values of $E_{1}^{\prime}$ indicate improvements over $\overline{O^{\prime}}$, and negative values of $E_{1}^{\prime}$ indicate that the model performed worse than $\overline{O^{\prime}}$. In an application such as this one, comparison of modeled residual to time trend residuals provides a more powerful indicator of model performance than comparison against residuals from the mean observed value. For example, observed discharge decreases almost monotonically through the growing season; substitution of a parametric trend for $\overline{O^{\prime}}$ in Equation 4.5 yields a more meaningful measure of the model's performance versus that trend rather than versus mean discharge.

We compared simulations of half-hourly and total catchment runoff during the study period to actual runoff measured by a US Forest Service stream gage at the outlet of USC. We also compared the model estimate of total ET during the study period to actual ET measured by the forest flux tower. These comparisons assess the ability of the model to represent accurately the seasonal hydrologic balance of USC, and provide an estimate 
of closure between observations and simulations of the major, catchment-scale loss terms from Equation 4.1.

Finally, by varying model inputs, we tested the sensitivity of water stress to meteorology and vegetation. Specifically, we systematically varied temperature and atmospheric vapor pressure inputs, running the model at higher and lower temperatures and atmospheric vapor pressures than actually observed during the study period. In addition to meteorology, we varied the spatial distribution and heterogeneity of vegetation, running the model with uniformly, randomly distributed vegetation and with homogeneous (mean height) vegetation in addition to actual vegetation. 


\section{Results and Discussion}

\section{Model Performance versus Observations}

Observed and modeled hydrological variables are shown in Figure 4.6. To assess the model's ability to simulate half-hourly conditions within the watershed, we compared half-hourly measurements of $E T$ from the forest flux tower to the half-hourly simulated ET averaged across all pixels in the watershed. For all time periods, we considered the footprint of the flux tower to be representative of conditions across USC. For the entire time series, $E_{1}^{\prime}$ (Equation 4.5) for modeled ET was $0.44( \pm 0.04)$ when compared to a baseline of mean observed ET, meaning that at the half-hourly time scale the model performed significantly better than the mean value of ET. Furthermore, the MAE between observed and simulated half-hourly ET was $0.06 \mathrm{~mm} \mathrm{hr}^{-1}$, or $1.5 \mathrm{~mm} \mathrm{day}^{-1}$. For the entire study period, our SVAT model estimated a total ET loss of $215 \mathrm{~mm}$ (46 $\mathrm{mm}$ of which was evaporation and $169 \mathrm{~mm}$ of which was transpiration), whereas the forest flux tower measured $213 \mathrm{~mm}$ of total ET.

In addition to $E T$, we compared simulated half-hourly runoff, $Q_{\text {sim }}$, with half-hourly observations of runoff, $Q_{o b s}$, at the watershed outlet. For the entire time series, $E_{1}^{\prime}$ for $Q_{\text {sim }}$ was $0.69( \pm 0.02)$ when compared to the mean of half-hourly $Q_{o b s}$, but $-2.85( \pm 0.22)$ when compared to a baseline function of a hyperbola fitted to the seasonal hydrograph (see [Scanlon, et al., 2000]). The negative coefficient of efficiency means that the simulation explained less variance in the observations than the baseline trend, which is not surprising in this case since the hyperbolic baseline function explains $98 \%$ of the variance in $Q_{o b s}$. The MAE between $Q_{\text {sim }}$ and $Q_{o b s}$ during the study period was $0.002 \mathrm{~mm}$ 
$\mathrm{hr}^{-1}$, or $0.04 \mathrm{~mm} \mathrm{day}^{-1}$. For the entire study period, our SVAT model estimated total runoff to be $16 \mathrm{~mm}$, whereas measured runoff totaled $18 \mathrm{~mm}$.
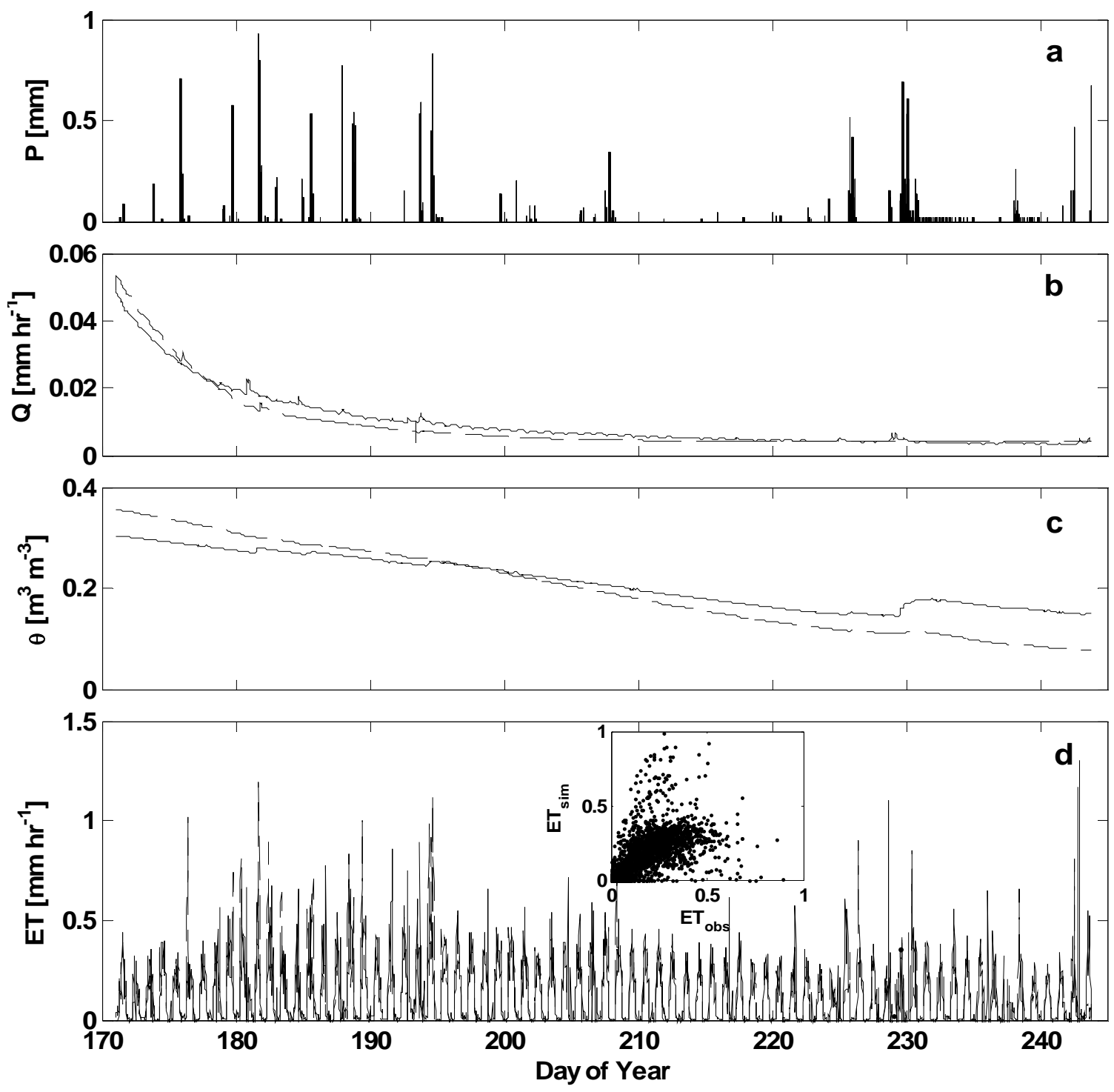

Figure 4.6: Time series of catchment-scale hydrological processes including (a) precipitation, (b) discharge, (c) soil moisture and (d) evapotranspiration where solid lines are observations and dashed lines are simulations. 
Assessing the validity of simulated soil moisture fields is difficult due to spatial variability inherent in soil moisture observations [Western, et al., 1999]. Accordingly, when we compared simulated soil moisture at the grid cell containing the forest flux tower to the depth-weighted average of soil moisture from the three time-domain reflectometry probes, we found $E_{1}^{\prime}$ to be $0.28( \pm 0.04)$ compared to a baseline of mean observed soil moisture, and MAE of $0.03 \mathrm{~m}^{3} \mathrm{~m}^{-3}$. Simulated soil moisture declined nearly twice as much $\left(0.28 \mathrm{~m}^{3} \mathrm{~m}^{-3}\right)$ during the study period as did observed soil moisture $\left(0.16 \mathrm{~m}^{3} \mathrm{~m}^{-3}\right)$ measured at the same grid cell. Despite a low coefficient of efficiency for simulated soil moisture at this particular location, simulated and measured soil moistures are highly correlated $\left(\mathrm{R}^{2}=0.97\right)$, suggesting that errors in simulated soil moistures are systematic through time. However, because soil moisture measurements are contained within one $5 \mathrm{~m} \times 5 \mathrm{~m}$ grid cell, we are unable to determine the spatial distribution of these systematic errors. Nevertheless, positive correlation between observed and simulated soil moistures indicate that the soil moisture model provides a reasonable estimate of the seasonal dynamics of the soil water balance in this system, and provides a useful basis for further calculations of water stress.

\section{Interpreting the Hydrologic Balance}

Equation 4.1 is helpful for interpreting the relative significance of the simulated water balance terms described previously. During the 72-day study period, $56 \mathrm{~mm}$ of precipitation fell over USC, $43 \mathrm{~mm}$ of which was evaporated from leaves or litter before entering the soil. Regardless of model error, very little precipitation infiltrated into the root zone relative to the amount of water removed from the root zone by transpiration. 
This result is consistent with earlier findings that snowmelt is the only significant source of soil moisture recharge in subalpine forests of the western U.S. [Running, 1980].

Vertical and lateral discharges of water from the root zone were also much smaller than transpiration. As a result, the decline in soil moisture was controlled primarily by transpiration (Figure 4.7) rather than by discharge throughout the entire study period, not simply when $\theta<\theta_{f c}$ as is specified by the model. This result also suggests that soil moisture variability is under local control of transpiration during the entire study period, and that, due to the consequently low unsaturated hydraulic conductivity, discharge and lateral redistribution of root zone moisture play a limited role in determining the pointscale water balance [e.g. Grayson, et al., 1997], at least for locations within the watershed having topography and vegetation similar to the vicinity of the flux tower. 


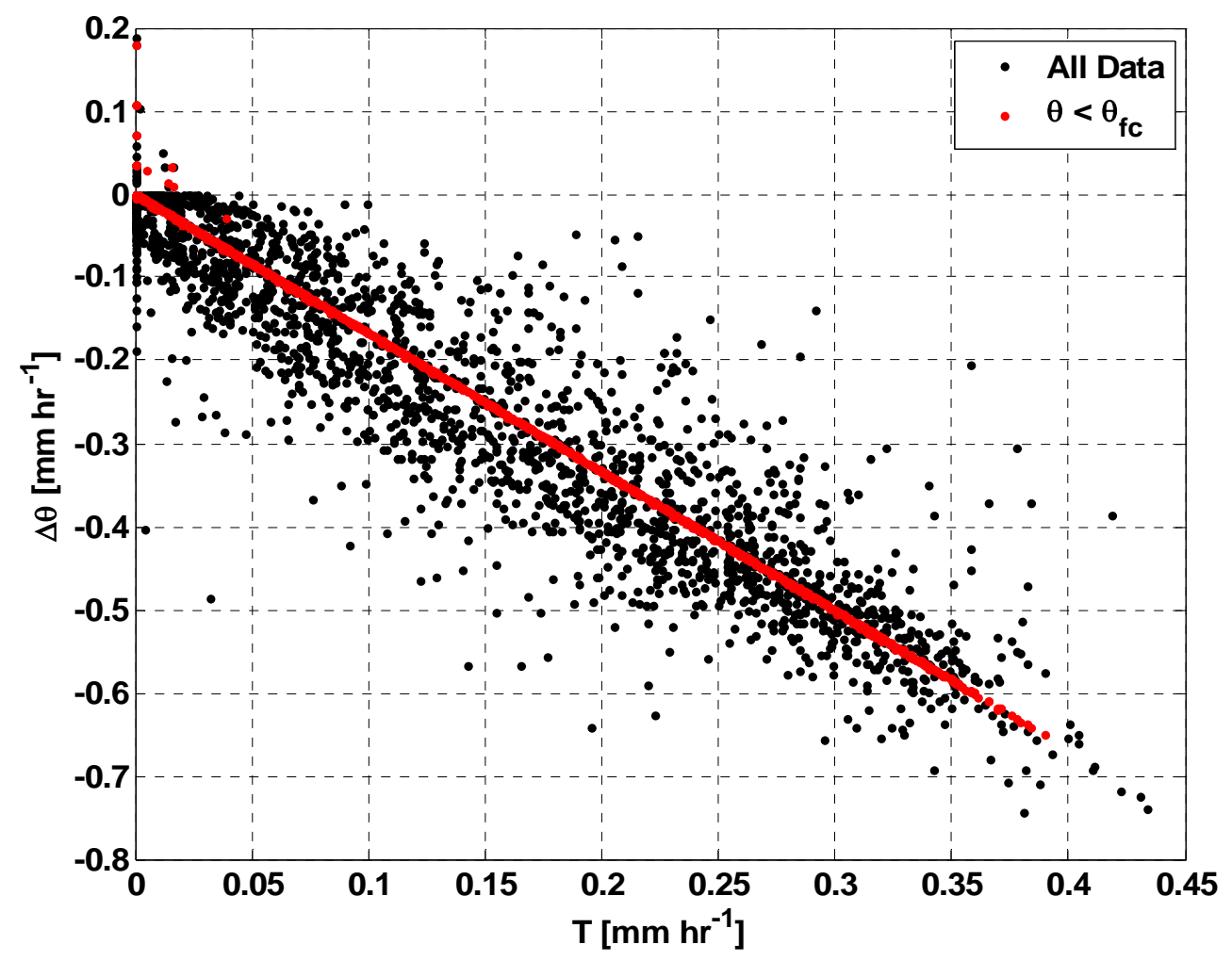

Figure 4.7: Change in simulated volumetric water content, $\theta$, at the forest flux tower as a function of catchment-averaged transpiration, $T$, for the entire study period (black), and for dry periods where soil moisture is less than field capacity (red). Regression slope for all periods: $-1.65\left(\mathrm{R}^{2}=0.80\right)$.

Little evidence exists to support any atmospheric source of plant or soil moisture (e.g. fog) other than $56 \mathrm{~mm}$ of precipitation during the study period. In certain systems, fog may ameliorate vegetation water stress [Dawson, 1998], or it may even affect the direct measurement of ET [e.g. Scanlon and Albertson, 2004]. In many high elevation forests, fog water and canopy condensation may contribute significantly to the hydrologic balance [Walmsley, et al., 1996]. However, low atmospheric humidity measured at USC (Figure 4.8) suggests that significant input from fog or canopy condensation was unlikely. Measured relative humidity was less than 0.38 for half of the study period and 
less than 0.95 for $94 \%$ of the study period (Figure 4.8). Although relative humidity (or a combined air temperature and dewpoint) analysis does not address the issue of fog water quantitatively, prediction of fog from high relative humidities $(\mathrm{RH}>95 \%)$ tends to overestimate fog frequency significantly [Walmsley, et al., 1999], meaning that fog may have occurred during less than $6 \%$ (109 hours) of the study period where relative humidity exceeded $95 \%$.

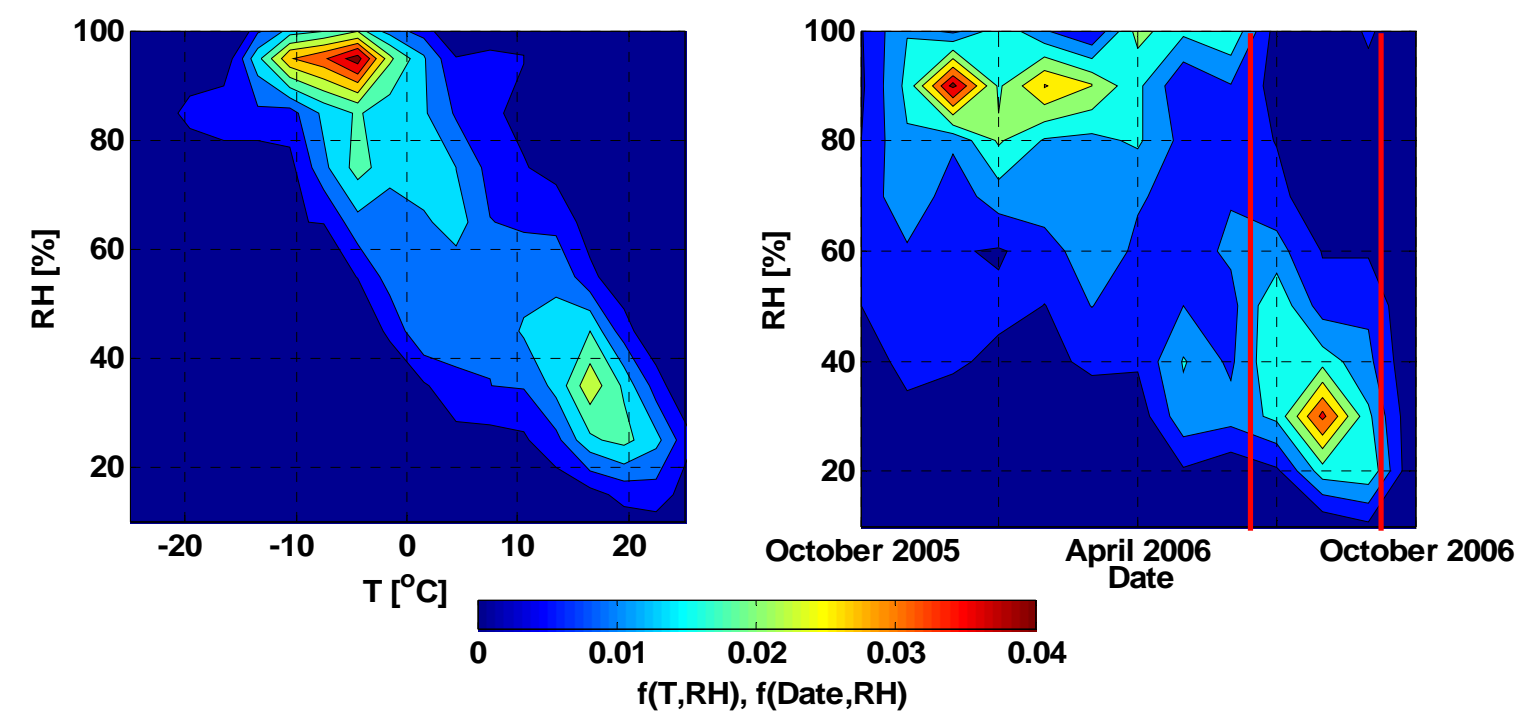

Figure 4.8: Joint probability distributions for relative humidity and temperature (left) and relative humidity and date (right) for October 2005 - October 2006. Red lines on right denote beginning and end of study period.

\section{Evaluating Vegetation Water Stress}

To our knowledge, this is the first study to use a process-based model of vegetation water stress applied to a detailed, catchment-scale study of hydrologic cycling and landatmosphere exchange. In the following sub-sections, we analyze temporal and spatial 
patterns of vegetation water stress and follow with a discussion 1) the controls on water stress and 2) effects of water stress on the hydrologic balance of USC.

\section{Controls on the Dynamic Water Stress Threshold}

The spatially-averaged, modeled dynamic threshold of vegetation water stress, $\psi *$ varied considerably during the study period (Figure 4.9a). A number of factors contributed to the variability in modeled $\psi *$ at both diurnal and seasonal time scales including spatial averages of measured photosynthetically active radiation (PAR) and atmospheric vapor pressure deficit (VPD, representing the combined effects of temperature and humidity), both of which exhibit strong diurnal variability and, to a lesser extend, seasonal variability. 

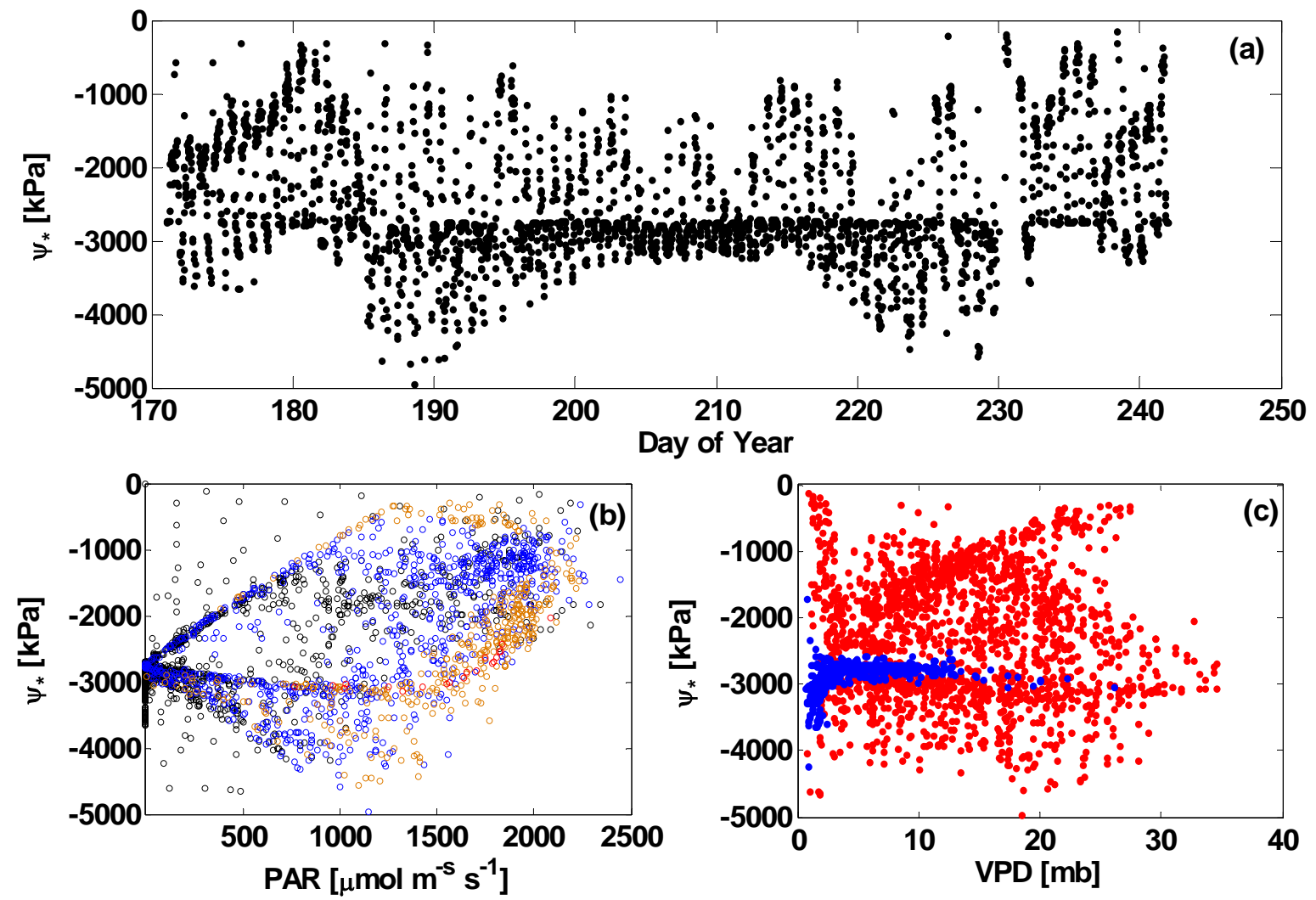

Figure 4.9: Half-hourly spatial averages of $\psi *$ (a) as a time series, (b) as a

function of PAR for four classes of VPD (see text) and (c) as a function of VPD for night (blue) and day (red) periods.

Photosynthetic demand for carbon (and thus photosynthesis-limited stomatal conductance) is strongly coupled to PAR, which results in a PAR-like diurnal pattern of maximum $\psi *$ (not shown). This pattern arises because maximum $\psi *$ relative to an independent variable represents the response of $\psi *$ to that variable in the absence of other limiting factors. The effect of PAR on maximum $\psi *$ is also apparent in Figure $4.9 \mathrm{~b}$, as are the interacting effects of PAR and VPD on $\psi *$. Maximum $\psi *$ becomes insensitive to PAR near $1200 \mu \mathrm{mol} \mathrm{m}-^{2} \mathrm{~s}^{-1}$, meaning that in the absence of other limiting factors, water stress maximizes at this level of light (which is approximately the $55^{\text {th }}$ percentile of 
daytime light levels during the study period). At low VPD (Figure 4.9b, black: VPD < $10 \mathrm{mb}$, blue: $10 \mathrm{mb}<\mathrm{VPD}<20 \mathrm{mb}$ ) PAR is the primary control on maximum $\psi_{*}$, whereas at higher VPD (orange: $20 \mathrm{mb}<\mathrm{VPD}<30 \mathrm{mb}$, red: VPD $>30 \mathrm{mb}$ ) the nature of the control is less apparent. There are also periods during which VPD controls maximum $\psi *$ (Figure 4.9c). Between approximately $5 \mathrm{mb}$ and $30 \mathrm{mb}$, maximum daytime $\psi *$ is positively correlated with VPD (where $\psi *$ is in the range of approximately -2000 $\mathrm{kPa}$ to $-400 \mathrm{kPa}$ ). This region may correspond to periods of increased PAR, during which VPD is likely to be most limiting to stomatal conductance and $\psi_{*}$. As a result, in this system, the dynamic threshold of vegetation water stress varies in response to PAR and VPD, and although the relationship is complex, $\psi *$ exhibits diurnal variability corresponding to plant demand for carbon and atmospheric demand for water vapor.

\section{Quantifying Actual Water Stress}

Actual water stress, the condition where soil water potential, $\psi^{*}$, does not meet a plant's demand for water, may be defined using the dynamic water stress threshold as $\psi_{s}<\psi_{*}$. However, this deterministic calculation of water stress does not account for uncertainty in the modeling of either of these variables. Assuming individual measurements of $\psi_{s}$ and $\psi *$ are subject to uncertainty in the model parameters, we considered the imbalance of available water and plant water demand, $\psi_{s}-\psi^{*}$, an indicator of the intensity of water stress rather than an absolute determinant of stress conditions (i.e. an on-off switch). By rescaling $\psi_{s}-\psi_{*}$, or $\Delta \psi$, by maximum and minimum global values of this variable during the study period, we define a function for the intensity of water stress as 


$$
I_{\text {stress }}=\frac{\max [\Delta \psi]-\Delta \psi}{\max [\Delta \psi]-\min [\Delta \psi]}
$$

This function assumes that at $\max [\Delta \psi]$ (i.e. the highest positive value) vegetation is minimally water stressed and at $\min [\Delta \psi]$ (i.e. the lowest negative value) vegetation is severely water stressed. In this manner, $I_{\text {stress }}$ provides a more intuitive metric than $\Delta \psi$ for quantifying the relative degree of water stress within the catchment during the study period. Due to uncertainty in the model estimates of both $\psi_{s}$ and $\psi_{*}$, all positive values of $\Delta \psi$ are not unstressed necessarily. For example, since $\min [\Delta \psi]$ reaches approximately $2000 \mathrm{kPa}$ and $\max [\Delta \psi]$ reaches approximately $5000 \mathrm{kPa}$ during the study period, an intermediate level of water stress (e.g. a value of $\Delta \psi$ halfway between $\min [\Delta \psi]$ and $\max [\Delta \psi])$ might be 0.5 calculated from equation 5 , rather than $1500 \mathrm{kPa}$ expressed in $\Delta \psi$ units. Accordingly, under minimum stress conditions, $I_{\text {stress }}=0$, and under maximum stress conditions, $I_{\text {stress }}=1$.

Watershed-averaged time series of $\psi_{s}, \psi^{*}$, and $I_{\text {stress }}$ are shown in Figure 4.10. Soil water potential (Figure 4.10a) declines in a steady, logarithmic pattern through the study period, whereas $\psi *$ (Figure $4.10 \mathrm{~b}$ ) varies diurnally in a pattern that, by definition, reflects the integrated effects of solar radiation and other meteorological conditions. As a result, $I_{\text {stress }}$ (Figure 4.10c) exhibits two scales of variability. At the seasonal scale, average daily $I_{\text {stress }}$ is negatively correlated (not shown) with $\psi_{s}(\rho=-0.66)$ whereas at the daily 
scale, half-hourly $I_{\text {stress }}$ is positively correlated (not shown) with $\psi *(\rho=0.96)$. Although the latter degree of correlation is not surprising (it is obvious that most of the variability in $I_{\text {stress }}$ comes from $\psi *$ ), it is important to note that the time scale of interest (half-hourly versus daily measurements or averages) will dictate which variable ( $\psi_{s}$ or $\left.\psi *\right)$ determines the variability of $I_{\text {stress. }}$. Additionally, it is important to note that daily averages of $I_{\text {stress }}$ include nighttime periods, during which there is no photosynthetic demand for carbon, and only a residual stomatal conductance. During these periods, likelihood that a plant will experience water stress is greatly reduced, and these periods lower the daily average values of $I_{\text {stress }}$. Therefore, daytime averages of $I_{\text {stress }}$ are greater (not shown). Nevertheless, daily average $I_{\text {stress }}$ provides an appropriate relative measure of the evolution of water stress through the growing season. 

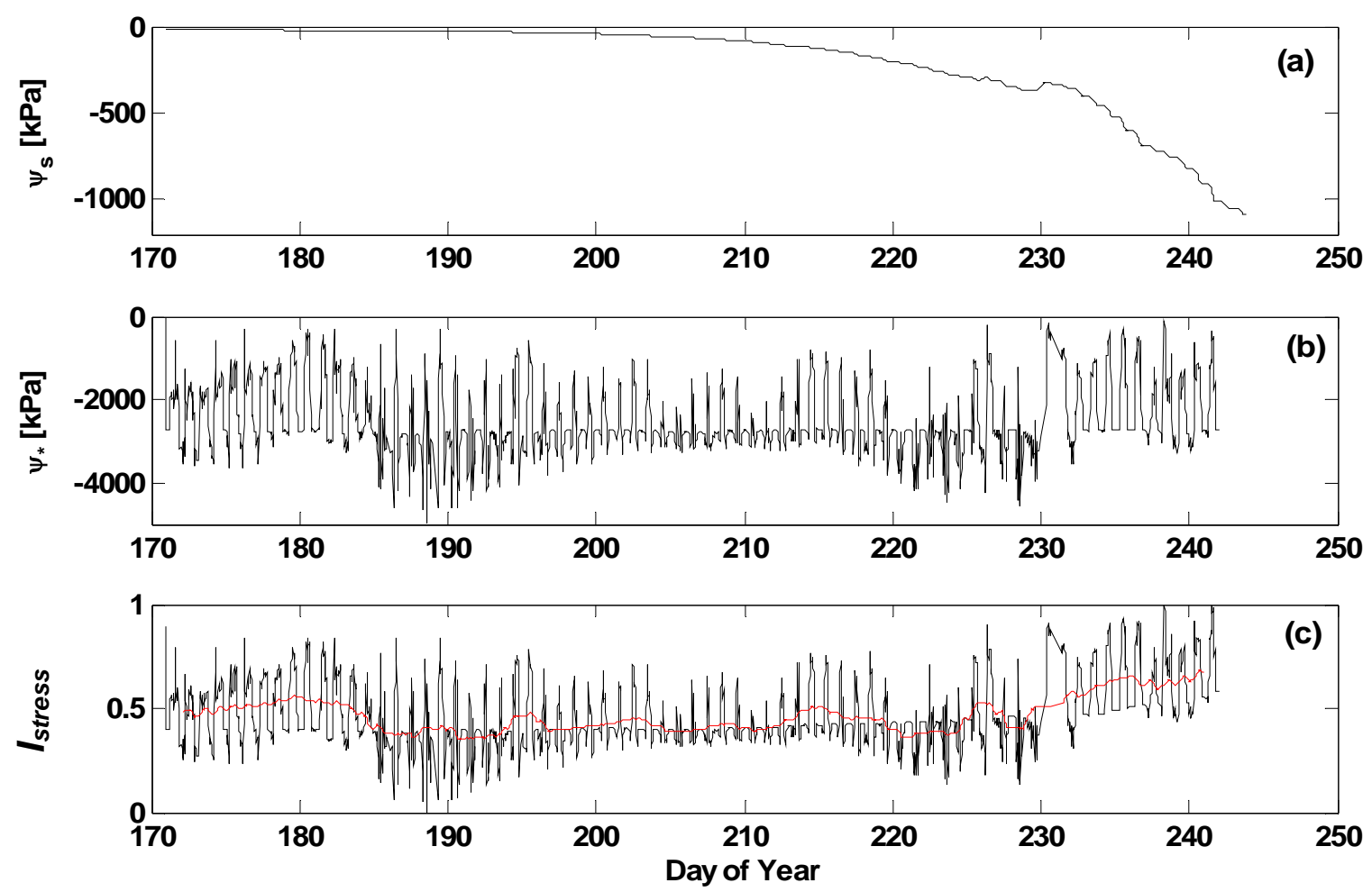

Figure 4.10: Time series of watershed averaged (a) soil water potential, $\psi_{s}$, (b) dynamic threshold of vegetation water stress $\psi *$ and (c) intensity of vegetation water stress, $I_{\text {stress, }}$, with daily average values shown (red).

This measure of the intensity of actual water stress is based on watershed averages of variables $\left(\psi *\right.$ and $\left.\psi_{s}\right)$, which may differ significantly across the watershed due to spatial heterogeneity in the topographic and vegetation features that control the local hydrologic balance (Figures 4.3 and 4.4). To explore the effects of these spatial heterogeneities, we evaluated actual water stress on a grid cell by grid cell basis for the entire study period. For each half hour, we determined the frequency distribution of $I_{\text {stress }}$ across the entire watershed, where $I_{\text {stress }}$ was calculated using the 2.5 and 97.5 percentiles of $\Delta \psi$ from all grid cells for the entire study period instead of absolute $\min [\Delta \psi]$ and $\max [\Delta \psi]$ values in 
Equation 4.5. This approximation, by definition, excluded some data from further analysis, but also eliminated the effects of spurious $\min [\Delta \psi]$ and $\max [\Delta \psi]$ on the formulation of $I_{\text {stress. }}$. To eliminate variability associated with daily fluctuations in solar radiation and other meteorological variables from a seasonal analysis of watershed-wide $I_{\text {stress }}$, and because significant ET occurs only during daylight, we examined half-hourly frequency distributions of daytime $I_{\text {stress }}$ only (Figure 4.11).
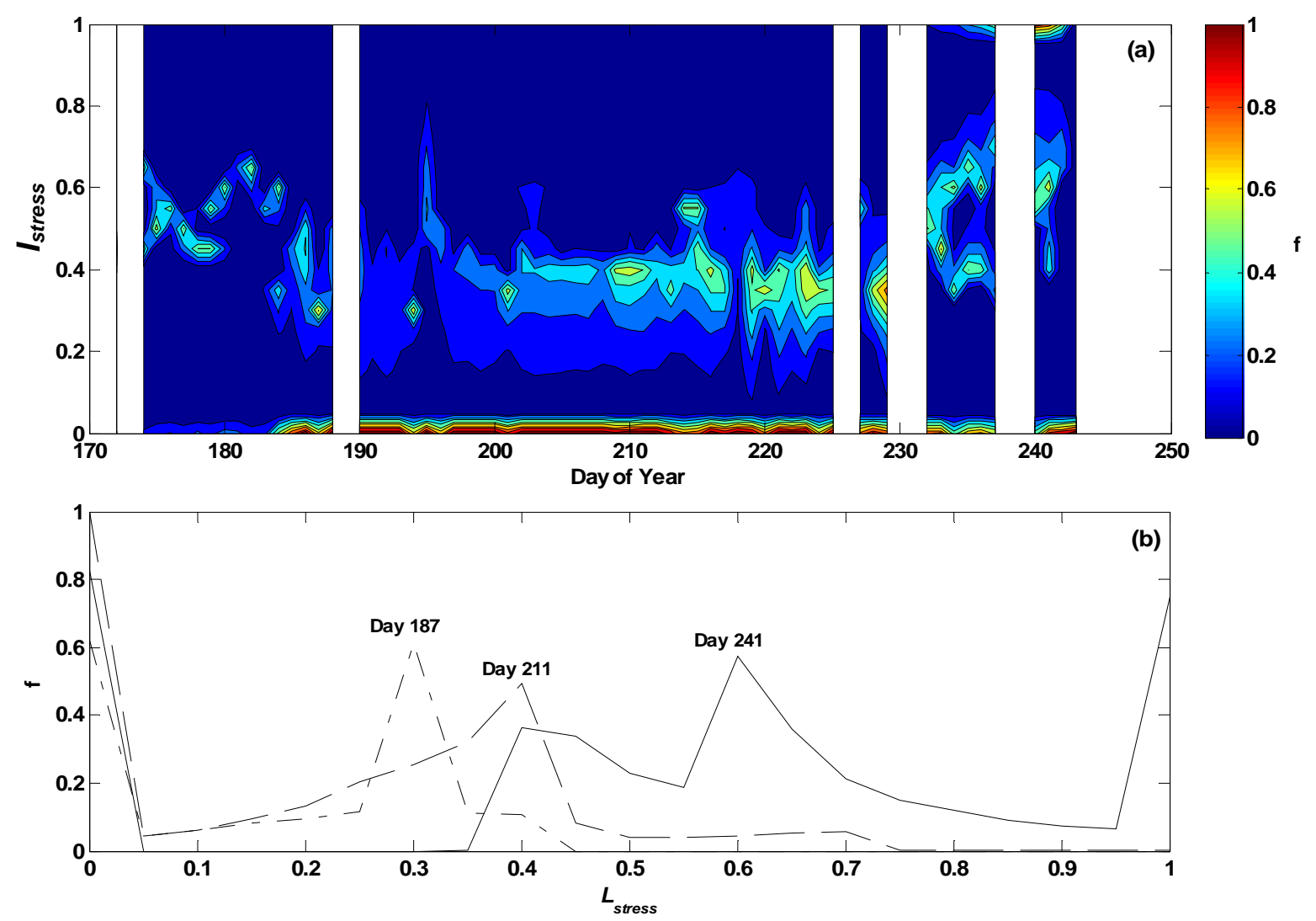

Figure 4.11: Relative distribution, f, of daytime $I_{\text {stress }}$ (a) through the entire study period and (b) for three selected days during the study period.

The distribution of $I_{\text {stress }}$, though highly nonparametric for any given daytime period, evolves in a predicable pattern during the study period (Figure 4.11a). Multiple modes of $I_{\text {stress }}$ persist throughout the study period, with a large fraction of the watershed 
experiencing the lowest intensity of water stress through most of the study period (e.g. the lower modes of Day 187 and Day 211). These modes may correspond to vegetation type, topography or both. In general, however, there is an intermediate mode of stress intensity that migrates from lower intensity to higher intensity through the course of the growing season (Figure 4.11b); this is the general trend captured by watershed-averaged $I_{\text {stress. }}$

To determine the effect of $I_{\text {stress }}$ on the land-atmosphere exchange of water vapor, we compared half-hourly watershed-averaged $I_{\text {stress }}$ to watershed-averaged transpiration (Figure 4.12). Even though watershed-averaged values integrate processes over a range of topographic conditions and vegetation, a relationship exists between the upper limit of transpiration for a given, average stress intensity. For daytime values, this upper limit of transpiration increases from minimum stress to moderate stress ( $I_{\text {stress }}$ of 0 to 0.5 ). Between moderate and severe stress conditions ( $I_{\text {stress }}$ of 0.5 to 1$)$, the relationship between watershed-averaged transpiration and stress intensity is less certain. This relationship suggests that maximum watershed-averaged transpiration may occur at some intermediate intensity of water stress (e.g. between 0.5 and 0.85 ). Mechanistically, this may correspond to low atmospheric demand for water vapor inhibiting transpiration at low stress intensity. 


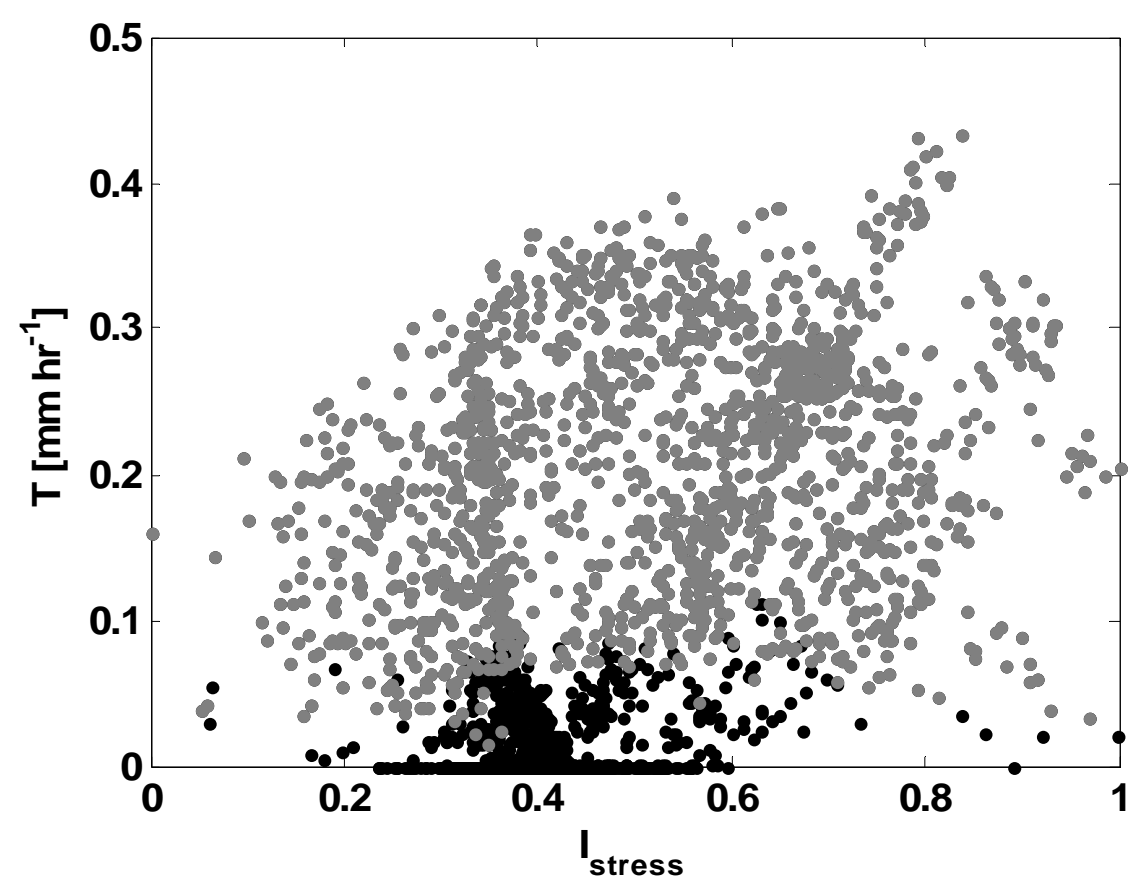

Figure 4.12: Watershed-averaged transpiration $(T)$ as a function of watershedaveraged stress intensity $\left(I_{\text {stress }}\right)$ with daytime values shown in gray and nighttime values shown in black.

To determine whether certain combinations of vegetation height and topography within the watershed were more susceptible to water stress than other areas, we calculated, for each grid cell, the frequency with which water stress exceeded the $90^{\text {th }}$ percentile of watershed-averaged $I_{\text {stress }}$ during the study period $\left(\mathrm{f}_{\text {stress } 90}\right)$, and compared these frequencies to $T I$ and $Z_{v e g}$. In addition to frequencies we calculated, for each grid cell, the average duration of excursions above this threshold intensity value and also compared these durations $\left(D_{\text {stress } 90}\right)$ to $T I$ and $Z_{v e g}$.

We found that topography and vegetation both affect the frequency and average duration of excursions above the $90^{\text {th }}$ percentile of watershed-averaged $I_{\text {stress }}$. In general, 
increasing $T I$ is associated with decreasing frequency of water stress. The effect of topography on the frequency of water stress is stronger for grasses and forbs than for trees (Figure 4.13a,b). Additionally, trees experience a relatively higher frequency of severe water stress than grasses and forbs, with grid cells having lower $Z_{v e g}$ (i.e. shorter trees) experiencing slightly higher frequencies of water stress than grid cells having higher $Z_{v e g}$ (i.e. taller trees). The potential for taller trees to reach deeper supplies of soil water is not explicitly parameterized in the modeling framework, but modeled light extinction through the canopy may lead to lower average PAR in these grid cells and a thus an overall reduced biochemical requirement for stomatal conductance. Of the combinations of $Z_{v e g}$ and $T I$, grasses and forbs on steeper slopes are most sensitive to topography with respect to the frequency of water stress. In these areas (Figure 4.13a,b region 0), small increases in $T I$ (and, by definition, increases in average soil moisture) lead to relatively large decreases in the frequency of severe water stress. 

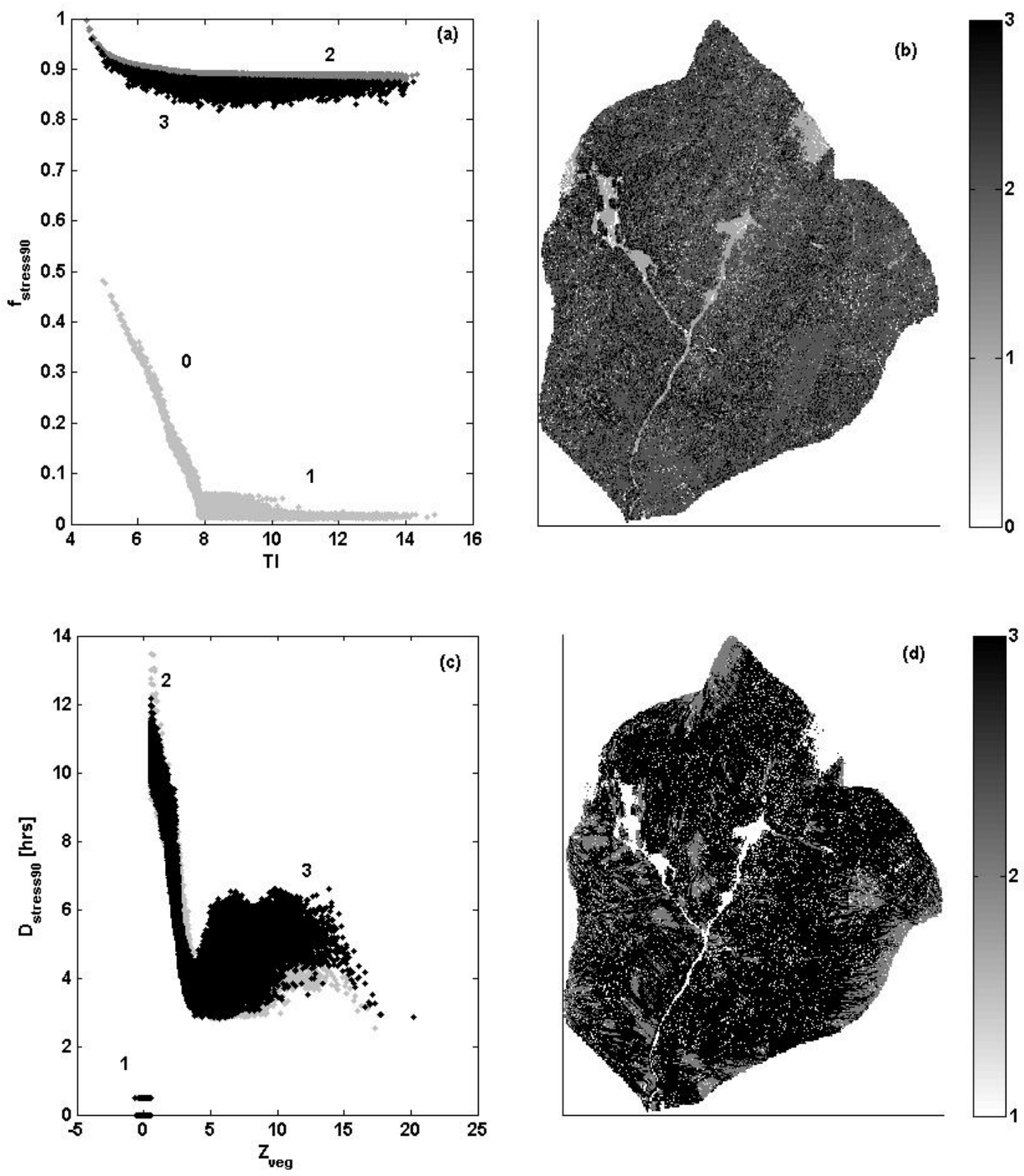

Figure 4.13: Frequency of exceeding the $90^{\text {th }}$ percentile of $I_{\text {stress }}$ versus (a) TI, shown (b) mapped back to the physical watershed, and average duration of excursions above the $90^{\text {th }}$ percentile of $I_{\text {stress }}$ by (c) $Z_{\text {veg }}$ shown (d) mapped back to the physical watershed. For (a) light gray shows $Z_{v e g}<0.5$, medium gray shows 
$0.5<Z_{v e g}<5.0$, black shows $Z_{v e g}>5.0 \mathrm{~m}$. For (c), gray shows $T I<8.0$ and black shows $T I>8.0$.

A relationship also exists between the average duration of severe water stress $\left(D_{\text {stress } 90}\right)$, and the topography and vegetation at a grid cell. On average, trees experience no more than one consecutive day of severe water stress (approximately 12 hours), even when low nighttime stress conditions are not considered (Figure 4.13c,d). However, most trees experience periods of sustained water stress lasting, on average, only a few hours. Below $Z_{v e g}$ of approximately $5 \mathrm{~m}$, the average duration of water stress decreases linearly with tree height, whereas above $Z_{v e g}=5 \mathrm{~m}$, the relationship is more complex. Grid cells containing grasses and forbs do not, in general, experience periods of severe water stress lasting more than approximately one half hour (Figure 4.13c, region 1).

Frequency and duration of water stress at discrete locations within the watershed may also have implications for seasonal fluxes of water vapor from those locations. In this modeling framework, $Z_{v e g}$ exerts the greatest control on transpiration, because we use this variable to scale fluxes from leaf to canopy levels (i.e. $Z_{v e g}$ is directly proportional to LAI). However, $Z_{v e g}$ does not explain all of the spatial variability in cumulative transpiration for the entire watershed. For areas with high TI (i.e. areas with higher average soil moisture), residuals of a linear regression between the upper boundary of the transpiration versus $Z_{\text {veg }}$ relationship are very close to 0 , but for low $T I$ areas, the boundary systematically overestimates transpiration (Figure 4.14). This result suggests that in areas with ample soil moisture, vegetation height (or LAI) may be the primary limitation to transpiration during the entire study period. These areas of the watershed 
(having residual $T$ in excess of $0.1 \mathrm{~m}$ ) experience a significantly higher frequency of severe water stress than other areas $(\mathrm{P}<0.05)$, and also experience significantly higher average durations of severe water stress than other areas of the watershed $(\mathrm{P}<0.05)$. Thus, where cumulative, seasonal transpiration is not coupled strongly to vegetation height (or LAI), water stress may provide one explanation for this decoupling.
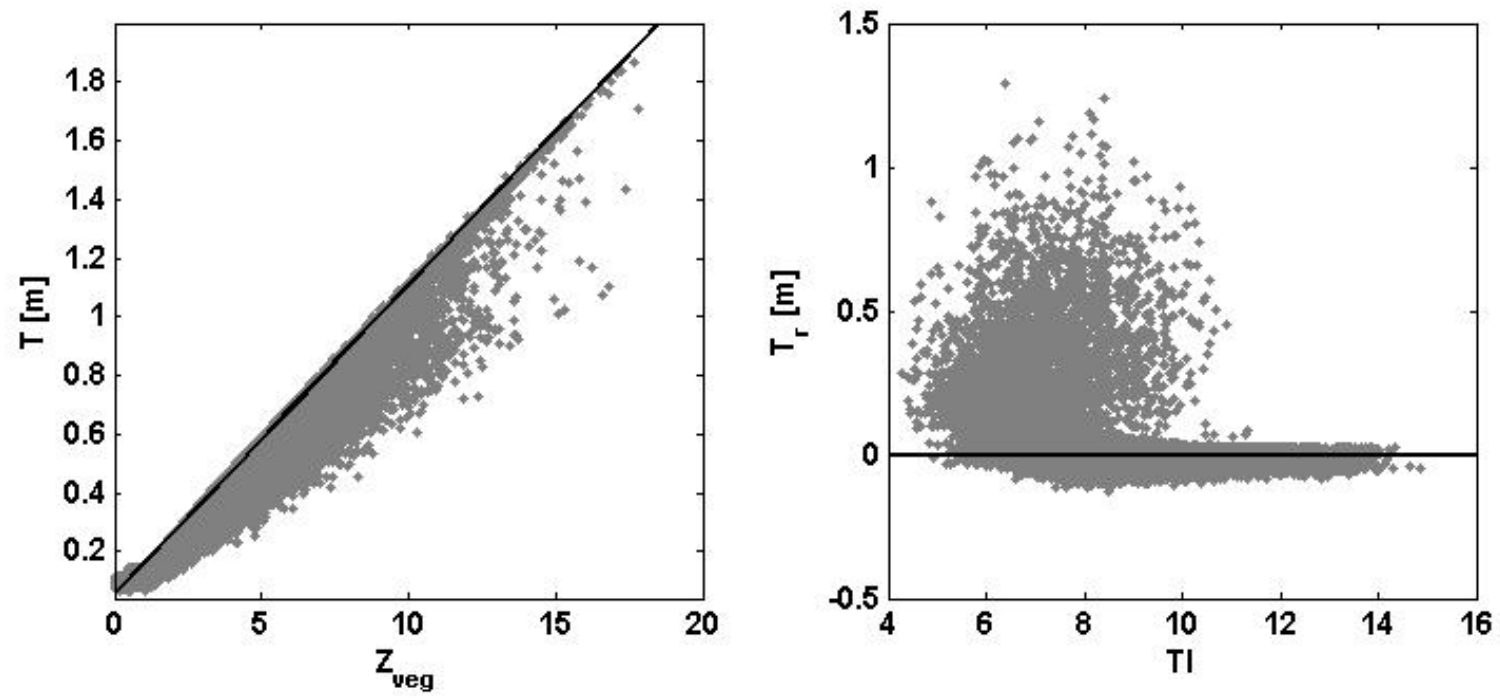

Figure 4.14: Cumulative seasonal transpiration as a function of $Z_{v e g}$ where the solid line is an approximate upper boundary of this relationship (left pane), and the residuals of transpiration around this boundary as a function of $T I$ (right pane).

\section{Effects of Varied Meteorology on Water Stress}

During the study period, air temperature measured at the forest flux tower was normally distributed $(\mathrm{P}<0.05)$ with a mean, $\overline{\mathrm{T}}$, of $16.0^{\circ} \mathrm{C}$ and a standard deviation, $\sigma_{T}$, of $5.2{ }^{\circ} \mathrm{C}$. Atmospheric vapor pressure derived from relative humidity and temperature measurements at the forest flux tower was also normally distributed $(\mathrm{P}<0.05)$ with a 
mean, $\overline{\mathrm{e}}$, of $7.4 \mathrm{mb}$ and a standard deviation, $\sigma_{e}$, of $2.1 \mathrm{mb}$. Using this information, we assessed the influence of temperature on vegetation water stress by running the model under both elevated temperature and lowered temperature conditions by increasing or decreasing half-hourly temperature at each grid cell by $\sigma_{T}$. Interpolated fields of atmospheric vapor pressure were not altered during these model runs; however, vapor pressure deficit did change as a result of the temperature-saturation vapor pressure relationship [e.g. [Richards, 1971]. Similarly, we assessed the influence of vapor pressure on vegetation water stress by running the model under both increased vapor pressure and lowered vapor pressure conditions by increasing or decreasing half-hourly vapor pressure at each grid cell by $\sigma_{e}$. Actual measured temperature and vapor pressure measured at the forest flux tower were correlated $(\rho=0.04)$; however, this correlation was not nearly as strong as the correlation between measured temperature and vapor pressure deficit $(\rho=0.93)$. During these simulations, maximum and minimum bounds for atmospheric vapor pressure were imposed $(0.1 \mathrm{mb}$ and saturation vapor pressure, respectively).

Altering temperature and atmospheric vapor pressure during the study period changed the distribution of watershed-averaged stress intensity. Model runs that increased vapor pressure deficit (increased temperature, decreased vapor pressure) tended to increase stress intensity, shifting the distribution of $I_{\text {stress }}$ toward greater stress conditions (Figure 4.15). Similarly, model runs that decreased vapor pressure deficit (decreased 
temperature, decreased vapor pressure) tended to decrease stress intensity, shifting the distribution toward conditions of reduced water stress.

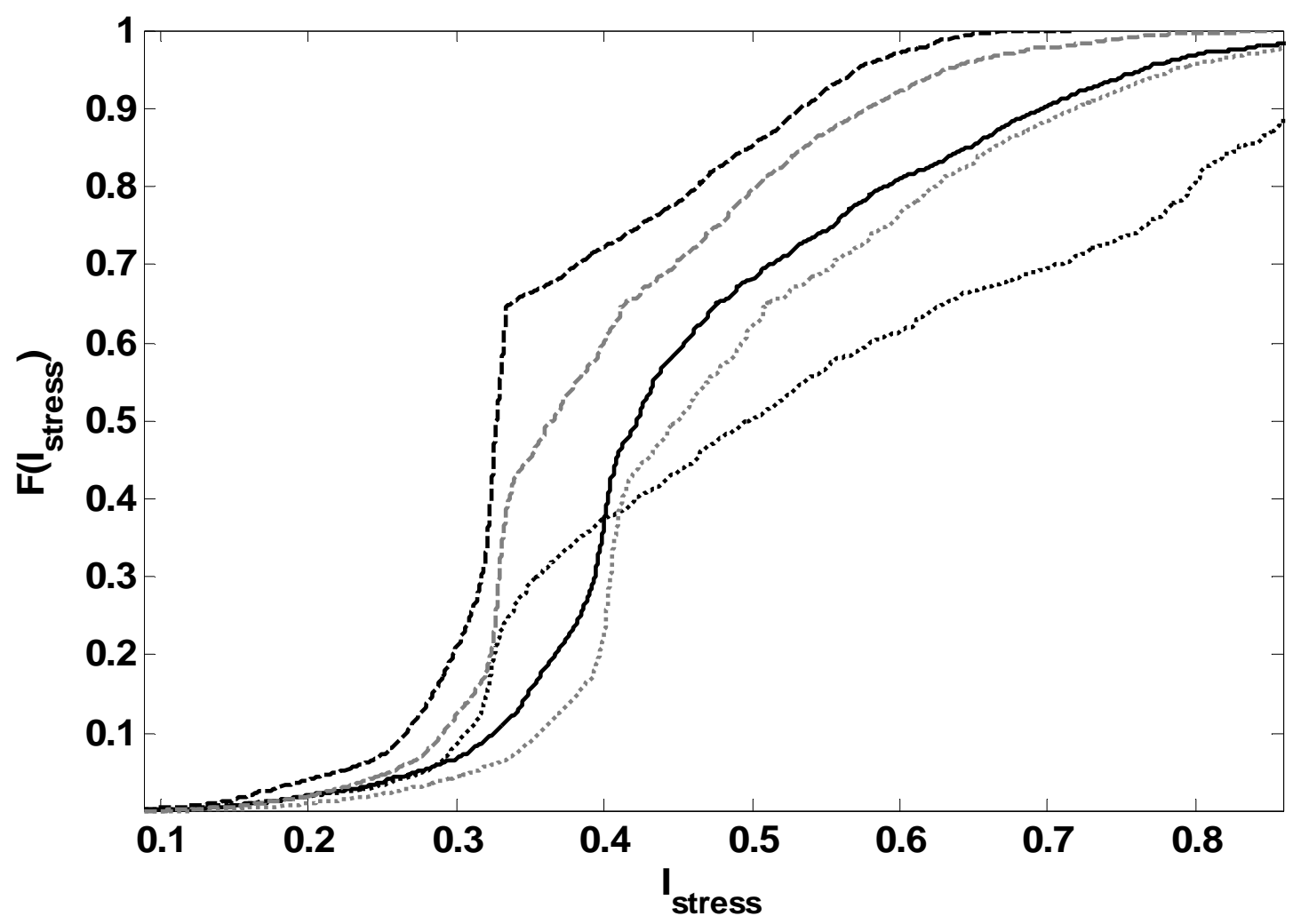

Figure 4.15: Cumulative distribution functions of $I_{\text {stress }}$ for actual conditions (solid black), increased temperature (dotted black), decreased temperature (dashed black), decreased vapor pressure (dotted gray) and increased vapor pressure (dotted gray).

Systematic variation of temperature and vapor pressure also caused changes in the relationship between topography, vegetation height and evapotranspiration (Figure 4.16), and also affected changes in correlations between these variable and water stress (Table 4.1). Changes in meteorology have slight effects on the average duration and frequency of severe water stress, with increased VPD model runs slightly increasing the duration of 
these events and decreased VPD model runs slightly decreasing the duration of these events (not shown). Increases in $D_{\text {stress } 90}$ of several hours may affect the local water balance, if not the catchment-scale water balance, since these increases are most likely to occur during daylight hours (Figure 4.10c), when the atmospheric demand for water vapor and the potential by plants to transport and transpire soil moisture are maximized.
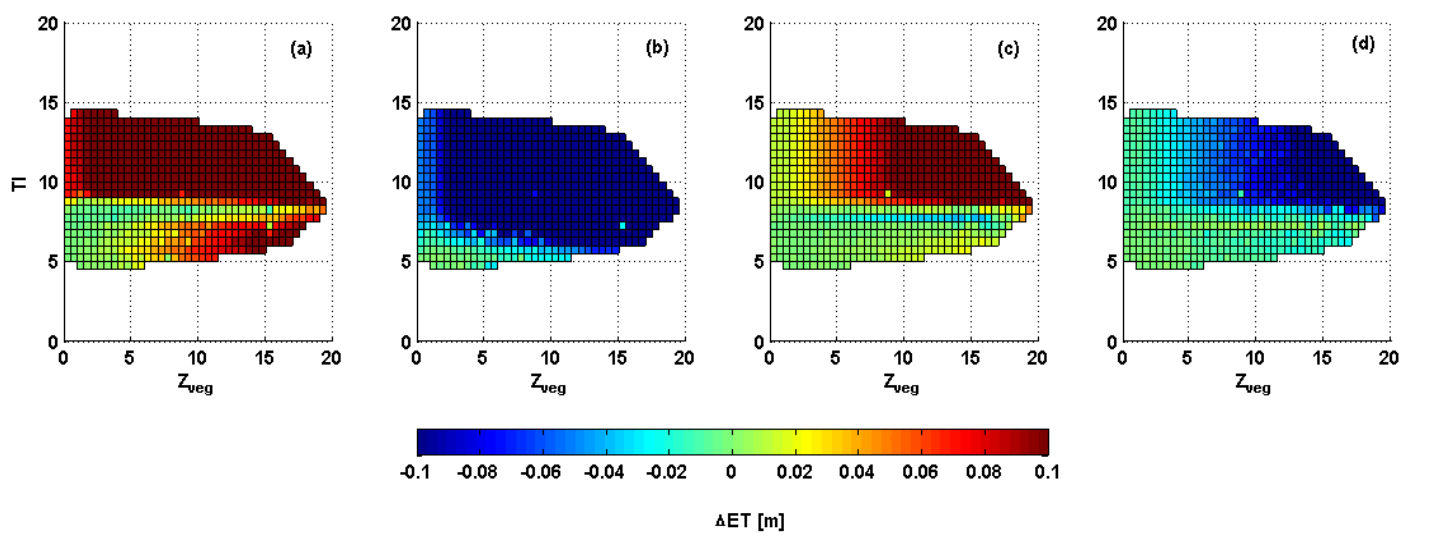

Figure 4.16: Changes from actual total, growing season evapotranspiration in the $T I$ versus $Z_{v e g}$ phase space for (a) increased temperature (b) decreased temperature (c) decreased vapor pressure and (d) increased vapor pressure.

Table 4.1: Spearman Correlation Coefficients for Water Stress versus Spatial Variables

\begin{tabular}{cccccccc}
\multicolumn{7}{c}{$\boldsymbol{D}_{\text {stress90 }}$} \\
& Actual & $\uparrow T$ & $\downarrow T$ & $\uparrow e$ & $\downarrow e$ & $Z_{\text {rnd }}$ & $Z_{\text {mean }}$ \\
\hline Zveg & 0.75 & 0 & 0.07 & 0.08 & 0.04 & 0 & 0 \\
$T I$ & 0.08 & 0.76 & 0.09 & 0.14 & 0.41 & 0.04 & 0.69 \\
Elev & -0.06 & -0.17 & -0.07 & -0.08 & -0.07 & -0.01 & -0.18 \\
& & \multicolumn{7}{c}{$\boldsymbol{f}_{\text {stress90 }}$} & & & & \\
& Actual & $\uparrow T$ & $\downarrow T$ & $\uparrow e$ & $\downarrow e$ & $Z_{\text {rnd }}$ & $Z_{\text {mean }}$ \\
\hline Zveg & 0.6 & 0.25 & 0.71 & 0.4 & 0.54 & 0 & 0 \\
TI & -0.19 & -0.16 & -0.13 & -0.59 & -0.36 & -0.02 & -0.22 \\
Elev & -0.62 & -0.33 & -0.61 & -0.22 & -0.58 & -0.02 & -0.38
\end{tabular}


One measure of the integrated effect of altered intensities of water stress is a change in total evapotranspiration during the study period. Because evaporation and transpiration are driven, to some extent, by the atmospheric demand for moisture, it is expected that altering meteorological conditions to increase this demand will result in two competing conditions: increased leaf or soil surface to atmosphere water vapor gradients and increased vegetation water stress. The former condition will tend to increase evapotranspiration in the absence of limitation by the latter condition. We found that changes in $E T$ do not occur evenly across the topography - vegetation phase space. In general, for $Z_{v e g}$ values greater than 5, ET is more responsive to changes in meteorology than for $Z_{v e g}$ values less than 5. Part of this pattern may result from a dependence of $Z_{v e g}$ on $T I$ (not shown), which may reflect adaptation of vegetation to its long-term hydrologic environment [Delzon, et al., 2004; Koch, et al., 2004]; however, exploration of this relationship is beyond the scope of this study.

Additionally, a discontinuity exists in the effect of increased temperature and vapor pressure and decreased vapor pressure on ET near $T I$ values of 8, with $E T$ at lower $T I$ values affected much less by meteorology than higher values. Areas of high TI, or areas that tend to be wetter throughout the study period, are able to supply the atmospheric demand for moisture and, in general, experience less water stress than areas of low $T I$ (Figure 4.13). Thus, in these wetter areas, ET is driven largely by meteorology (i.e. the atmospheric demand for moisture). By increasing or decreasing temperature and vapor pressure by one standard deviation, ET in these meteorology-sensitive areas may change by as much as $100 \mathrm{~mm}$, or approximately $50 \%$ during the study period. In areas that are 
already subject to water stress, ET tends to change little at all in response to changes in meteorology, particularly for areas of low $Z_{v e g}$. An exception would be that $E T$ from areas of low $T I$ and high $Z_{v e g}$ may be sensitive to changes in temperature (Figure 4.16a,b), even though they are subject to frequent water stress (Figure 4.13).

Together, these features of the phase space suggest that areas of the watershed sharing certain characteristics of topography and vegetation (e.g. taller vegetation in areas that tend to be wetter) may be much more sensitive to climate change than other areas of the watershed. These areas may contain trees growing along riparian corridors or in the local topographic depressions dispersed throughout the watershed and may represent species that have the capacity to transpire large amounts of water (i.e. high LAI) as well as adequate water supplies all season long. Although identification of particular tree species in these areas is beyond the scope of this study, mapping these areas of topography and vegetation back to the physical watershed (Figure 4.17) may prove useful for future studies involving spatially distributed data such as remotely sensed spectral data. Finally, these areas contributed significantly more ET during the growing season than other areas of the watershed $(\mathrm{P}<0.05)$, producing, by weighted average, more than ten percent of the total ET flux during the study period despite occupying only four percent of the land area of USC. Thus, ET from an area contributing disproportionately to the hydrologic balance of this watershed is most sensitive to changes in average meteorological conditions during the course of a growing season. 


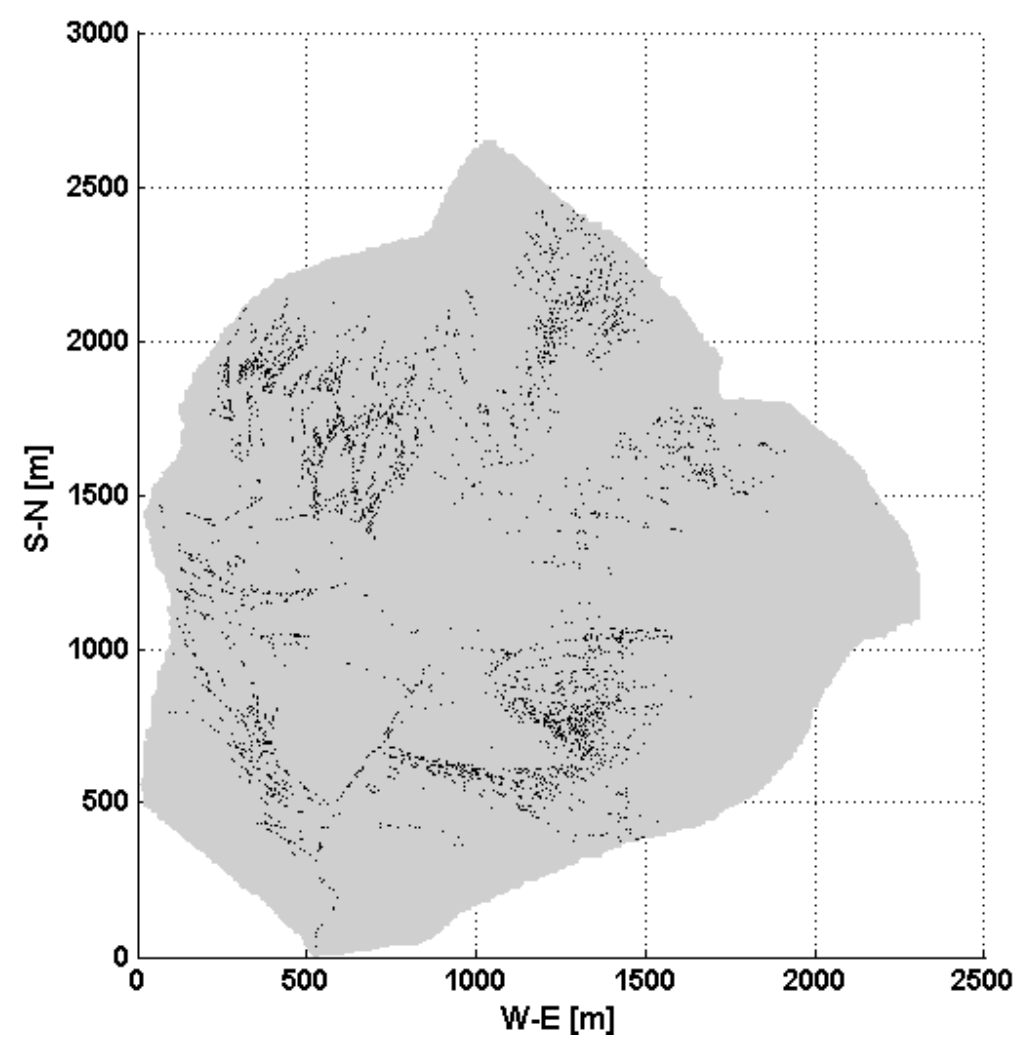

Figure 4.17: Masked areas (black) of high $Z_{\text {veg }}$ and high $T I$ in USC.

\section{Effects of Vegetation Distribution on Water Stress}

Randomly redistributing vegetation within USC (Figure 4.18) did not affect our ability to predict runoff. Coefficients of efficiency between $Q_{\text {sim }}$ and $Q_{o b s}$ were the same for actual and randomly distributed vegetation (0.71). When all vegetation heterogeneity was removed from the model (i.e. $Z_{v e g}$ set to a constant value of mean $Z_{v e g}$ ), the model estimated $Q_{o b s}$ with less certainty $\left(E_{1}{ }^{\prime}=0.59\right)$. 

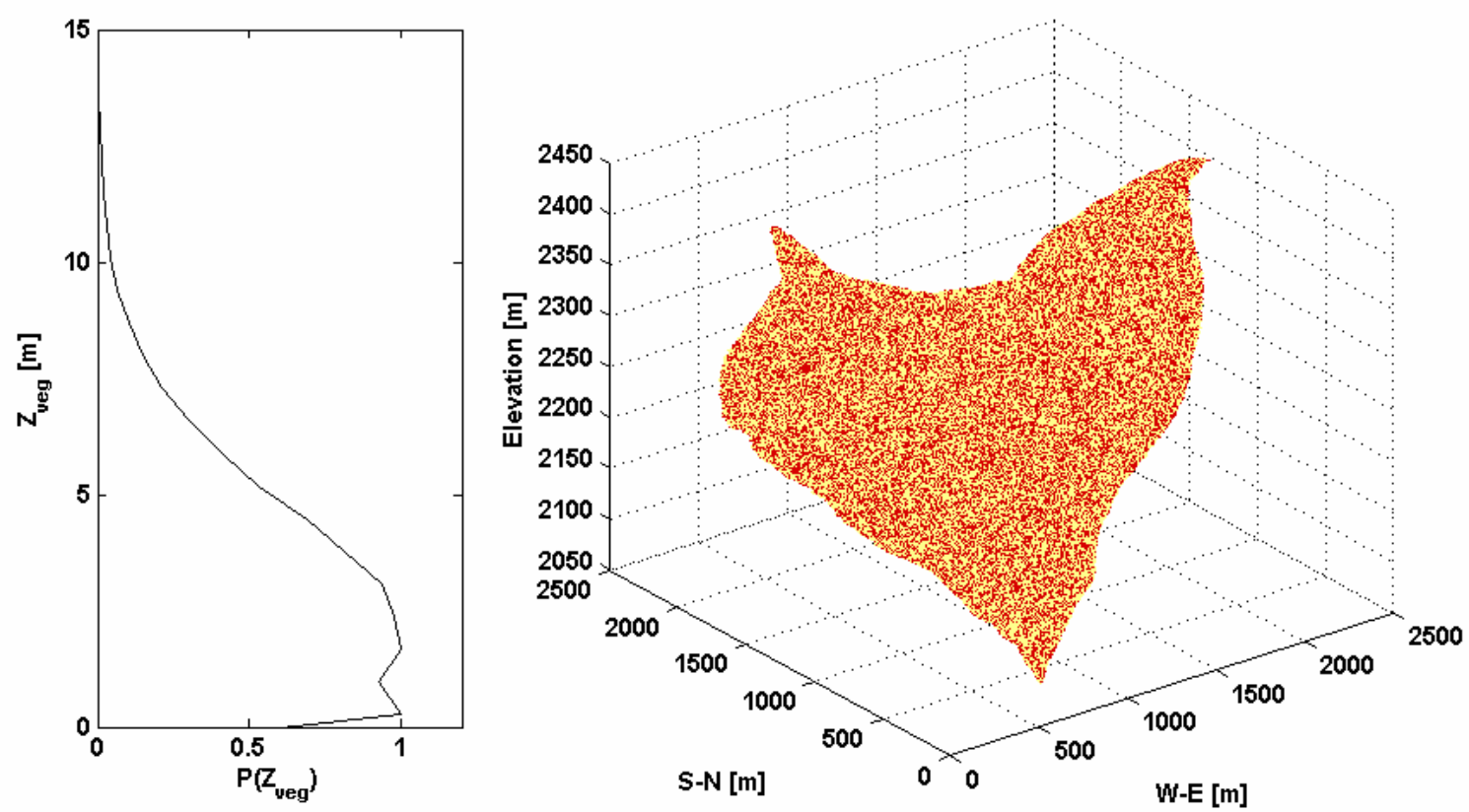

Figure 4.18: Frequency distribution (left) and watershed map (right) of randomly distributed vegetation model input.

In general, changing the distribution of vegetation in the watershed significantly affected the distribution of $I_{\text {stress }}$ through the study period (Figure 4.19). For both conditions (random vegetation and mean, uniform vegetation), median $I_{\text {stress }}$ decreased significantly versus actual vegetation $(\mathrm{P}<0.05)$; however, for mean, uniform vegetation, the intensity of late season water stress increased more rapidly and sooner than water stress intensity for actual vegetation (Figure 4.20). Additionally, there was no change in catchmentaveraged water balance terms between actual vegetation and randomly-distributed vegetation. These results suggest that the increased frequency of water stress experienced by shorter vegetation (Figure 4.13) may be partly masked in the actual distribution by the presence of taller vegetation that experiences severe water stress less frequently. And although the seasonal distribution of watershed-averaged stress intensity 
may suggest that shorter, uniform vegetation experiences less stress, this same distribution of vegetation creates greater overall stress intensity at the end of the season. The actual vegetation, though experiencing higher average water stress than the mean, uniform case, distributes stress more evenly through time. These results support earlier findings that the actual distribution of vegetation may correspond to some condition of feasible, ecological optimality [e.g. Caylor, et al., 2004].

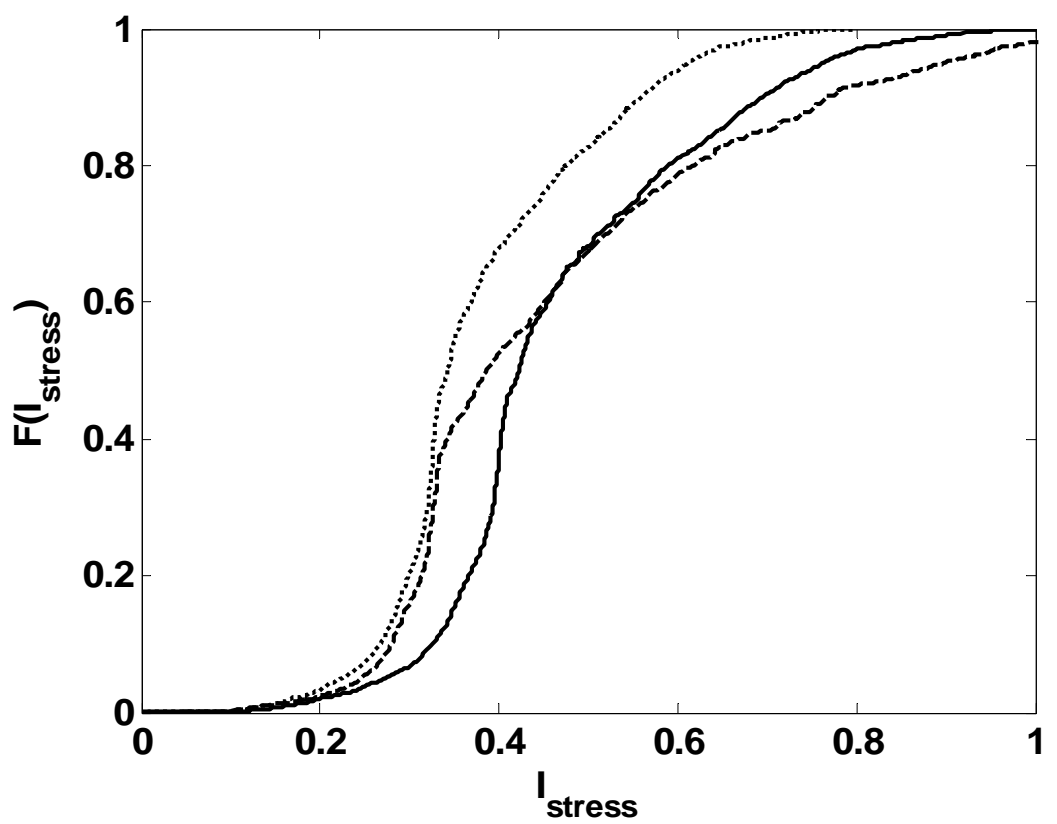

Figure 4.19: Frequency distributions of Istress for actual vegetation (solid line), random vegetation (dotted line) and mean, uniform vegetation (dashed line). 


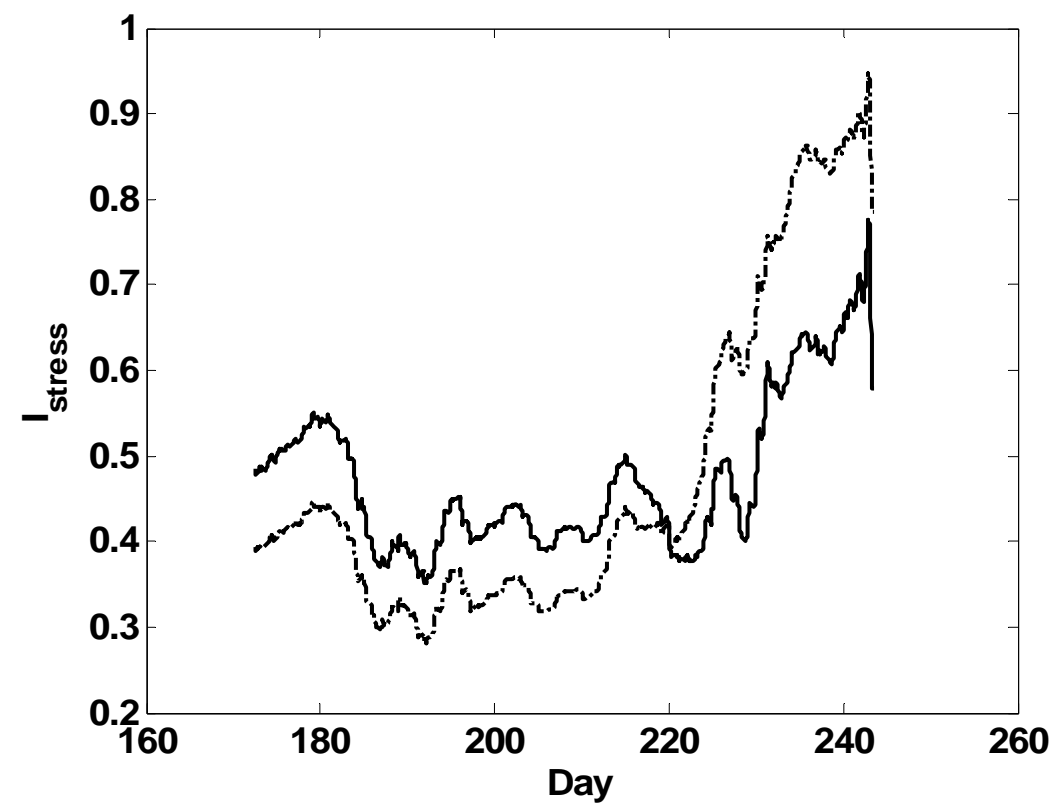

Figure 4.20: Time series of three day moving averages of $I_{\text {stress }}$ for actual vegetation (solid line) and uniform, mean vegetation (broken line).

Effects of Meteorology and Vegetation Distribution on the Catchment-Scale Water Balance

Individual components of the water balance varied in response to altered meteorological conditions and altered vegetation distributions. Alterations in either temperature or humidity affect atmospheric vapor pressure deficit (Figure 4.21), which, as the atmospheric demand for water vapor, exerts considerable control on evapotranspiration. As a result, increasing vapor pressure deficit either by increasing temperature or decreasing atmospheric vapor pressure caused an increase in simulated $E T$ (Table 4.2). Equation 4.1 confirms that these increases were accompanied by decreased discharge, and a greater reduction in soil moisture $(\Delta \theta)$. 

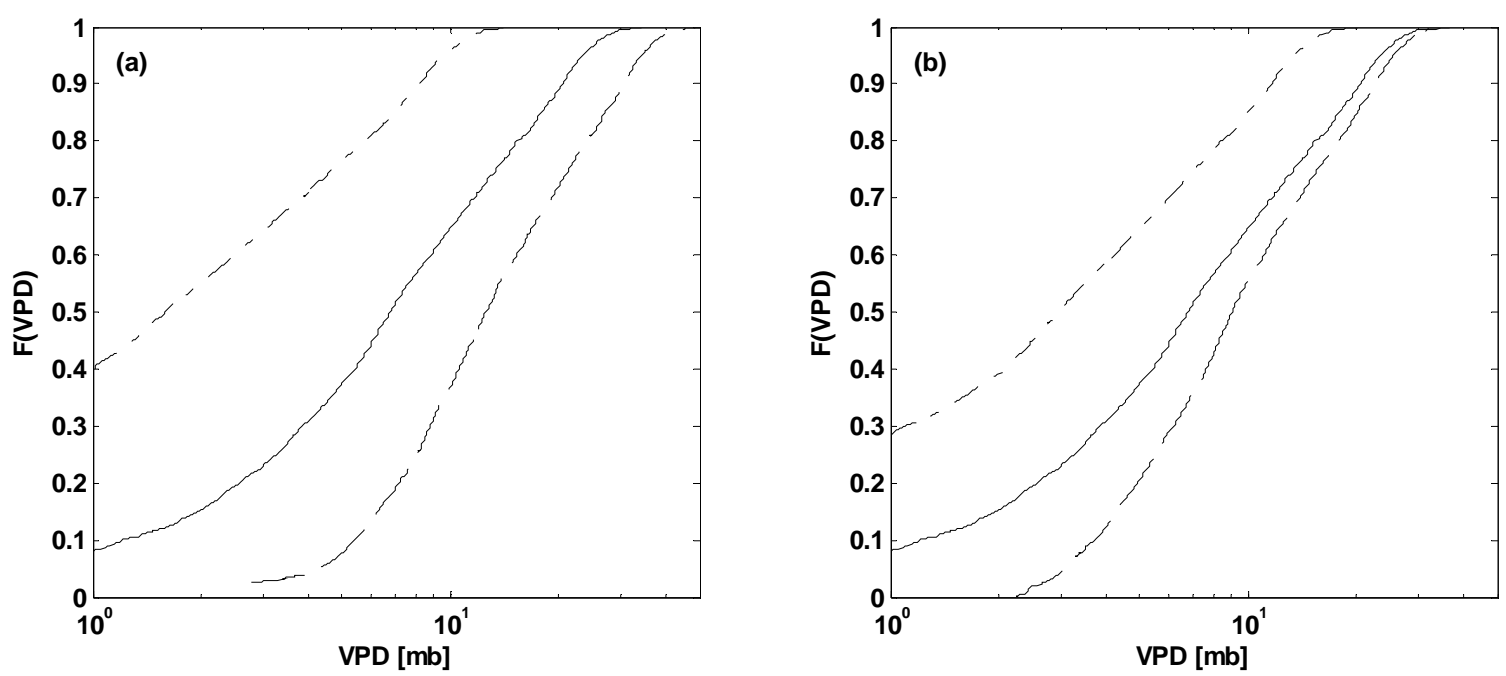

Figure 4.21: Frequency distributions of VPD for changes in (a) temperature and

(b) atmospheric vapor pressure. For both panes, solid line is actual half-hourly meteorology, dashed line is increased value and broken line is decreased value.

Table 4.2: Principal Water Balance Terms for Each Model Run

\begin{tabular}{lccccccc} 
& Actual & $\uparrow T$ & $\downarrow T$ & $\uparrow e$ & $\downarrow e$ & $Z_{\text {rnd }}$ & $Z_{\text {mean }}$ \\
\hline$Q_{r z}$ & 8.6 & 6.8 & 12.7 & 9.5 & 8.0 & 8.6 & 7.8 \\
$Q_{g w}$ & 6.7 & 6.4 & 6.7 & 6.6 & 6.8 & 6.7 & 6.4 \\
$Q_{o f}$ & 0.6 & 0.5 & 0.7 & 0.6 & 0.6 & 0.6 & 0.5 \\
$Q_{t o t}$ & 15.9 & 13.7 & 20.0 & 16.7 & 15.4 & 15.9 & 14.7 \\
$E T$ & 215 & 232 & 165 & 202 & 222 & 215 & 219 \\
$\Delta \theta$ & -282 & -305 & -216 & -271 & -292 & -282 & -300
\end{tabular}

As a result of changing atmospheric demand for water vapor, catchment-average $E T$ varies across the varied-meteorology model runs. When VPD increases, there is an accompanying increase in ET, resulting in 1) greater depletion of soil moisture and 2) reduced catchment runoff (Figure 4.22). Although these effects of increased VPD manifested at the watershed scale are intuitive, this study reveals the degree to which $E T$ across the catchment is affected by spatially uniform changes in VPD. These 
heterogeneous patterns of ET are explained, in part, by spatial patterns of topography and vegetation (Figure 4.16). These patterns may also be explained by changes in water stress, since limitation of ET by stomatal conductance is the basis of the definition of the dynamic threshold for vegetation water stress.
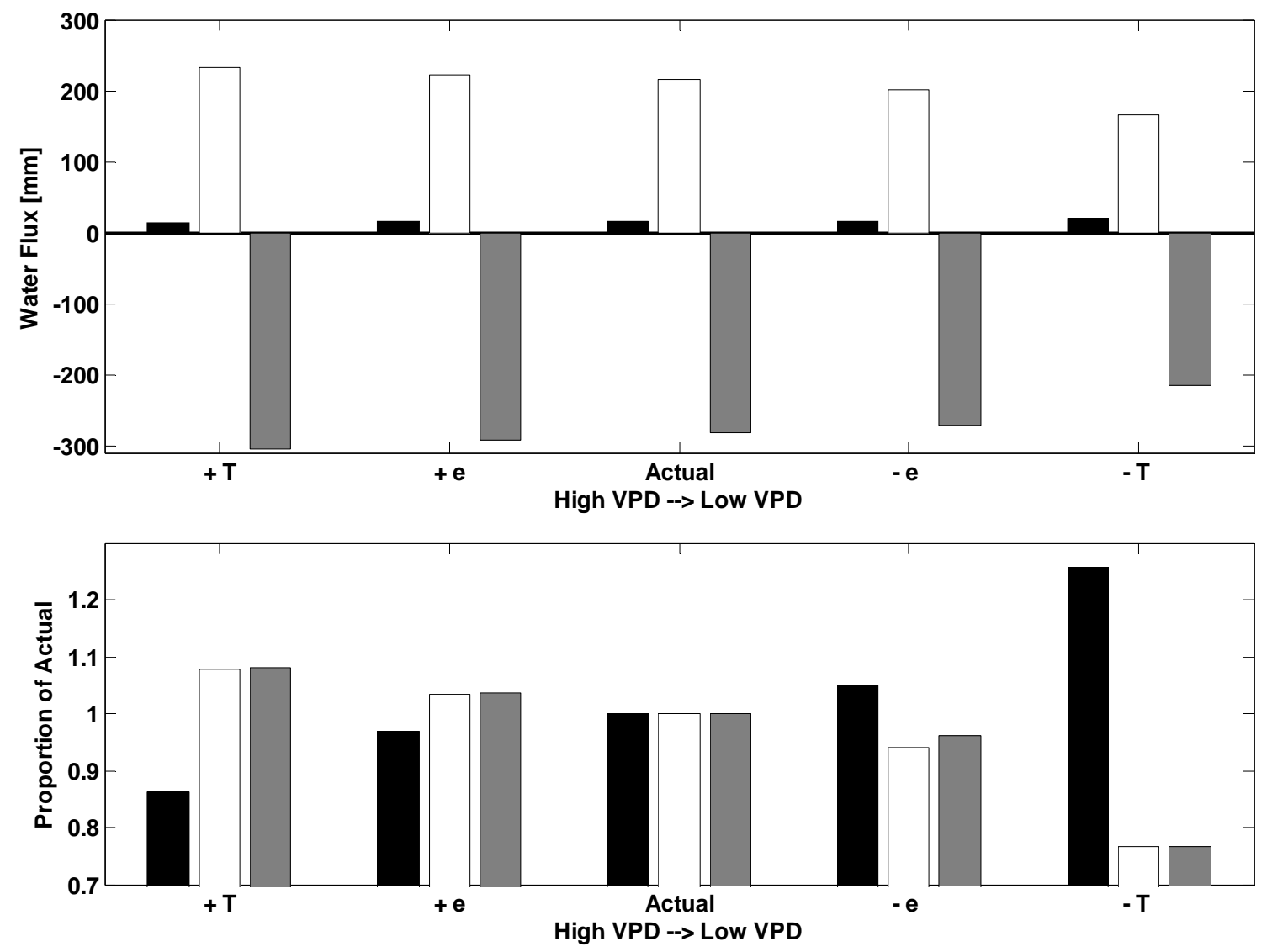

Figure 4.22: Major water balance terms from Table 4.2, including runoff (black), evapotranspiration (white) and decline in soil moisture (gray) for growing season simulations of altered meteorology, in absolute units (upper pane) and relative to actual meteorology (lower pane). 


\section{Conclusions and Implications}

This study provides insight into catchment-scale water stress as a complex phenomenon, dependent upon meteorology, topography and vegetation, and its spatial and temporal heterogeneities. Spatial and temporal patterns in water stress are, to some extent, predictable, and may be used to interpret the catchment-scale hydrologic cycle. Using a modified SVAT model, we have been able to demonstrate controls on water stress, and associated implications for evapotranspiration, runoff and soil moisture status.

Specifically, we have shown that the intensity of vegetation water stress varies at two distinct time scales: diurnally, water stress varies with photosynthetically active radiation and vapor pressure deficit; and seasonally, the intensity of water stress increases steadily as soil water potential decreases. The intensity of water stress also varies spatially through the course of a growing season, with persistent modes of very high and very low stress, and a migrating mode of intermediate stress intensity that represents the general trend of the watershed toward higher water stress during dry, late season conditions. Thus, the temporal heterogeneity of water stress varies at relatively high frequency (daily) in response to changing micrometeorological conditions, and it also varies at relatively low frequency (seasonal) in response to declining soil moisture, itself a nonlinear function of atmospheric, vegetation and soil conditions. For this reason, the degree of temporal variability in the intensity of water stress is sensitive to the distribution of vegetation across a topographically heterogeneous watershed, characterized by relatively steep slopes that dry relatively quickly during the growing season and valley bottoms that remain relatively wet through the growing season. 
As expected, relatively wet areas (represented by high $T I$ ) that include valley bottoms or local topographic depressions experienced severe water stress less frequently and, on average, for shorter durations than drier areas of the watershed. In general, vegetation in these wetter areas met the atmospheric demand for water vapor through transpiration; therefore, in these areas transpiration was tightly correlated with $Z_{\text {veg }}$ (itself directly proportional to leaf area index). In drier areas, less transpiration occurred, suggesting limitation by soil water availability.

We also demonstrated that certain areas of the watershed (with respect to combinations of topography and vegetation, specifically tall vegetation in wet areas) 1) are very sensitive to changes in meteorology, and 2) contribute disproportionately to the catchment-scale transpiration flux. These results led to further hypotheses concerning the composition of vegetation within these areas; specifically, this research raises further questions about characteristic tree species inhabiting relatively wet areas of montane forests, the disproportionate contribution of these species to the catchment-scale water balance, and the sensitivity of their transpiration fluxes to climate change.

The recent IPCC assessment [IPCC, 2007] suggests that during the twenty-first century, increased frequency and temperature of 'hot days' and decreased frequency and increased temperature of 'cold days' is 'virtually certain.' A number of studies suggest that the western United States and particularly the Rocky Mountains are particularly sensitive to potential climate change with respect to water resources, carbon sequestration and wildfires [Schimel, et al., 2002; Bales, et al., 2006; Westerling, et al., 2006], all of which 
are inextricably related to vegetation water stress. This study aids in the interpretation of the effects of current climate and climate change on this sensitive region by linking ecological and hydrological processes contributing to vegetation water stress to the landatmosphere exchange of water vapor, and more generally, to the hydrologic balance of a forested, subalpine watershed in the northern Rocky Mountains. 


\section{References}

Albertson, J. D., and G. Kiely (2001), On the structure of soil moisture time series in the context of land surface models, Journal of Hydrology, 243, 101.

Bales, R. C., N. P. Molotch, T. H. Painter, M. D. Dettinger, R. Rice, and J. Dozier (2006), Mountain hydrology of the western United States, Water Resources Research, 42.

Ball, J. T., I. E. Woodrow, and J. A. Berry (1987), A model predicting stomatal conductance and its contribution to the control of photosynthesis under different environmental conditions, Progress in Photosynthesis Research, 4, 221-224.

Beven, K. J., and M. J. Kirkby (1979), A Physically Based, Variable Contributing Area Model of Basin Hydrology, Hydrological Sciences Bulletin, 24.

Boegh, E., M. Thorsen, M. B. Butts, S. Hansen, J. S. Christiansen, P. Abrahamsen, C. B. Hasager, N. O. Jensen, P. Van der Keur, and J. C. Refsgaard (2004), Incorporating remote sensing data in physically based distributed agro-hydrological modelling, Journal of Hydrology, 287, 279-299.

Boisvenue, C., and S. W. Running (2006), Impacts of climate change on natural forest productivity - evidence since the middle of the 20th century, Global Change Biology, 12, 862-882.

Brubaker, K. L., and D. Entekhabi (1996), Asymmetric Recovery from Wet versus Dry Soil Moisture Anomalies, Journal of Applied Meteorology, 35, 94-109.

Buckley, T. N. (2005), The control of stomata by water balance, New Phytologist, 168, 275-292.

Buckley, T. N., K. A. Mott, and G. D. Farquhar (2003), A hydromechanical and biochemical model of stomatal conductance, Plant, Cell and Environment, 26, 17671785 .

Campbell, G. S., and J. M. Norman (1998), An Introduction to Environmental Biophysics, Springer.

Caylor, K. K., T. M. Scanlon, and I. Rodriguez-Iturbe (2004), Feasible optimality of vegetation patterns in river basins, Geophysical Research Letters, 31.

Clapp, R. B., and G. M. Hornberger (1978), Empirical Equations for Some Soil Hydraulic Properties, Water Resources Research, 14.

Collatz, G. J., J. T. Ball, C. Grivet, and J. A. Berry (1991), Physiological and environmental regulation of stomatal conductance, photosynthesis and transpiration: a 
model that includes a laminar boundary layer, Agricultural and Forest Meteorology, 54, 107-136.

D'Odorico, P., and A. Porporato (2004), Preferential states in soil moisture and climate dynamics, Proceedings of the National Academy of Sciences, 101, 8848-8851.

D'Odorico, P., and A. Porporato (2006), Soil moisture dynamics in water-limited ecosystems, in Dryland Ecohydrology, edited by P. D'Odorico and A. Porporato, p. 341, Springer, Dordrecht, The Netherlands.

Dai, Y., R. E. Dickinson, and Y. P. Wang (2004), A Two-Big-Leaf Model for Canopy Temperature, Photosynthesis, and Stomatal Conductance, Journal of Climate, 17, 22812299.

Daly, E., A. Porporato, and I. Rodriguez-Iturbe (2004), Coupled dynamics of photosynthesis, transpiration, and soil water balance. I. Upscaling from hourly to daily time scale, J. Hydrometeor, 5, 546-558.

Dawson, T. E. (1998), Fog in the California redwood forest: ecosystem inputs and use by plants, Oecologia, 117, 476.

Delzon, S., M. Sartore, R. Burlett, R. Dewar, and D. Loustau (2004), Hydraulic responses to height growth in maritime pine trees, Plant, Cell and Environment, 27, 1077-1087.

Detto, M., N. Montaldo, J. D. Albertson, M. Mancini, and G. Katul (2006), Soil moisture and vegetation controls on evapotranspiration in a heterogeneous Mediterranean ecosystem on Sardinia, Italy, Water Resources Research, 42, W08419, doi:08410.01029/02005WR004693.

Dickinson, R. E., J. A. Berry, G. B. Bonan, G. J. Collatz, C. B. Field, I. Y. Fung, M. Goulden, W. A. Hoffmann, R. B. Jackson, R. Myneni, P. J. Sellers, and M. Shaikh (2002), Nitrogen controls on climate model evapotranspiration, Journal of Climate, 15, 278-295.

Dingman, S. L. (2002), Physical Hydrology, 656 pp., Prentice-Hall, Inc., Engelwood Cliffs, NJ.

Dubayah, R. O., and J. B. Drake (2000), Lidar Remote Sensing for Forestry, Journal of Forestry, 98, 44.

Eagleson, P. S. (1978), Climate, Soil, and Vegetation--1. Introduction to Water Balance Dynamics, Water Resources Research, 14, 705-712. 
Emanuel, R. E., P. D'Odorico, and H. E. Epstein (2007), Evidence of Optimal Water Use Among a Range of North American Ecosystems, Geophysical Research Letters, 34, L07401, doi:10.1029/2006GL028909.

Famiglietti, J. S., and E. F. Wood (1994), Application of multiscale water and energy balance models on a tallgrass prairie, Water Resources Research, 30, 3079-3094.

Farquhar, G. D., S. Von Caemmerer, and J. A. Berry (1980), A biochemical model of photosynthetic CO2 in leaves of C3 species., Planta, 149, 78-90.

Fuentes, J. D., den Hartog, G., Neumann, H. H., and Gillespie, T. J. (1994), Measurements and modelling of ozone deposition to wet foliage., in Air Pollutants and the Leaf Cuticle, Percy K. E. et al. Eds., Springer-Verlager 239-253.

Gao, Q., P. Zhao, X. Zeng, X. Cai, and W. Shen (2002), A model of stomatal conductance to quantify the relationship between leaf transpiration, microclimate and soil water stress, Plant, Cell and Environment, 25, 1373-1381.

Gollan, T., J. B. Passioura, and R. Munns (1986), Soil-Water Status Affects The Stomatal Conductance Of Fully Turgid Wheat And Sunflower Leaves, Australian Journal Of Plant Physiology, 13, 459-464.

Grayson, R. B., A. W. Western, F. H. S. Chiew, and G. Bloschl (1997), Preferred states in spatial soil moisture patterns: Local and nonlocal controls, Water Resources Research, 33, 2897-2908.

Green, W. H., and G. A. Ampt (1911), Studies on soil physics, 1. The flow of air and water through soils, Journal of Agricultural Science, 4, 1-24.

Guswa, A. J. (2005), Soil-moisture limits on plant uptake: An upscaled relationship for water-limited ecosystems, Advances in Water Resources, 28, 543-552.

Hale, M., and D. Orchutt (1987), The Physiology of Plants Under Stress, John Wiley, New York.

Hicks, B. B., Baldocchi, D. D., Meyers, T. P., Hosker, R. P., Matt, D. R. (1987), A preliminary multiple resistance routine for deriving dry deposition velocities from measured quantiles, Water Air Soil Pollut. 36, 311-330.

Hjerdt, K. N., J. J. McDonnell, J. Seibert, and A. Rodhe (2004), A new topographic index to quantify downslope controls on local drainage, Water Resources Research, 40.

Houghton, R. A., J. L. Hackler, and K. T. Lawrence (1999), The US carbon budget: Contributions from land-use change, Science, 285, 574-578. 
Houser, P. R., W. J. Shuttleworth, J. S. Famiglietti, H. V. Gupta, K. H. Syed, and D. C. Goodrich (1998), Integration of soil moisture remote sensing and hydrologic modeling using data assimilation, Water Resources Research, 34, 3405-3420.

IPCC (2007), WGI Fourth Assessment Report: Summary for Policymakers.

Ivanov, V. Y., E. R. Vivoni, R. L. Bras, and D. Entekhabi (2004), Preserving highresolution surface and rainfall data in operational-scale basin hydrology: a fullydistributed physically-based approach, Journal of Hydrology, 298, 80-111.

Jackson, R. B., E. G. Jobbágy, R. Avissar, S. Baidya Roy, D. J. Barrett, C. W. Cook, K. A. Farley, D. C. leMaitre, B. A. McCarl, and B. C. Murray (2005), Trading water for carbon with biological carbon sequestration, Science, 310, 1944-1947.

Jarvis, P. G. (1976), The interpretation of the variations in leaf water potential and stomatal conductance found in canopies in the field, Philosophical Transactions of the Royal Society of London Series B-Biological Sciences, 273, 593-610.

Jolly, W. M., J. M. Graham, A. Michaelis, R. Nemani, S. W. Running, W. M. Jolly, J. M. Graham, A. Michaelis, R. Nemani, and S. W. Running (2005), A flexible, integrated system for generating meteorological surfaces derived from point sources across multiple geographic scales, Environmental Modelling and Software, 20, 873-882.

Katul, G., R. Leuning, and R. Oren (2003), Relationship between plant hydraulic and biochemical properties derived from a steady-state coupled water and carbon transport model, Plant, Cell and Environment, 26, 339-350.

Katul, G. G., C. T. Lai, J. D. Albertson, B. Vidakovic, K. V. R. Schaefer, C. I. Hsieh, and R. Oren (2001), Quantifying the Complexity in Mapping Energy Inputs and Hydrologic State Variables into Land-Surface Fluxes, Geophysical Research Letters, 28, 3305-3307.

Keane, R. E., E. D. Reinhardt, J. Scott, K. Gray, and J. Reardon (2005), Estimating forest canopy bulk density using six indirect methods, Canadian Journal of Forest Research, $35,724-739$.

Koch, G. W., S. C. Sillett, G. M. Jennings, and S. D. Davis (2004), The limits to tree height, Nature, 428, 851.

Koster, R. D., P. A. Dirmeyer, Z. C. Guo, G. Bonan, E. Chan, P. Cox, C. T. Gordon, S. Kanae, E. Kowalczyk, D. Lawrence, P. Liu, C. H. Lu, S. Malyshev, B. McAvaney, K. Mitchell, D. Mocko, T. Oki, K. Oleson, A. Pitman, Y. C. Sud, C. M. Taylor, D. Verseghy, R. Vasic, Y. K. Xue, and T. Yamada (2004), Regions of strong coupling between soil moisture and precipitation, Science, 305, 1138-1140. 
Kumar, L., A. K. Skidmore, and E. Knowles (1997), Modelling topographic variation in solar radiation in a GIS environment, International Journal of Geographical Information Science, 11, 475-497.

Kustas, W. P., and J. M. Norman (1999), Evaluation of soil and vegetation heat flux predictions using a simple two-source model with radiometric temperatures for partial canopy cover, Agricultural and Forest Meteorology, 94, 13.

Lefsky, M. A., W. B. Cohen, G. G. Parker, and D. J. Harding (2002), Lidar remote sensing for ecosystem studies, Bioscience, 52, 19-30.

Legates, D. R., and G. J. McCabe (1999), Evaluating the use of" goodness-of-fit" measures in hydrologic and hydroclimatic model validation, Water Resources Research, $35,233-241$.

Leuning, R. (1995), A critical appraisal of a combined stomatal-photosynthesis model for C3 plants, Plant, Cell and Environment, 18, 339-355.

McCaughey, W. W. (1996), Tenderfoot Creek Experimental Forest, in Experimental Forests, Ranges, and Watersheds in the Northern Rocky Mountains: A compendium of Outdoor Laboratories in Utah, Idaho, and Montana, edited by W. C. Schmidt and J. L. Friede, United States Department of Agriculture, Forest Service.

Mu, Q., M. Zhao, F. A. Heinsch, M. Liu, H. Tian, and S. W. Running (2007), Evaluating water stress controls on primary production in biogeochemical and remote sensing based models, JGR - Biogeosciences, 112, G01012, doi:01010.01029/02006JG00179.

Nemani, R. R., C. D. Keeling, H. Hashimoto, W. M. Jolly, S. C. Piper, C. J. Tucker, R. B. Myneni, and S. W. Running (2003), Climate-Driven Increases in Global Terrestrial Net Primary Production from 1982 to 1999, Science, 300, 1560-1563.

Noy-Meir, I. (1973), Desert Ecosystems: Environment and Producers, Annual Review of Ecology and Systematics, 4, 25-51.

Olioso, A., H. Chauki, D. Courault, and J. P. Wigneron (1999), Estimation of Evapotranspiration and Photosynthesis by Assimilation of Remote Sensing Data into SVAT Models, Remote Sensing of Environment, 68, 341-356.

Oren, R., B. E. Ewers, P. Todd, N. Phillips, and G. Katul (1998), Water Balance Delineates the Soil Layer in Which Moisture Affects Canopy Conductance, Ecological Applications, 8, 990-1002.

Palmer, M., E. Bernhardt, E. Chornesky, S. Collins, A. Dobson, C. Duke, B. Gold, R. Jacobson, S. Kingsland, R. Kranz, M. Mappin, M. L. Martinez, F. Micheli, J. Morse, M. 
Pace, M. Pascual, S. Palumbi, O. J. Reichman, A. Simons, A. Townsend, and M. Turner (2004), Ecology for a Crowded Planet, Science, 304, 1251-1252.

Passioura, J. B. (2002), Soil conditions and plant growth, Plant, Cell and Environment, 25, 311-318.

Pataki, D. E., and R. Oren (2003), Species differences in stomatal control of water loss at the canopy scale in a mature bottomland deciduous forest, Advances In Water Resources, 26, 1267-1278.

Pierce, K. B., T. Lookingbill, and D. Urban (2005), A simple method for estimating potential relative radiation (PRR) for landscape-scale vegetation analysis, Landscape Ecology, 20, 137-147.

Porporato, A., F. Laio, L. Ridolfi, and I. Rodriguez-Iturbe (2001), Plants in watercontrolled ecosystems: active role in hydrologic processes and response to water stress III. Vegetation water stress, Advances in Water Resources, 24, 725-744.

Priestley, C. H. B., and R. J. Taylor (1972), On the assessment of surface heat flux and evaporation using large-scale parameters, Monthly Weather Review, 100, 81-92.

Reich, P. B., and T. M. Hinckley (1989), Influence of Pre-Dawn Water Potential and Soil-To-Leaf Hydraulic Conductance on Maximum Daily Leaf Diffusive Conductance in Two Oak Species, Functional Ecology, 3, 719-726.

Richards, J. M. (1971), Simple expression for the saturation vapor pressure of water in the range -50 degrees to 140 degrees, Journal of Physics D Applied Physics, 4, L15-L18.

Riveros-Iregui, D. A., R. E. Emanuel, D. J. Muth, B. L. McGlynn, H. E. Epstein, D. L. Welsch, and V. J. Pacific (In Review), Hysteresis between Soil Temperature and Soil $\mathrm{CO} 2$ is controlled by Soil Water Content, TBD.

Rodriguez-Iturbe, I., P. D'Odorico, A. Porporato, and L. Ridolfi (1999), On the spatial and temporal links between vegetation, climate, and soil moisture, Water Resources Research, 35, 3709-3722.

Rodriguez-Iturbe, I., D. Entekhabi, and R. L. Bras (1991), Nonlinear Dynamics of SoilMoisture at Climate Scales.1. Stochastic-Analysis, Water Resources Research, 27, 18991906.

Running, S. W. (1980), Relating Plant Capacitance to the Water Relations of Pinus Contorta, Forest Ecology and Management, 2, 237-252.

Ryan, M. G., and R. H. Waring (1992), Maintenance Respiration and Stand Development in a Subalpine Lodgepole Pine Forest, Ecology, 73, 2100-2108. 
Saab, I. N., R. E. Sharp, J. Pritchard, and G. S. Voetberg (1990), Increased Endogenous Abscisic Acid Maintains Primary Root Growth and Inhibits Shoot Growth of Maize Seedlings at Low Water Potentials 1, Plant Physiology, 93, 1329-1336.

Scanlon, T. M., and J. D. Albertson (2004), Canopy scale measurements of CO2 and water vapor exchange along a precipitation gradient in southern Africa, Global Change Biology, 10, 329-341.

Scanlon, T. M., G. Kiely, and R. Amboldi (2005), Model determination of non-point source phosphorus transport pathways in a fertilized grassland catchment, Hydrological Processes, 19, 2801-2814.

Scanlon, T. M., J. P. Raffensperger, G. M. Hornberger, and R. B. Clapp (2000), Shallow subsurface storm flow in a forested headwater catchment: Observations and modeling using a modified TOPMODEL, Water Resources Research, 36, 2575-2586.

Schimel, D., T. G. F. Kittel, S. Running, R. Monson, A. Turnispeed, and D. Anderson (2002), Carbon sequestration studied in western US mountains, Eos, Transactions American Geophysical Union, 83.

Schmugge, T. J., W. P. Kustas, J. C. Ritchie, T. J. Jackson, and A. Rango (2002), Remote sensing in hydrology, Advances in Water Resources, 25, 1367-1385.

Seibert, J., and B. L. McGlynn (2007), A new triangular multiple flow direction algorithm for computing upslope areas from gridded digital elevation models, Water Resources Research, 43, XXX-XXX.

Walmsley, J. L., W. R. Burrows, and R. S. Schemenauer (1999), The Use of Routine Weather Observations to Calculate Liquid Water Content in Summertime High-Elevation Fog, Journal of Applied Meteorology, 38, 369-384.

Walmsley, J. L., R. S. Schemenauer, and H. A. Bridgman (1996), A Method for Estimating the Hydrologic Input from Fog in Mountainous Terrain, Journal of Applied Meteorology, 35, 2237-2249.

Westerling, A. L., H. G. Hidalgo, D. R. Cayan, and T. W. Swetnam (2006), Warming and Earlier Spring Increases Western U. S. Forest Wildfire Activity, Science, 1128834.

Western, A. W., R. B. Grayson, G. Bloschl, G. R. Willgoose, and T. A. McMahon (1999), Observed spatial organization of soil moisture and its relation to terrain indices, Water Resources Research, 35, 797-810. 
Woods, S. W., R. Ahl, J. Sappington, and W. McCaughey (2006), Snow accumulation in thinned lodgepole pine stands, Montana, USA, Forest Ecology and Management, 235, 202-211. 


\section{Chapter 5: Summary}

This dissertation brings to the environmental sciences a new framework for quantifying vegetation water stress and evaluating its impact on the land-atmosphere exchange of water vapor. In doing so, it draws from deep but sometimes disparate bodies of research in the fields of land-surface hydrology and ecohydrology, plant ecophysiology and micrometeorology, and synthesizes a novel and interdisciplinary approach to addressing questions of plant-water relations and the hydrology of vegetated landscapes.

The scientific contribution of this dissertation is twofold. First, the dynamic threshold of vegetation water stress is presented as a means by which multiple environmental constraints on stomatal conductance may be represented in a single variable, and second, the concept of spatially and temporally heterogeneous water stress is evaluated, along with its implications for leaf level and watershed scale ecohydrological processes. These findings are presented in the three preceding chapters (2-4).

In Chapter 2, limitations of current stomatal conductance modeling schemes were discussed, and I presented a framework for modeling stomatal conductance that also calculated a dynamic threshold for vegetation water stress. Of the two principle process based frameworks that previously existed for modeling stomatal conductance, one addressed biochemical processes of photosynthesis at the expense of hydrodynamic reality, whereas the other captured steady-state hydrodynamics without fully incorporating the biochemistry of photosynthesis. By joining these two types of models, 
I quantified a balancing stomatal conductance between the two, providing an objective, process-based definition for a well known but poorly understood ecohydrological threshold. I validated the model using eddy covariance data from Blandy Experimental Farm, then tested the sensitivity of the model to changes in parameters and meteorological conditions. The major finding of this chapter was that the threshold soil water potential at which plants experience moisture stress was not only dependent upon soil and vegetation properties (as had been demonstrated previously), but was also dependent upon meteorological conditions, namely, insolation, humidity and temperature. This modeling study still suggested that vegetation felt water stress when soil water dropped below some threshold; only now, the threshold was mobile.

Neither the existing models that I used nor my unified framework provides a true representation of reality; several biophysical processes are parameterized and simplified, as are the plant and soil hydrodynamics. Some processes, such as the abscisic acid signalling between roots and leaves, are ignored altogether. The simple fact is that both plant physiologists and land surface hydrologists will likely find portions of the utilized models too simple for their liking; however, I emphasize above all that I have introduced a modeling framework, and by introducing biochemical and hydrodynamic models of one's choice, the framework is implemented successfully. Furthermore, I argue that the modeling framework, as introduced, provides parity between biological and hydrological processes as well as some semblance of parsimony that has, in general, been lacking in previous mechanistic studies of multiple limitations on stomatal conductance. Wherever possible, through the course of this project, I have attempted to heed the advice of 
Susanne von Caemmerer, who said, "Simplicity is often the key to making a model useful" [von Caemmerer, 2000].

Chapter 3 began as an ecophysiological survey and a means to estimate ecophysiological model parameters. However, with the knowledge that soil moisture varied significantly across the study site and through the study period, I began to examine relationships between ecophysiological measurements and soil moisture. For a given vegetation type (trees and herbaceous plants), ecophysiological model parameters did not vary significantly in space or through time. However, vegetation water stress did vary significantly in space and time, suggesting that spatial and temporal heterogeneity in leaflevel fluxes may arise from divergent hydrological and meteorological conditions rather than from different plant characteristics within single vegetation type. Increased control over leaf chamber conditions (e.g. light control) during future experiments may reveal significant differences in these parameters.

I believe that a deeper significance of the survey measurements that supported the bulk of this chapter will only be revealed when these measurements are placed in the context of multiple years' data from the Tenderfoot Creek Experimental Forest. At that point, we will have a better understanding of the relative importance of spatial and temporal variability in these measurements at multiple scales. Until then, like many other surveys, continued work on this project will require regular and disciplined collection of data using the LI6400 Portable Photosynthesis System. 
In Chapter 4, I integrated the dynamic water stress threshold into a SVAT model to simulate, given prescribed meteorology, soil moisture, stomatal conductance, water stress and evapotranspiration. For lack of a practical, analytical framework for quantifying the spatial and temporal heterogeneities in soil moisture and solving Equation 4.1, I used TOPMODEL; however, I included a newer measure of slope, the downstream index, to simulate hydraulic gradients within the watershed. Coupled with high resolution lidar data of topography and vegetation, TOPMODEL provided the best available means of representing subsurface catchment hydrology in a spatially distributed fashion.

At the watershed scale, the intensity of water stress varied temporally and spatially, and was linked both to topography and vegetation, and also to meteorology and soil water availability. This work is important because it scales the previous findings of water stress from the leaf level to the watershed level, and it shows that factors limiting evapotranspiration at the leaf level do not disappear entirely as spatial and temporal scales increase; rather, the nature of these limitations take new and surprising forms. As the nature of these limitations change with scale, we often dismiss the principle of Liebig's Law as irrelevant; however, aspects of smaller scales, such as the major influence of insolation on leaf level biochemistry, persist at larger scales, only changed somewhat by factors such as light extinction through the plant canopy, topographic shading, and cloud cover. In fact, Liebig himself may have preferred his ideas be applied at broader spatial scales: 
The mere observation of a wood or meadow is infinitely better adapted to decide so simple a question than all the trivial experiments under a glass globe; the only difference is that instead of one plant there are thousands. [Liebig, $1852]$.

In this chapter, there were, indeed thousands of plants under virtual consideration. Among the combinations of vegetation and topography within the watershed were areas whose cumulative, seasonal evapotranspiration was highly sensitive to climate change (i.e. changes in vapor pressure deficit). These areas also contributed disproportionately to whole-catchment evapotranspiration, and were highlighted for future analysis. The distribution, timing and sensitivity of water stress in the northern Rocky Mountains has implications for the terrestrial carbon balance, regional water issues, and wildfires, necessitating further study in the Tenderfoot Creek Experimental Forest.

In conclusion, in answering several salient questions, this dissertation has spawned a host of additional questions, including the following: What is the relationship between topography and vegetation at the small watershed scale $\left(<10 \mathrm{~km}^{2}\right)$, will high resolution lidar data bear out this relationship, and is this an example of ecological optimality? How would one quantify long-term water stress history (years to decades), and how would it relate to current soil and vegetation properties? To what extent is secondary succession a long-term record of water stress? The tools and techniques developed in this dissertation will not, by themselves, answer these questions. They may aid in the interpretation of new data or contribute to new frameworks that incorporate active remote sensing 
technologies such as lidar and radar, but like the $\operatorname{artist}^{1}$, it is the scientist's responsibility to direct these tools in the search for an order.

\section{References}

Bullock, L. (1974), CE prof Giorgini connects art, science, in Purdue Exponent, edited, p. $1 \mathrm{a}$.

Liebig, J. v. (1852), Liebig's Complete Works on Chemistry, 500 pp., Peterson, Philadelphia.

von Caemmerer, S. (2000), Biochemical Models of Leaf Photosynthesis, 165 pp., CSIRO Publishing, Collingwood, Australia.

\footnotetext{
${ }^{1}$ To rephrase a quote by Aldo Giorgini in the Purdue Exponent: Bullock, L. (1974), CE prof Giorgini connects art, science, in Purdue Exponent, edited, p. 1a.
} 